Florida International University FIU Digital Commons

5-11-2017

\title{
Teachers as Facilitators or Barriers of Parent Involvement: Experiences of African American Mothers of Children in Special Education Programs
}

Princess Briggs

Florida International University, princessb828@gmail.com

DOI: $10.25148 /$ etd.FIDC001908

Follow this and additional works at: https://digitalcommons.fiu.edu/etd

Part of the Bilingual, Multilingual, and Multicultural Education Commons, $\underline{\text { Communication }}$ Commons, Disability and Equity in Education Commons, Special Education and Teaching Commons, Teacher Education and Professional Development Commons, and the Urban Studies and Planning Commons

\section{Recommended Citation}

Briggs, Princess, "Teachers as Facilitators or Barriers of Parent Involvement: Experiences of African American Mothers of Children in Special Education Programs" (2017). FIU Electronic Theses and Dissertations. 3486.

https://digitalcommons.fiu.edu/etd/3486 


\section{FLORIDA INTERNATIONAL UNIVERSITY}

Miami, Florida

\section{TEACHERS AS FACILITATORS OR BARRIERS OF PARENT INVOLVEMENT: EXPERIENCES OF AFRICAN AMERICAN MOTHERS OF CHILDREN IN SPECIAL EDUCATION PROGRAMS}

A dissertation submitted in partial fulfillment of the requirements for the degree of DOCTOR OF EDUCATION

in

EXCEPTIONAL STUDENT EDUCATION

by

Princess Briggs

2017 
To: Dean Michael R. Heithaus

College of Arts, Sciences and Education

This dissertation, written by Princess Briggs, and entitled Teachers as Facilitators or Barriers of Parent Involvement: Experiences of African American Mothers of Children in Special Education Programs, having been approved in respect to style and intellectual content, is referred to you for judgment.

We have read this dissertation and recommend that it be approved.

\section{Liana Gonzalez}

Tonette Rocco

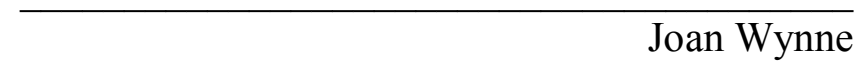

Elizabeth Cramer, Major Professor

Date of Defense: May 11, 2017

The dissertation of Princess Briggs is approved.

Dean Michael R. Heithaus
College of Arts, Sciences and Education

College of Arts, Sciences and Education

Andrés G. Gil

Vice President for Research and Economic Development and Dean of the University Graduate School

Florida International University, 2017 
(C) Copyright 2017 by Princess Briggs

All rights reserved. 


\section{DEDICATION}

I dedicate this dissertation to my brothers, Robert Briggs and Tydire Blanford, both of whom have shown the world that ability lies within disability. This dissertation is also dedicated to my son, Torrance Williams, who carries the torch of compassion for humanity into the next generation, reminding us that it is not differences, but the unwillingness to celebrate our differences that divides us. 


\section{ACKNOWLEDGMENTS}

I would like to thank the Lord, Jesus Christ for working all things for my good. From the time that I was a small child, the flame of learning and teaching has burned deep within my soul. As I approach the finish line of my dissertation, I believe with all sincerity that every circumstance and happenstance was divinely orchestrated to guide me into my life's ministry of teaching parents, educators, and all people about children with special needs.

I would also like to extend my heartfelt appreciation to my dissertation chairperson, Dr. Elizabeth Cramer. There were many times throughout this journey that she pushed me past my points of comfort to greater levels of professional experiences and accomplishments. She has shown that she is dedicated to my current and future success.

Dr. Joan Wynne has been such an inspiration to me. She has challenged my beliefs and broadened my view of the world and the people in it. She believes in my strengths and provides me with opportunities that deepen me personally and professionally. For that I am truly grateful.

I am thankful for the other members of my committee, Dr. Liana Gonzalez and Dr. Tonette Rocco. Their support and guidance have helped me to organize and accurately articulate my thoughts in this arduous process. Likewise, Dr. Linda Bliss has been an invaluable asset throughout my program. I am appreciative of all the detailed feedback she has provided, as well as the personal support she has given to me.

This journey would not have been as life-changing, enriching, and enjoyable as it has been without the support of the Project E.D.U.C.A.T.E. cohort and other FIU colleagues. Having this support system contributed to my success in the program. 
Words cannot express the gratitude I have for my mother who was the inspiration of this dissertation. Many days and nights we discussed her lived experiences as a parent of a child with a disability. She was candid about her past encounters with teachers and school administrators, and eager to hear about current policies and practices. We often exchanged roles of pupil and professor. I am most grateful for her unending belief in me and support of my endeavors.

Finally, I am grateful for my grandmother, godmother, uncle, son, sister-friend, pastor and other family and friends who were with me in this process. During those days that I was barely holding myself together, you all stood beside me and never left me alone. I will never forget. 
ABSTRACT OF THE DISSERTATION

\section{TEACHERS AS FACILITATORS OR BARRIERS OF PARENT INVOLVEMENT: \\ EXPERIENCES OF AFRICAN AMERICAN MOTHERS OF CHILDREN IN SPECIAL EDUCATION PROGRAMS}

by

Princess Briggs

Florida International University, 2017

Miami, Florida

\section{Professor Elizabeth Cramer, Major Professor}

Parents in disenfranchised groups, namely African American parents of children with special needs, are less likely to be involved in their child's education, although involvement is associated with positive educational outcomes. The purpose of this study was to investigate African American parents' perceptions of special education programs, of teacher actions, and of school policies that influence parent involvement of African American parents of children with special needs.

A phenomenological study was conducted with 15 African American mothers of children with special needs. These parents participated in individual face-to-face interviews, which included a discussion of the child's Individualized Education Plan. Audio recordings from the interviews were transcribed and data from the transcriptions were thoroughly analyzed.

The findings were categorized into four overall themes. In theme one, Perceptions of Parent Involvement, it was found that these mothers perceived themselves as being involved in their children's education. In theme two, Facilitators of Parent Involvement, 
it was found that parents were more compelled to be involved in their children's education when educators communicated effectively, valued parent input, and exhibited love and positive attitudes towards parents and children. Findings showed that the absence of these traits were Barriers of Parent Involvement, which was theme three. In the last theme, Recommendations to Teachers and School Administrators to Increase Parent Involvement, study participants shared several recommendations to increase parent involvement.

My study concluded that professionals in the field should broaden their definition of parent involvement to include home-based activities of African American parents of children with special needs, such as engaging their children in home learning activities to teach them independence. Moreover, parents felt more compelled to visit the school and engage in other parent involvement activities, like attending school meetings, for example, when they perceived that school personnel valued parents' contributions. These parents' views were similar to insights gathered from African American parents in previous research. However, views that emerged from this current research that are different from previous studies include parents' recommendations that school personnel communicate with parents using the parents' preferred method, and that teachers and school staff exhibit love and positive attitudes towards parents and children. 


\section{TABLE OF CONTENTS}

CHAPTER

PAGE

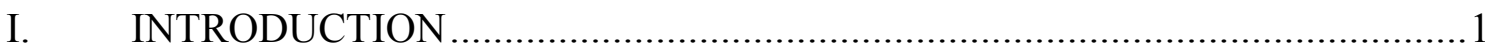

Parent Involvement Defined ..........................................................

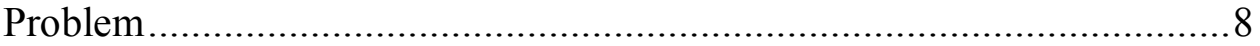

Purpose Statement and Research Questions ……………....................... 11

Conceptual Framework................................................................... 12

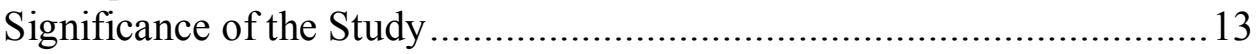

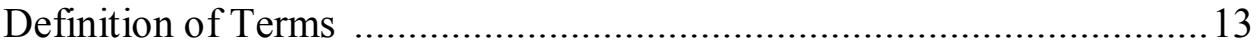

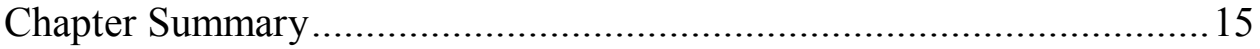

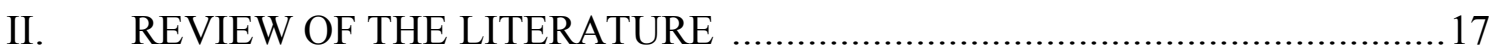

Definitions and Dimensions of Parent Involvement ...............................18

The Importance of Parent Involvement ................................................26

Lack of Parent Involvement in Urban Education......................................22

Lack of Parent Involvement in Urban Special Education ........................28

Factors that Increase Parent Involvement in Special Education ................29

Chapter Summary ................................................................................ 41

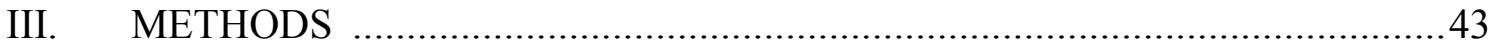

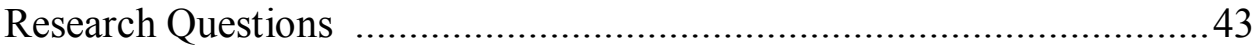

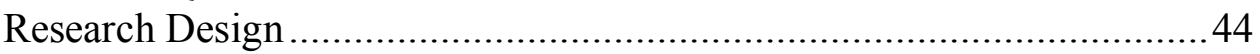

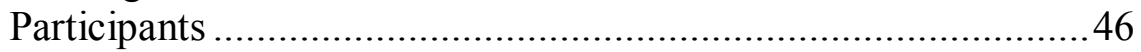

Data Collection ………........................................................ 50

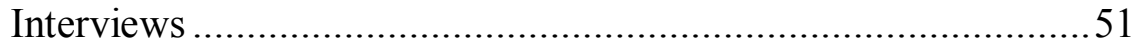

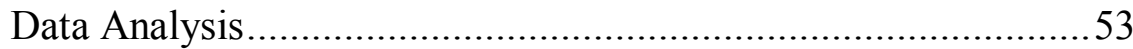

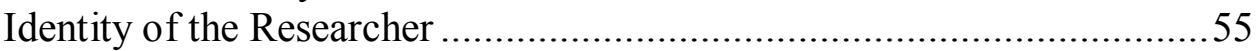

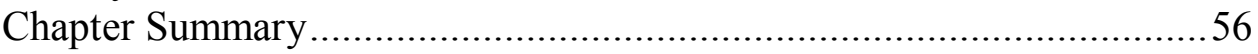

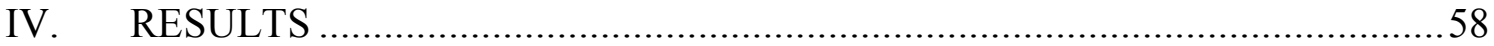

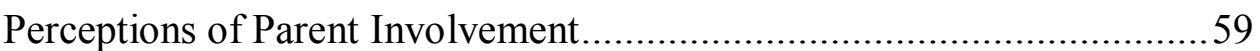

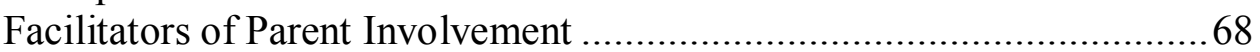

Barriers to Parent Involvement .............................................................96

Recommendations to Teachers and School Administrators to Increase

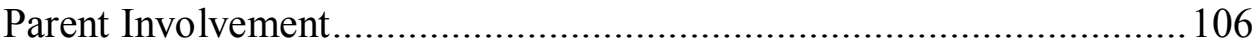

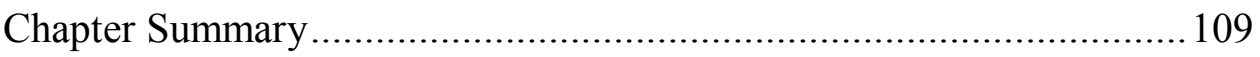

V. OVERVIEW, RECOMMENDATIONS, CONCLUSION .............................110

Broader Perspectives of Parent Involvement .......................................111

Facilitators and Barriers to Parent Involvement.....................................118

Parents' Recommendations to Increase Parent Involvement ................... 124

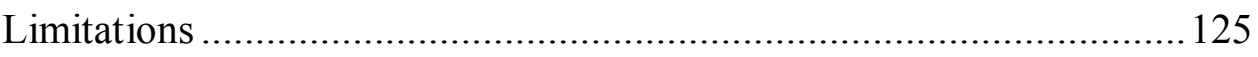

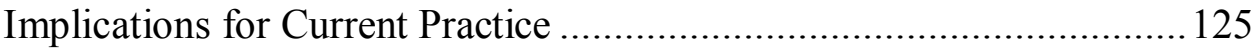


Recommendations for Future Research......................................... 127

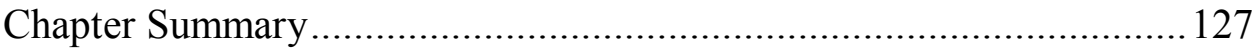

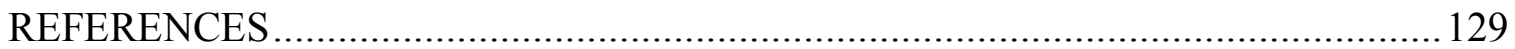

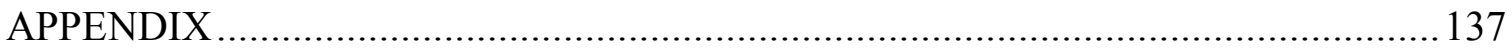

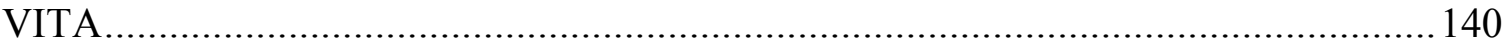




\section{CHAPTER I}

\section{INTRODUCTION}

In 2001, the No Child Left Behind Act, which has been reauthorized and now renamed the Every Student Succeeds Act (ESSA), mandated that states, districts, and schools implement programs, activities, and procedures to involve parents in their child's education. The intent of the law required not only that these programs, activities, and procedures be available to parents, but also that parents be involved at the development and decision-making levels. With respect to children with disabilities, a fundamental tenet of the 2004 reauthorization of the Individuals with Disabilities Education Act (IDEA) is the involvement of parents at multiple levels and in multiple areas of the child's education (IDEA, 2004), including evaluation, educational placement, and educational planning.

The IDEA also stipulates that parents are equal members of their child's Individualized Education Program (IEP; IDEA, 2004). The IEP is a document that is developed annually during the IEP team meeting where members of the team, including the parents, discuss and plan the services that will be provided for the child (Florida Department of Education, 2012). The IEP acts as "the primary vehicle for communicating the school district's commitment to addressing the unique educational needs of a student with a disability" (Beech, 2012, p. 9). Parents are key members of the IEP team. With extensive knowledge of their child's strengths, needs, interests and unique abilities, and having the opportunity to provide suggestions for how the child can be best educated, it is imperative that parents are involved (U.S. Department of Education, n.d.). 
Effective parent involvement programs yield a number of positive outcomes. When parents are actively engaged in their child's education, children experience higher grade point averages (Anderson \& Minke, 2007), increased reading, writing, and math achievement (Ferrara \& Ferrara, 2005; Pena, 2000), greater achievement on standardized tests (Jeynes, 2003) and higher graduation rates (Ferrara \& Ferrara, 2005). Research supports lower incidence of grade retentions (Anderson \& Minke, 2007; Ferrara \& Ferrara, 2005) and dropping out (Anderson \& Minke, 2007), and lower rates of special education placement (Anderson \& Minke, 2007) when parents are involved. Behaviorally, children of involved parents have greater attendance rates (Ferrara \& Ferrara, 2005), and are able to regulate their behavior and display age-appropriate social skills (Bower \& Griffin, 2011).

Although the law requires that states, districts, and schools develop programs and policies to include parents as active members of their child's education, and although the law provides specific guidelines with respect to parents of students with special needs, not all children and families experience the theoretical benefits of parent involvement. There is an abundance of literature that reports a lack of parent involvement for some families (Ferrara \& Ferrara, 2005; Jeynes, 2003; McDermott \& Rothenberg, 2000; Spann, Kohler, \& Soenksen, 2003). Parents have shared a number of factors that dissuaded them from being more involved in their child's education. Some parents reported feeling alienated or disconnected from their child's classroom and school (McDermott \& Rothenberg, 2000; Pena, 2000), linguistically diverse parents cited language barriers as a deterrent to their involvement (Durand, 2011; Pena, 2000), and parents in some cultural 
minority groups, specifically African American parents, reported that feelings of disrespect kept them away from their child's school (Williams, 2007).

With regard to African American parents specifically, there are a number of barriers that impede parent involvement. Many parents indicate that their limited resources hinder their involvement in their child's education (Cousins \& Mickelson, 2011; Williams \& Sanchez, 2011). For example, as a result of work and day-to-day family obligations, many parents lack the necessary time to dedicate to their children's school matters (Cousins \& Mickelson, 2011; Williams \& Sanchez, 2011). In addition to limited time, some parents assert that lack of access (e.g., scheduling conflicts), lack of financial resources, and lack of awareness (i.e., unaware of school policies or misinformed about school events) are deterrents in their school involvement activities (Williams \& Sanchez, 2011).

African American parents have also identified racial and cultural impediments that have led to their limited involvement. According to Brandon (2007), when interacting with educators, African American parents feel out of place, experience real and perceived discrimination, including overt racism from school staff (Cousins \& Mickelson, 2011), and experience a sense of estrangement. Some parents do not feel invited or welcomed in the school, and they feel as though their voices are not being heard (Cousins \& Mickelson, 2011). When educators do not respect cultural differences (Kalyanpur, \& Harry, 2012) and differences in parenting styles, they alienate African American parents (Cousins \& Mickelson, 2011; Thompson, 2003) and weaken the connection between the parents and the school (Brandon, 2007). 
African American parents of children with disabilities report similar experiences with regard to parent involvement. However, they also express the belief that school and district policies prevent them from being involved in their children's education (Brandon, Higgins, Pierce, Tandy, \& Sileo, 2010; McDermott \& Rothenberg, 2000; Williams, 2007). School officials, in regards to African American parents of children with disabilities, are culturally disconnected (Kalyanpur \& Harry, 2004).

When considered collectively, laws mandating that schools, districts, and states, in collaboration with parents, develop comprehensive parent involvement programs (i.e., ESSA), legislative action outlining specific requirements to ensure the involvement of parents of children with disabilities at various levels of educational decision-making (i.e., IDEA), and evidence supporting positive outcomes for children whose parents participate in their education, it can be inferred that parent involvement of children with disabilities is essential for positive student outcomes. The importance of parent involvement for positive outcomes of students with disabilities is also supported in the research literature (Spann, Kohler, \& Soenksen, 2003), though not as strongly supported as research supporting parent involvement of parents of the dominant culture (White middle class) whose children are educated in general education programs.

\section{Parent Involvement Defined}

Scholars agree that parent involvement is a significant factor in the educational development of children. Children benefit from greater academic achievement when teachers and parents work together. However, when asked to provide a definition of the concept of parent involvement, federal law, scholars, teachers, and parents have conceptually different ideas. 


\section{Legislation}

Section 1118, Parental Involvement, of the Every Student Succeeds Act Subsection (d), entitled Shared Responsibilities for High Student Academic Achievement, specifies that, as part of the school-level parental involvement policy, each school, in conjunction with parents, must develop a "school-parent compact that outlines how parents, the entire school staff, and students will share the responsibility for improved student academic achievement and the means by which the school and parents will build and develop a partnership to help children achieve the State's high standards" (U.S. Department of Education: Part A, n.d.). More specifically, the law states that this compact must describe "the ways in which each parent will be responsible for supporting their child's learning."

The examples of said responsibilities provided in the verbiage of this law include parent involvement at home by monitoring attendance, homework, and the amount of time children spend watching television. Some examples of in-school parent involvement activities outlined in this law include volunteering in the child's classroom and participating in decisions relating to the child's education. On-going communication between teachers and parents must also be addressed. At minimum, according to the law, the school must hold parent-teacher conferences annually to discuss parent involvement initiatives, provide frequent reports to parents about their child's progress, and to ensure that the parents have reasonable access to staff, be provided opportunities to volunteer and have opportunities to observe classroom activities (U.S. Department of Education: Part A, n.d.). 


\section{Research Literature}

In the research literature, scholars have traditionally defined parental involvement as "either supporting student academic achievement or participating in school-initiated functions" (Bower \& Griffin, 2011, p. 78). The school-centered definition mirrors the definitions created by policymakers. More recent research on parent involvement has included the work of theorists in the field, including Eccles and Harold (in Anderson \& Minke, 2007), Epstein (in Cousins \& Mickelson, 2011), and Hoover-Dempsey and Sandler (in Williams \& Sanchez, 2012). Although these theorists differ in the specific components of their models, they share two notions - that parent involvement is a multifaceted phenomenon that must be viewed from several perspectives, and that differences in cultural beliefs and attitudes have an effect on the ways parents are involved in their child's education (Anderson \& Minke; Cousins \& Mickelson; Williams \& Sanchez).

\section{Educators}

Just as researchers have developed a parent involvement framework (Banerjee et al., 2011; Bower \& Griffin, 2011), so have school administrators and teachers. School personnel judge parents as either involved or not involved on the basis of the parent's presence in the school (Anderson \& Minke, 2007; Bower \& Griffin, 2011). Educators regard parents as being involved in their child's academic development when they observe parents being engaged in in-class activities, such as volunteering, donating supplies, and purchasing snacks. In-school activities, attending school meetings or events, or participating in school groups or on educational boards for example, may also constitute involvement when considered from the perspective of teachers. However, the unidirectional concept (i.e., direct parent to school support) negates the types of 
involvement exhibited by non-dominant cultural groups (Durand, 2011; Williams \& Sanchez, 2012).

\section{Parents}

Parents of the dominant culture in America, that is White European descendants, embrace the traditional definitions of parent involvement as outlined in the legislation and by researchers and educators in the field (Bower \& Griffin, 2011). In contrast, parents of non-dominant cultures (e.g., Hispanics and African Americans) place an emphasis on community and family when practicing parent involvement. Specifically, these parents focus on those actions and behaviors that help with keeping the child in school (Anderson \& Minke, 2007; Durand, 2011). Some examples of these activities may include nurturing the child, instilling cultural values such as familismo, or family cohesiveness and interdependence (also see Durand, 2011), and talking with the child (Bower \& Griffin, 2011). Essentially, parents of minority cultures consider themselves to be actively involved in their child's education by making sure that the child arrives at school physically and mentally prepared to learn (Durand, 2011).

\section{African American Parents}

African American parents consider in-school and at-home activities as relevant parent involvement efforts (Cousins \& Mickelson, 2011; Williams \& Sanchez, 2012). In addition to traditional in-school activities, such as attending school meetings and volunteering (Tyson \& Hill, 2009), these parents are also actively involved in their child's education outside the school walls (Cousins \& Mickelson, 2011; Williams \& Sanchez, 2012). African American parents ensure that their children's basic needs are met and they assist with homework activities (Banerjee, Harrell, \& Johnson, 2011). In 
addition to these activities, African American parents also engage children in family activities and teach their children life lessons, which are considered essential to their children's educational growth (Williams \& Sanchez, 2012).

\section{Problem}

Research strongly supports the view that parent involvement increases student outcomes (Anderson \& Minke, 2007; Bailey, Silvern, Bradham, \& Ross, 2004; Banerjee et al., 2011; Jeynes, 2003), and to promote parent involvement for all learners, the law mandates collaborative efforts between schools and parents. There remains, however, a large segment of parents for whom these laws have had little positive influence. Families that are marginalized on the basis of their race, culture, and/or language, and those that are economically disadvantaged experience the lowest rates of parent involvement (Durand, 2011; McDermott \& Rothenberg, 2000; Pena, 2000). Of these minority groups, African Americans have the lowest rates of participation (McDermott \& Rothenberg; Williams, 2007).

African American parents, primarily, report feeling alienated from their child's school (Williams, 2007; Williams \& Sanchez, 2012). These parents perceive that the public education system is designed for the benefit of the majority culture with little regard for its negative impact on others (McDermott \& Rothenberg, 2000). African American families of children with disabilities report deeper feelings of disconnectedness. For example, aside from feeling mistreated and ignored at IEP meetings, parents feel that referral and evaluation procedures are not appropriate (Williams, 2007); they feel that school officials are culturally disconnected from minority children (Kalyanpur \& Harry, 2004). With a lack of trust and connectedness with the 
school, African American parents of children with disabilities are the least likely to be involved with their child's school, as compared to parents of other cultural groups.

Researchers have investigated the relationship between parents and classroom teachers to identify specific teacher characteristics and/or actions that encourage parent involvement in the African American community; unfortunately, only small numbers of African American parents were asked to participate in these studies. For example, Lewis, Kim, and Bey (2011) conducted a qualitative study of an inner-city school located in a northeastern city of the United States. The researchers interviewed classroom teachers and the school principal about their school's practices that promote parent involvement. Parents were not asked to participate in the study. Another study was conducted to investigate the effectiveness of the implementation of strategies outlined in the Epstein Model of parent involvement (Bower \& Griffin, 2011). Again, teachers and school administrators participated in the study; no parents were selected to participate in the study.

There are few empirical studies, however, that do include the voices of African American families. Anderson and Minke (2007) conducted a study to investigate parent involvement in an urban district. Approximately half of the parents in their study were African American. Similarly, McDermott and Rothenberg (2000) conducted a study of urban parents' level of school involvement. Three of the six mothers who participated in the study were African American.

Studies investigating parent involvement in the African American community rarely include the voices of African American parents. When adding another dimension, specifically special education, parents' voices are nearly non-existent (Davis, Brown, 
Bantz, \& Manno, 2005). However, Harry (2008) places Latino and African American parent voices at the forefront in her article about parent-teacher collaboration in the special education setting. Likewise, Williams (2007) included the rich, thick descriptions from the African American participants in her study as they discussed their discontent with their children's special education programs.

Even when considering the cultural norms of non-dominant cultures, parent involvement of African American families is the lowest amongst marginalized cultural groups (Davis et al., 2005). With student academic achievement at the forefront of stakeholders' goals, it would be advantageous for lawmakers, administrators, teachers, and parents to operate from an understanding that the concept of parent involvement varies among different cultural groups (Pena, 2000; Williams \& Sanchez, 2012). Because African Americans are less likely to be involved than other racial/ethnic groups (McDermott \& Rothenberg, 2000; Williams, 2007), it is critically important for administrators and teachers to recognize the various reasons that these parents are involved and are not involved in their child's education.

As it is currently written, ESSA does not address or recognize cultural differences and how these differences impact the levels and types of involvement parents engage in with respect to their child's education (U.S. Department of Education: Part A, n.d.). Authors of scholarly works also build their concepts of parent involvement from a school-centered definition or description (Anderson \& Minke, 2007; Bower \& Griffin, 2011). Educators focus their parent involvement efforts and programs on school-level activities and ideas (Durand, 2011). And parents, especially those groups who have not been traditionally disenfranchised, have adopted the school-centered, school-generated 
concept of what it means to be involved in their child's education (Bower \& Griffin, 2011). Regrettably, these traditional definitions of parent involvement, developed and sustained by those in power in the United States, fail to recognize or support sources of social capital that disenfranchised cultural groups rely on when supporting their children educationally (Diamond, Wang, \& Gomez, 2006; Trainor, 2008).

In light of research conducted with minority families of children with special needs, the literature supports the understanding that there are teacher qualities and actions that promote parent involvement (Durand, 2011; Kalyanpur \& Harry, 2004), and teacher qualities and actions that discourage parent involvement (McDermott \& Rothenberg, 2000; Williams, 2007). Parents in this disenfranchised group have reported that, in addition to limited personal resources and a lack of teachers and school staff who are culturally competent, school policies designed and developed by the dominant culture further marginalizes families whose children are African American and in special education programs (Cousins \& Mickelson, 2011; McDermott \& Rothenberg, 2000;

Williams \& Sanchez, 2011). Because the concept of parent involvement is subjective and influenced by culture (Bower \& Griffin, 2011), and because special education adds another dimension to what it means to be involved (Harry, 2008), the parents in the present study had the opportunity to explain their understanding of this concept.

\section{Purpose Statement and Research Questions}

The purpose of my study was to investigate African American parents' perceptions of special education programs, of teacher actions, and of school policies that influence parent involvement of African American parents of children with special needs. The research questions were as follows: 
From the point of view of the African American parents of children with disabilities:

1. How do African American parents of children with disabilities perceive their involvement in their child's special education program?

2. How do African American parents of children with disabilities perceive their involvement with their child's classroom teacher?

3. How do African American parents of children with disabilities perceive their involvement in their child's school?

\section{Conceptual Framework}

Epstein's Model of Parent Involvement (Epstein, 2009) considers school, family, and community elements and includes six components of school-based and family-based factors: (a) parenting, (b) communication, (c) involvement at school, (d) learning at home, (e) decision-making, and (f) collaborating with the community. In addition to helping children succeed in school, family, school, and community partnerships improve school programming and climate, provide services and supports to families, including parenting skills, and connect the families to others in the school and in the community (Epstein, 2009). When the school, the family, and the community interact effectively, the child is more likely to receive common messages about the importance of attending school and being a member of the community (Epstein, 2009).

The interaction between the parent and the teacher or school is significant in the parent involvement framework. Researchers investigating parent involvement in the African American community reported that parents indicated that the attitudes and actions of teachers and school personnel largely influenced whether they were involved 
or not involved, and to what extent they became involved (Anderson \& Minke, 2007; McDermott \& Rothenberg, 2000; Pena, 2005, Williams \& Sanchez, 2012). My dissertation study will use Epstein's parent involvement framework as a foundation to investigate parents' perceptions of the interactions between themselves and their child's teacher, and to what extent this interaction increases or decreases their level of involvement.

\section{Significance of the Study}

The study adds to the literature by providing explicit descriptions of parent perceptions of their own educational involvement, teacher practices that promote or inhibit that involvement, and school policies that dictate involvement activities as perceived by African American parents of students with disabilities. As this segment of the population is often missing from literature that provides best practices to promote parent/teacher interactions, the study provides insight for practices that teachers should and should not employ when interacting with African American parents of children with disabilities.

\section{Definition of Terms}

The following section provides definitions of terms referred to throughout this study. These include terms and acronyms used universally in the field of special education.

African American:

African American individuals are those of African descent living in the United States, excluding individuals of Caribbean descent. 


\section{Culturally and Linguistically Diverse (CLD) Learners:}

CLD students are those whose cultural and linguistic background is different from mainstream American culture.

\section{Individualized Education Program (IEP):}

“The term 'individualized education program' means a written statement for each handicapped child developed in any meeting by a representative of the local educational agency or an intermediate educational unit who shall be qualified to provide, or supervise the provision of, specially designed instruction to meet the unique needs of handicapped children, the teacher, the parents or guardian" (IDEA-B, 2004).

Parent:

A natural or adoptive parent of a child, a guardian, an individual acting in the place of a natural or adoptive parent (including a grandparent, stepparent, or other relative) with whom the child lives, or an individual who is legally responsible for the child's welfare, (IDEA, 2004).

\section{Parent Involvement:}

Adopted from the Epstein Model, any activity that establishes a home environment that supports children as students, communicating with teachers and schools, volunteering at school, helping children learn at home, participating in decisionmaking at the school, and collaborating with the community (Lewis, Kim, and Bey, 2011).

\section{Special Education:}

Special education is instruction that is specially designed to meet the unique needs of a child with a disability. Specially designed instruction means adapting the content, 
methodology, or delivery of instruction to address the unique needs of the child that result from his or her disability, and to ensure the child's access to the general education curriculum so that he or she can meet the educational standards that apply to all children within the jurisdiction of the school system (Center for Parent Information and Resources, n.d.).

Student with Disabilities:

Child with a disability means a child evaluated as having mental retardation, a hearing impairment (including deafness), a speech or language impairment, a visual impairment (including blindness), a serious emotional disturbance, an orthopedic impairment, autism, traumatic brain injury, other health impairment, a specific learning disability, deaf-blindness, or multiple disabilities, and who, by reason thereof, needs special education and related services (IDEA, 2004).

\section{Chapter Summary}

Currently, there is a scant amount of research dedicated to providing a platform from which African American parents of children with disabilities have voiced their experiences with and perceptions of parent involvement (Davis et al., 2005). Because parent involvement is an essential element in the academic growth of students, and because African American parents are the least likely to be involved, lack of parent involvement may be a contributing factor in the achievement gap between African American students and their White counterparts. Additionally, laws and mandates, such as ESSA, have been developed to ensure that schools are engaging parents in various capacities (Epstein, 2005). Unfortunately, not all parents are being supported in their efforts to be involved in their child's education, specifically African American parents of 
children with disabilities. This current study has been developed to engage these parents in dialogue about what parent involvement means to them, about their own level of involvement, and about what their child's teacher or school does to enhance or discourage their desire to be involved.

Chapter 2 contains a review of the literature pertaining to parent involvement. It starts with providing various definitions and dimensions of parent involvement. It considers traditional and non-traditional perspectives. The chapter moves on to discuss the importance of parent involvement and how it impacts the child's academic and socialemotional development. Next, the chapter highlights research studies pertaining to the lack of parent involvement in urban education and in urban special education. The chapter ends with a discussion of dissertation studies that were conducted with African American parents of children with special needs. 


\section{CHAPTER II}

\section{REVIEW OF THE LITERATURE}

The review of the literature has been organized in two parts. Part one provides a general overview of research that explores parent involvement. Part two includes specific aspects of various studies that highlight parents' voices as they articulate their understandings of parent involvement.

The first section of part one explores various aspects of parent involvement from several perspectives, that is the perspectives of researchers, teachers and administrators, and parents. It includes a discussion of the various definitions and views from traditional or mainstream societies to culturally and linguistically diverse communities. The next section of the literature review discusses the importance of parent involvement. That is, it looks at the positive outcomes for both the student and the parent. The two sections that follow explore the lack of parent involvement in urban education and, more specifically, in urban special education. These sections discuss the decline of parent involvement amongst Hispanic and African American populations and explore factors that may contribute to these trends. A discussion of the factors that increase parent involvement in special education follows these two sections.

Part two of the literature review outlines specific studies that explore factors that enhance parent involvement. It then follows with a discussion about the limited research dedicated to highlighting parents' voices as they share their experiences with teachers and school administrators, experiences that either increase or decrease their level of involvement. 


\section{Definitions and Dimensions of Parent Involvement}

One of the principles of the Every Student Succeeds Act (ESSA) requires that school districts receiving federal Title I funding ensure that parents are involved in their child's education in ways that will increase students' academic achievement (Jacobi, Wittreich, \& Hogue, 2003). As Epstein (2005) outlines, there are four principles driving this law. First, ESSA requires that multiple entities, including states, districts, and schools, work together to implement parent involvement and partnership policies. Second, parent involvement policies must be linked to school improvement and management; that is, linking curriculum, instruction, and assessment to student achievement. The law also requires that schools and families share information and decision-making for student learning and communicate at the home, school, and community levels. Lastly, ESSA requires that all families, not just those who are already involved or most accessible, be included in parent involvement programs. In essence, the Act mandates that local education agencies (LEA) and schools consult with parents to adopt policies that will build the capacity for parent involvement (Jacobi et al., 2003). The LEA must provide a written document that outlines their intent to help parents understand that they and their child's educators are equal partners in the child's academic achievement (Elias \& Schwab, 2004; Jacobi et al., 2003).

Although the federal government seems to have a comprehensive outline for how parent involvement is defined, and explicit requirements for how states and education agencies must support parents in their understanding of parent involvement, there has been little consensus with how researchers, practitioners, and parents define the term (Anderson \& Minke, 2007; Feuerstein, 2000; Lewis, Kim, \& Bey, 2011). Perhaps the 
variation in meaning stems from a vast difference in the cultures of children being educated in American classrooms (Ford, 2012). For example, when defining parent involvement, it must be understood that there are cultural differences in the concept of parent. In European American households, parents are typically viewed as a child's biological mother and father; however, in African American and Hispanic American households, parenting is conceptualized differently to include grandparents, aunts, uncles, and partners (Banerjee, Harrell, \& Johnson, 2011; Durand, 2011; Lopez, Scribner, \& Mahitivanichch, 2001; Williams, Sanchez, \& Hunnell, 2011).

Joyce Epstein, a noted researcher and theorist in the field of parent involvement in education, defines parent involvement in terms of six components or types (Bower \& Griffin, 2011; Epstein \& Van Voorhis, 2010; Lee \& Bowen, 2006; Lewis et al., 2011). Type 1, Participating in Parenting, is defined as a supportive home environment; Type 2, Communicating with Teachers and schools, is defined as having effective home-school and school-home communication; Type 3, Volunteering at School, is defined as parents' providing help and support at school; Type 4, Helping Children Learn at Home, is defined as parents helping children with homework and other curriculum-based activities; Type 5, Participating in Decision-Making at School, is defined as parents being involved with decisions through the leadership roles in the school; and Type 6, Collaborating with the Community, is defined as parents' connections with community resources and services (Lewis et al., 2011). In reviewing research that did not explicitly refer to Epstein's six-trait theory, quantitative and qualitative researchers alike used scales, surveys, and open-ended questions that resembled a number of Epstein's six traits (Feuerstein, 2000; Pena, 2000). 
Other researchers in the field have recognized that the concept of a parent being involved in his/her child's education cannot be summed up in any number of predetermined traits or characteristics. They have acknowledged that the ever-evolving American family unit and its nuances must be perceived in a way that recognizes and gives credence to non-mainstream cultures and lifestyles as well. To this end, Williams, Sanchez, and Hunnell (2011), in their work with African American parents, use the construct school-family partnership instead of parental involvement to define how "people, roles, organizations, and events are interrelated" (p. 689). They explain that the term parental involvement is misleading because it does not acknowledge the interaction between the parents, the school personnel and the school system (Williams et al., 2011), all of which are imperative to student achievement.

In their qualitative research with migrant families from Texas, Lopez and his colleagues (2001) introduced the idea of home involvement. Rather than aiming to get parents into the schools to participate in parent involvement activities, the school personnel at one of the schools in their study were proactive in reaching out to the parents and families of their students. Home involvement required school staff to visit the homes and communities where their students were being raised. The school staff saw themselves as being committed to the students and families that they serve, rather than being committed to a predetermined set of tasks or roles. Once the teachers and school staff learned about the uniqueness of the families, the educators were able to share valuable information about community resources available to them. As the families began to utilize these community resources to get their basic needs met, they were able to focus more on their children's education rather than on their personal day-to-day challenges. 
Parents and families were then more receptive to contributing to the academic success of their children, school, and community (Lopez, Scribner, \& Mahitivanichch, 2001).

Just as researchers differ in the definitions and theories that they use to discuss the concept of parent involvement, practitioners and parents view involvement differently as well. Parents of non-mainstream groups "take a more community-centric view that includes keeping their children safe and getting them to school, whereas teachers define involvement primarily as parental presence at school" (Anderson \& Minke, 2007, p. 311). That is, parents concern themselves with whatever is necessary to keep their child in school, while teachers are interested in seeing parents present at the school. With these distinct differences in how parent involvement is determined, teachers who are not sensitive to cultural differences and parents who are not aware of teacher expectations may find it difficult to work together to meet the needs of the child (Anderson \& Minke; Pena, 2000).

Beyond the differences that exist between parents and practitioners when defining parent involvement, there are also differences in the ways various cultures become involved in their children's education. In the United States, the dominant culture (i.e., European-American) considers that a parent is involved in his/her child's education when the parent participates in school-related activities and is visibly present in the classroom (Anderson \& Minke, 2007; Lewis, Kim, \& Bey, 2011). The parent's role, according to White middle-class standards, includes activities such as volunteering in the classroom or school, attending school meetings (often held during school hours), sitting on advisory boards, and being involved in school decision-making proceedings. These activities necessitate a pool of resources that may not be accessible to all families (Anderson \& 
Minke, 2007; Banerjee, Harrell, \& Johnson, 2011; Lewis, Kim, \& Bey, 2011), specifically parents from Hispanic American, Chinese-American, and African American communities.

A clear distinction of parent involvement expectations is evident between migrant families and school personnel (Lopez, Scribner, \& Mahitivanichcha, 2001). Schools define parental involvement in terms of supporting student academic achievement or participation in formal school-initiated functions. However, parents in migrant communities define parent involvement in terms of informal activities such as providing nurturance, instilling cultural values, talking to their children, sending their children to school clean and rested, checking homework, and a variety of other activities. In the Lopez et al. study, when parents did not contribute in ways that teachers and school administrators saw as meaningful, it was assumed that these parents lacked the adequate educational environment for their children. This assumption contributed to deficit thinking by the school personnel.

Teachers and school officials are often uncertain about how to involve parents in meaningful ways; therefore, they are lax in encouraging parents to become involved (Lopez et al., 2001). Class and racial stereotypes hinder school officials from treating migrant parents as partners, decreasing the likelihood for respectful and genuine connections between parents and school personnel. In turn, parents refrain from voicing their opinions or concerns; they become frustrated when schools negate their cultural values and beliefs and when schools create barriers that impede their involvement efforts. Lopez et al. concluded that school personnel often perceive parents' actions (or inactions) as evidence of a lack of resources, knowledge, and skills, which are necessary, in the 
school's opinion, to provide a meaningful educational environment for their child. These beliefs further alienate parents and personify the deficit mentality.

Similar sentiments were shared by Latina mothers when asked about their parent involvement practices (Durand, 2011). According to these Hispanic women, family decisions and practices follow the three standards of familismo, respeto, and educacion. Familismo, or reliance on family members, refers to instilling the value of family closeness, cohesion, and interdependence. Intergenerational and extended kin are primary sources of support, where the commitment to the family over individual needs and desires is upheld. Respeto is the maintenance of harmonious interpersonal relationships through respect for self and others. And educacion interconnects moral, interpersonal, and academic goals. Parents view themselves as responsible for children's social and moral development, while the teacher is seen exclusively as the academic instructor.

In the Chinese-American culture, family relationships are also significant in the educational development of children (Diamond, Wang, \& Gomez, 2004). Being involved in their children's education required a reliance on community-based resources (ethnic cultural capital), particularly for working class parents. Members of this community gain child care and monetary support from family members, churches, and other significant community adults. With communal support, or social capital, extended kin and co-ethnic friends compensate for limitations in other forms of capital, such as limited money and time for educational participation.

Chinese American families are less likely to be active in schools than White middle-class families, but involve themselves in their children's education through home- 
based activities. Diamond et al. (2004) refer to this type of involvement as "backstage/behind the scene" involvement. For Chinese American communities, "access to these resources depended on immersion in the cultural traditions of the community, making this immersion a form of cultural capital (Diamond et al., 2004). School teachers and administrators' recognition of these non-dominant forms of social capital is necessary in building a stronger connection between the school and the communities.

In the African American community, parent involvement encompasses in-school and at-home activities (Cousins \& Mickelson, 2011; Diamond et al., 2004; Howard \& Reynolds, 2008). In-school activities, especially for middle-class African American families, include those that are traditionally recognized by school personnel, including attending school events, having planned and impromptu meetings with the teachers, and participating in Parent Teachers Association (PTA) and school governance meetings.

In addition to traditional forms of parent involvement, however, at-home activities are also significant in the African American community (Cousins \& Mickelson, 2011; McDermott \&Rothenberg, 2000). These activities include motivating children and monitoring their academic success, and creatively supplementing children's education with additional social and academic resources. Parent involvement outside of the school setting also includes providing physical and emotional support, such as providing basic needs, family activities, educational assistance, and conversations centering on life lessons (Williams \& Sanchez, 2012).

As a result of limited resources and capital, including money, education, time (Diamond, Wang, \& Gomez, 2004), and shared parenting (Cousins \& Mickelson, 2011), and because of their own school experiences (McDermott \&Rothenberg, 2000), some 
parents in the African American community have limited parent involvement experiences. Being able to maneuver between the space (the school) and capital (the school culture) is contingent on the parent's ability to articulate what he/she knows and wants on behalf of the child. According to Howard and Reynolds (2008), when parents are equipped with information and have a developed "knowledge of the 'traditional' capital school operate within" (p. 91), parents are more able to engage in their children's education, thus creating a greater possibility of framing how and when they will become involved.

Kalyanpur and Harry (2012) suggest that building parent-professional relationships requires individuals to develop the awareness that their culture can be different from the culture of another. This process of "awareness", that they have coined Cultural Reciprocity, requires that one moves beyond the awareness of cultural differences to self-awareness. This transition, they posit, will help the professional to confront and challenge the contradictions between their cultural values and their professional practices.

As described in the aforementioned research, there are broad ranges of characteristics and attributes that formulate the concept of parent involvement, and several characteristics are common among theorists, researchers, practitioners, and parents. They range from being passive and indirect, like making sure that children eat a good meal and go to bed at a good time during school nights, to being actively involved in the day-to-day operations of the classroom and school through volunteerism and decision-making. Though there may be some differences in opinion about how parent 
involvement should be defined, research outlined in the following section will show that there is agreement that parent involvement is beneficial to the achievement of children.

\section{The Importance of Parent Involvement}

There are many positive outcomes associated with parent involvement in education. Research conducted by Anderson and Minke (2007) and by Williams et al., (2011) found that when parents were involved, students experienced higher grade point averages, increased achievement in reading, writing and math, fewer grade retentions, and lower rates of placement in special education programs. In addition to these academic outcomes, the presence of parent involvement in schools is associated with increased graduation rates, as Ferrara \& Ferrara (2005) found in their study, and lower dropout rates, increased abilities to self-regulate behaviors, and higher levels of social skills (Anderson \& Minke, 2007).

Not only do students experience positive outcomes when parents are involved in their education, but schools and parents also benefit. In terms of school advantages, schools that have quality and ongoing parent involvement programs outperform schools that do not have such programs in place (Pena, 2000). These schools are also able to take advantage of available parent resources when parents volunteer and provide support for the school in various ways (Pena, 2000).

Parents also benefit when they are involved in their child's school. For example, parents are able to receive training (Lopez et al., 2001) and learn about community resources (Quezada, 2003). In these settings, parents develop a better attitude, become more active, and some even seek more education for themselves (Pena, 2000). 
Ultimately, parents seek higher aspirations for their children and children achieve greater school success.

\section{Lack of Parent Involvement in Urban Education}

The presence of parent involvement positively affects student academic achievement across economic, social, and cultural boundaries (Jeynes, 2003; Lee \& Bowen, 2006). Researchers working with students and parents in the inner-city and in the suburbs, and those living inside and outside of the United States have indicated that parent involvement increases student academic outcomes (Jeynes, 2003). However, given these facts, there still remains a decline in parent involvement in education. A general explanation for this is the idea that more parents are joining the workforce, modern life is more fast-paced, and the role of family is declining and changing (Jeynes, 2003).

Among racially, ethnically, and linguistically diverse populations, additional factors contribute to the decline or the absence of parent involvement in schools. For example, among Mexican American parents, there is a cultural belief that the education of students is the responsibility of the school, and that intervening in the teacher's duties is wrong (Durand 2010; Pena, 2000). Other factors that negatively impact parent involvement include language barriers and the lack of an adequate Spanish interpreter, friction between parent cliques at the school site and in the neighborhood, parents' limited education and literacy skills, teacher attitudes and behaviors, and cultural and family influences (Pena, 2000).

Similar to the factors that contribute to Mexican American parents limited participation, low-income families living in urban communities are also reluctant to be involved in their child's school. These parents perceive themselves not as partners in their 
child's education, but as a person outside of the school system; thus, the education of children is seen as the responsibility of those in the school (McDermott \& Rothenberg, 2000). Also affecting parents' willingness to become involved is the parent's level of confidence in his/her own ability to make a difference in the education of the child (AlKandari \& Al-Qashan, 2010; McDermott \& Rothenberg, 2000). Schools in urban communities that failed to make parents feel comfortable and valued contributed to the parents' unwillingness to become involved (Cooper, 2003; McDermott \& Rothenberg, 2000).

\section{Lack of Parent Involvement in Urban Special Education}

Just as there is a lack of parent involvement in urban classrooms, there is also limited parent involvement in special education classrooms in urban communities. In addition to the factors that contribute to the reluctance of urban parents to become involved in their child's education, several factors specific to the special education setting have a negative impact on parent involvement. To start, problems with finding an appropriate interpreter deters some families from attending parent conferences, such as Individualized Education Plan (IEP) meetings where important educational decisions and future goals for the child are discussed (Pang, 2011). Because school personnel often use jargon that is unfamiliar to parents, and because some parents are unclear about the IEP process in general, some families choose to either not attend the meeting, or to relinquish educational decisions to the teacher and school staff (Pang, 2011; Parette \& Petch-Hogan, 2000).

Another barrier that deters families from being fully engaged in their child's education and parent conferences is inconvenient meeting times and locations (Pang, 
2011). Many parents work during school hours, and if they miss time from work to attend meetings, their wages will be lost. For some families, this could result in not having enough money to buy food or to pay utility bills. The lack of adequate transportation to and from the meetings is another deterrent for some parents of children with special needs (Pang, 2011; Parette \& Petch-Hogan, 2000).

During IEP meetings and other types of parent conferences, conflicts may arise between the school and the family, creating yet another barrier for successful parent involvement. For example, the school's recommendations for the student may not be aligned with the family's desires, expectations, or capacities (Kalyanpur, \& Harry, 2012; Pang, 2011; Parette \& Petch-Hogan, 2000). Misunderstandings may also develop from misread body language, nonverbal communication (i.e., head nodding), or culturally specific communication cues (Pang, 2011). These conflicts may cause discord and feelings of neglect, embarrassment, and frustration (Kalyanpur, \& Harry, 2012; Pang, 2011).

\section{Factors that Increase Parent Involvement in Special Education}

In examining the above literature related to parent involvement in education, scholarly journals are replete with articles that declare the importance of parent involvement in a child's education. Supporting those assertions, there have been numerous studies conducted that provide evidence of the importance of parents and caregivers being involved in a child's academic development (e.g., Anderson \& Minke, 2007; Humphries, Strickland, \& Keenan, 2014; Williams et al., 2011). Researchers and other experts in the field of education have developed theories and paradigms to measure, 
classify, and qualify behaviors that parents exhibit with respect to their child's academic performance.

The current review of recent literature will outline several studies that provide research-based suggestions regarding the enhancement of parent-involvement behaviors in schools. The review will also show that there is limited research highlighting the voices of African American parents and their opinion of teacher behaviors that increase parent involvement in special education.

In a quantitative study conducted by Bailey, Silvern, Brabham, and Ross (2004), researchers were interested in determining if an interactive reading homework assignment would increase parent involvement and increase students' reading comprehension. Seven second-grade classes across three different schools in southeastern Alabama with a total of 84 students and their parents participated in this research project. Neither race nor ethnicity was mentioned; however, the majority of the students in the sample population qualified for free or reduced lunch. The experimental groups in one school received an interactive homework assignment, and parents received instruction about the importance of doing homework with their children. The experimental groups in the second school received the interactive homework, but parents did not receive any additional instruction. The last school contained the control groups, where the students did not receive the interactive homework, nor were parents provided any instruction.

The children in the experimental groups where students received the interactive homework and the parents received instruction on the importance of homework outperformed both of the other schools, and the school that was provided the interactive homework only outperformed the control group schools. Parents in both experimental 
groups reported that they spent double the amount of time with their children who had the interactive work. There was no significant difference found between groups of parents who received instruction about the importance of homework and the groups that did not receive this instruction.

The results of this experiment indicated that homework assignments that require parent and child interaction increases parent involvement and increases student performance in reading inference skills. According to these researchers (Bailey et al., 2004), parent-child interaction promotes educational interest for both the parent and the child. The research methodology employed in their study was quantitative in nature, which limited any opportunity to gather information from parents, students, or teachers about other aspects of this interactive homework that may have influenced the results. Nonetheless, these investigators provided several suggestions for promoting parent involvement in school. Some include: (a) when assigning homework, incorporate elements that will increase the likelihood of parent-child interaction, (b) consider parent and student interests, and (c) encourage parent homework workshop sessions.

Lewis, Kim, and Bey (2011) conducted qualitative research to investigate teaching practices and strategies that promote parent involvement in the inner-city of a major city in the northeastern United States. They used Epstein's definition of parental involvement to address six components of parent and school interaction. Two teachers from an elementary school were identified by teachers and parents as having successful interactions with their students' parents who are African American. Ms. Hall taught first grade and had 24 years of teaching experience. Mr. Jake taught fourth grade and had four years of teaching experience. Ms. Hall, who is also African American, was born and 
educated in the same community as the school. Her family dynamics were similar to those of the students in her class. Mr. Jake, an African American male, was born in a nearby county and attended college in a different state. His does not have any children, but relates to his students by remembering his own upbringing.

Both study participants engaged in one-hour, semi-structured and open-ended interviews three times during the study period. These two teachers were also observed in an effort to gather additional information about their interactions with their students and their students' parents. Five main strategies emerged from the interviews and observations. These included "practicing parent outreach, establishing a relationship with parents, creating a positive classroom climate, teaching to involve parents, and making the community-school connection" (Lewis, Kim, \& Bey, 2011. p. 226).

In practicing outreach to parents, both participants used telephone calls to communicate positive information with parents, used progress reports and report cards to inform parents of their child's academic standing, created class newsletters to showcase student work and progress, and visited homes to connect with parents and to show their commitment and interest in their students. In contrast, however, the teachers had different strategies for establishing relationships with parents. For example, Hall encouraged her parents to help their children with their homework in the way that was most comfortable to the parents, or "the old way", as some parents referred to it. She also stayed after school to tutor some of her students. Mr. Jake established relationships by providing opportunities for his parents to experience their child's progress. He invited one father, for example, to stay and listen to his son read. After listening to his son, the father shared that he did not know that his son could read as well as he did. 
Both teachers in their study used a child-centered approach to create a positive classroom climate. For example, one teacher shared that it was necessary for her to perform many duties in her classroom (i.e., teacher, doctor, nurse, problem-solver, and lawyer) because these functions were important to the academic success of her students. A further illustration of this child-centered approach is the unique display one of the participants placed in his classroom - a wall labeled Important African Americans, where the pictures of his students, their parents, and other family members are displayed.

Another finding from their study is that both participants involved their students' parents in their teaching. In addition to having the parents sign their child's homework, one participant offers training workshops that prepare parents to teach a lesson in their child's classroom. Likewise, the other participant in the study involves his parents in his teaching by assigning roles to the parents and allowing the parents to participate according to what motivates his students.

Connecting the parents to the school was the final strategy that the researchers observed in these two inner-city teachers. One strategy that was used included asking parents to reach out to other parents in the community to relay information and to get permission for various activities. As one of the participants explained, when the school has a good reputation, the parents are more compelled to be involved. He explained that the parents and students know that they are all welcomed at the school, no matter which street in the community they lived on.

Lewis, Kim, and Bey (2011) highlighted strategies that two teachers have used to increase parent-teacher interactions in the African American community However, their study shares a similar limitation as the 2004 study conducted by Bailey and colleagues. 
That is, although this qualitative study highlighted the thoughts and emotions of the participants, it was designed to reflect the thoughts and dynamics of the classroom teachers. The voice of African American parents was lacking from the study.

In contrast to the aforementioned studies that did not provide a platform for parents' concerns, the thoughts and concerns of parents are recognized in the qualitative research by Williams, Sanchez, and Hunnell (2011). These researchers assert that the term parental involvement is misleading and does not incorporate the role of school personnel and the interaction between the parent and the school as a system. They prefer the term school-family partnerships, derived from four ecological principles, including interdependence, cycling of resources, adaptation, and succession. These principles, according to these researchers, convey the importance of interactions between individuals and their environment. The purpose of their study was to investigate how ecological principles are reflected in the school-parent partnerships of an African American innercity high school in a large Midwest school district.

Everett (pseudonym) High School's population had 92\% students of color, with $86 \%$ from low-income families. Fifteen parents of high school students and 10 school personnel were randomly selected for the study. Of these 25 adults, most were African American women between the ages of 24 and 62, and 50\% reported a total household income of less than $\$ 50,000$. The participants participated in a semi-structured interview. The interview consisted of four sections. Participants were asked (a) about their background and demographic information; (b) about their conceptualization, including descriptions and beliefs, of school-family partnerships; (c) to provide specific examples pertaining to their experience with school-family partnerships; and (d) about 
characteristics and practices that encourage or hinder school-family partnerships in the African American community.

The four themes that emerged from their study were effective communication, initiation of contact, provide and protect, and contextual conditions. Both parents and school personnel spoke of the importance of an interdependent relationship between the parents and the school. They discussed that the parents and the school personnel maintain effective communication by the school's use of an open-door policy, the parents' commitment to informing the school when there is something happening at home that affects the child's progress in school, and by the parents and school personnel sharing their cell phone numbers and email addresses to communicate effectively. The participants in the study emphasized that both the school and the parents were responsible for the school-family partnership, and responsible for making sure that the partnership was effective for both parties.

Initiation of contact was another theme that emerged from their study. Either the parents or the school personnel initiated the contact. When parents initiated contact, for example, it was for the purpose of obtaining necessary school documents, to discuss issues that were reported by the child, or to discuss the student's academic progress. When discussions about school-initiated contact arose, both parents and school personnel agreed that the primary reason the school contacted the parent was during times that the child was in trouble. However, the school also initiated contact to share information about an upcoming event or to share information about school resources available to the families. 
All participants in the study agreed that resources were not always equally available to all students, whether within the school or outside the school in the community or child's home. Parents reported that they would bear the burden of supporting students who needed to eat, needed shelter, or needed clothes to wear, for example. Both parents and school personnel discussed the importance of keeping children safe in school and in the community. They noted that fights occurred at the school as a normal occurrence; therefore, parents and school personnel would walk the halls and report any signs of trouble to the office or to school police.

The last theme, contextual conditions, spoke to the changes that occurred at the school over time, as described and experienced by parents and school personnel. They reported that violence has escalated to be more physically threatening than in the past, and as a result, the school had to change its approach in managing the students. Additionally, the parents and school personnel saw changes in school-parent partnerships as children transitioned from elementary school to high school. Only two parents shared that they were more involved in their children's high school education than they were in elementary school.

Although parents' perspectives were considered in the study, there were still some limitations. First, the parents were selected from a group of parents who are involved in the education of their child. However, parents who do not participate in school-family partnerships at this school were not included in the study. Additionally, there was no specific mention of parents whose children struggle academically or behaviorally.

To explore parent perspectives of parent involvement in a more diverse student population, with parents who do not typically come to the school, Mapp (2003) 
conducted a study at Patrick O’Hearn Elementary School, in Boston, Massachusetts, which boasts a 90\% parent participation rate in the school's home- or school-based family engagement activities. Of their 220 students, $67 \%$ qualify of free of reduced lunch, $25 \%$ are children with special needs, and the majority of the students are African American, with 34\% being White, 6\% being Hispanic, and 5\% being Asian.

After receiving a grant to enhance the relationship between schools, parents, and the community, the O'Hearn Family Outreach program was developed. In addition to school staff, the members consisted of 15 volunteer parents and grandparents from diverse backgrounds, including African American, White, and Latino. Parents of children with special needs were also represented in the program. Collectively, the group became interested in learning why some parents had never visited the school. As a result, they began visiting those homes and encouraging the parents to come out to the school by sharing how parents are respected and welcomed in the school. The results of these visits were so positive that the team decided to make home visits to new families a new policy at the school.

A study was conducted at the school to identify factors that lead to successful educational partnerships between O'Hearn Elementary staff and families. The chosen methodology was that of a qualitative case study. Eighteen parents were chosen to be engaged in a one-on-one in-depth interview. Five of these parents had children enrolled in the special education program at the school, nine of the parents were African American, eight were White, and one was Hispanic. The interviews averaged 2-3 hours in length. 
Five major themes emerged from the findings. In theme one, "Parents wanted their children to do well in school, and they had a genuine and deep-seated desire to help their children succeed academically" (Mapp, 2003, p. 42). Regardless of their ethnicity, socio-economic level, or family dynamics, all the parents in her study showed a level of concern for their child's success. The second theme was, "Parents understood clearly that their involvement helped their children's educational development" (Mapp, 2003, p. 42). When the parents saw a change in their child's behaviors and feelings about school after the parents' involvement, the parents were more motivated to remain connected to the school. Parents' involvement behaviors were more evident in theme number three, "Parents were involved in their children's education both at home and at school. Many were involved in ways not recognized by school staff with a narrow vision of what constitutes legitimate participation” (Mapp, 2003, p. 43).

Some of the behaviors that parents reported engaging in were not always accepted as parent involvement by school personnel. Themes four and five addressed the parents' personal experiences with school and how those experiences impacted their participation in their child's education. When parents felt welcomed by the staff, honored for their participation in the school, and connected to what their child was learning, the parents were more compelled to participate.

In a qualitative study of mothers of children with disabilities, Sheldon, Angell, Stoner, and Roseland (2010) aimed to investigate the level of trust held by the parents for the school principals. A snowball sampling method was used to recruit the participants. The 16 mothers ranged in age from 18 to 55, most were White, with only one being African American and three being Hispanic. The mothers resided in a range of 
geographical areas, including rural, suburban, and urban communities in a Midwest state. All of the participants were engaged in a semi-structured face-to-face interview, with the interviews ranging from 60 to 90 minutes.

The results of the study revealed that these mothers recognized approachability and authentic care as positive personal attributes in a school principal. Some mothers shared that the principal at their child's school was easy to approach and talk to. Some mothers also shared that they had visited with the school's principal several times. These mothers attributed the principals' approachability and authentic care with the care the principals showed to the students. They trusted principals who treated their children with care. However, not all mothers had this same experience. Although they agreed that approachability and authentic care were positive attributes, some mothers did not feel that their school's principal carried that quality.

Professional attributes recognized by the mothers in their study included the accessibility of the principal and the principal's knowledge of the child's special need. The mothers expressed how much they appreciated the time the principals took away from their busy schedules to answer their questions or listen to their concerns. Further deepening the mothers' trust was the principals' willingness to learn about their child's disability. One mother shared that her principal had no knowledge of her child's disability. The mother offered to provide an in-service to the entire staff, including the principal. The principals accepted her offer. This raised her level of trust and appreciation for the principal.

The principals' actions with the system, the schools, and the families were other positive attributes the mothers recognized. For example, when the principal attended IEP 
meetings, some of the mothers felt that the principal was making an effort to learn about the child. However, one mother reported that her child's principal attended only one IEP meeting because the mother was threatening the school with due process. Most participants reported that their schools' principals did not attend IEP meetings on a regular basis. However, attending IEP meetings was generally perceived as a positive and trustworthy action. Actions that led to distrust were also shared by the parents. For instance, one parent shared that her son's principals refused to have him evaluated when she requested it; he insisted that her son was just a disruptive child.

As outlined above, research highlighting the voices of African American parents of children with disabilities is limited. However, research projects that investigate parent involvement in the African American community and how it affects student achievement are increasing. For example, there is a growing body of dissertation research related to parent involvement of African American parents of children with disabilities. Thompson (2014) conducted a study of African American parents and their perceptions of their son's special education program. The results of her study indicated that parent involvement obstacles included lack of communication between parents and the IEP team, parents' limited knowledge of special education law, and the school staff's lack of understanding of the cultural needs of diverse students. The obstacles to parent involvement of African American parents indicated in her dissertation study echoes the results of empirical studies conducted by researchers in the field (Williams \& Sanchez, 2012).

Just as researchers in the field of special education have investigated teachers' attitudes and perceptions of African American parents (Harry, 2008; Williams, 2007), in 
her dissertation research, Stanley (2013) investigated how African American mothers advocated for their children with special needs. Similar to the results of both the Harry (2008) and Williams (2007) studies, Stanley found that African American parents reported fewer instances of advocacy attempts and levels of parent involvement when they perceived that teachers had negative perceptions of the African American parents.

\section{Chapter Summary}

In reviewing the literature as outlined in this chapter, parent involvement impacts student achievement. However, as the literature also reveals, parents in urban communities are less likely to be involved in their child's education than are parents of the mainstream culture. Although limited in research, the literature supports that parents of children with special needs in urban communities have the least amount of involvement. This phenomenon is due to a number of factors. One significant factor lies in the reality that the concept of parent involvement differs among school administrators, teachers, and parents (Eccles \& Harold, 1993; Epstein, 1987; Hoover-Dempsey \& Sandler, 1995). Additionally, parents of non-mainstream cultures face life circumstances that impede their level of involvement (Durand, 2011; Williams \& Sanchez, 2012). There are some studies that highlight the voices of parents of children with special needs in urban communities with respect to their thoughts of what increases or decreases their level of involvement. These qualitative studies are few in number, providing an opportunity for additional research in this area.

Chapter 3 outlines the methods used to examine the research questions for this current study. It discusses and provides a premise for the chosen research design, setting, and study participants. Chapter 3 also provides an overview of the data collection 
procedures, and outlines how the data will be analyzed. At the close of the chapter, the identity of the researcher will be discussed. 


\section{CHAPTER III}

\section{METHODS}

A phenomenological study design was used to explore parent perceptions of teacher characteristics that influence parent involvement of African American parents of children with special needs. In the first section of this chapter, the research questions are outlined. Next, the research design is discussed, followed by the setting and then the procedures for selecting the study participants. Data collection and data analysis guidelines are discussed towards the end of the chapter.

\section{Research Questions}

It is important to understand that much of the existing research that investigates parent involvement premises its definition of involvement on the mainstream culture. However, because the concept of parent involvement is subjective and influenced by cultural norms and expectations (Bower \& Griffin, 2011), including the culture of special education (Harry, 2008), parent involvement must be defined with respect to cultural differences, including variations that may exist within cultural groups.

Furthermore, researchers investigating strategies that increase involvement questioned school principals, teachers, and parents (Feuerstein, 2000; Sheldon et al., 2010); however, these studies' participants were rarely inclusive of parents from urban communities (Davis et al., 2005). Cultural differences between urban communities and mainstream communities significantly impact what it means to be involved (Durand, 2005; Lewis, Kim, \& Bey, 2011); consequently, strategies to increase parent involvement will likely be different. Therefore, not only should the voices of mainstream parents be considered when researching parent involvement, but the voices of parents of children 
with special needs from urban communities should also be prominent in the literature, perhaps more-so because this group is impacted the greatest.

The purpose of the present study was to investigate African American parent perceptions of teacher traits, characteristics, or actions that either promote or inhibit their level of involvement in the educational development of their child with special needs. The research questions were as follows:

From the point of view of African American parents of children with disabilities:

1. How do African American parents of children with disabilities perceive their involvement in their child's special education program?

2. How do African American parents of children with disabilities perceive their involvement with their child's classroom teacher?

3. How do African American parents of children with disabilities perceive their involvement in their child's school?

\section{Research Design}

The study examined African American parents' descriptions of parent involvement and their perceptions of teacher traits, characteristics, or actions that either promote or inhibit their level of involvement in the educational development of their child with special needs. A phenomenological design was used to select participants, gather and analyze data. This study contributes to the literature by giving a voice to African American parents of children with special needs.

In phenomenological research, the researcher investigates the essence of the phenomenon experienced by the study participants (Patton, 1990). That is, the researcher tries to understand the "relevant events, factors, and moments that make up the 
individual's conscious moments" (Paul, Kleinhammer-Tramill, \& Fowler, 2009, p. 169). By investigating the relationship between the study participant and his or her experiences, the researcher is able to explore the fundamental nature of that particular lived experience. For this study, the phenomenon of being an African American parent involved in the educational process of a child with special needs will be explored.

I used the semi-structured interview as a primary source of data collection. To gain a clear understanding of how parents perceive involvement, interview questions and probes allowed them to discuss and describe various aspects of involvement that are important to them, which informed the first research question, how do African American parents of children with disabilities perceive their involvement in their child's special education program? The second and third research questions, how do African American parents of children with disabilities perceive their involvement with their child's classroom teacher (question two) and in their child's school (question three), also require that participants be given the opportunity to discuss their experiences with their child's teacher and if they felt the teacher's behavior impacted their desire to be involved in their child's school. By refraining from a rigorous predetermined set of interview questions, participants had the opportunity to deeply explore the concept of involvement, from large themes to small nuances (Creswell et al., 2007).

The Education for All Handicapped Children Act of 1975 assured that all children with a disability have available to them an individualized education program (IEP). "The term 'individualized education program' means a written statement for each handicapped child developed in any meeting by a representative of the local educational agency or an intermediate educational unit who shall be qualified to provide, or supervise the provision 
of, specially designed instruction to meet the unique needs of handicapped children, the teacher, the parents or guardian" (IDEA-B, 2004). Therefore, in addition to specifying how the child's unique needs will be met, the IEP must also include information specific to the parents of children with special needs.

I also reviewed the IEP documents of the children of study participants to verify that the students have been formally evaluated and recognized as having a disability. The "parent statement" section of the document will also be reviewed with the study participants to ascertain the degree to which educators recorded parent's concerns during the meeting, and whether the parents felt that those concerns were addressed in the IEP document. Because mainstream culture places significant emphasis on attending IEP meetings as a basic premise for parent involvement in special education (Pang, 2011), the discussion of the IEP document informed the first research question, how do African American parents of children with disabilities perceive their involvement in their child's special education program.

\section{Participants}

Data from this study were collected from African American parents of children with an active IEP residing in the southeastern region of Florida. According to the National Center for Educational Statistics (2), this region holds the two largest school districts in Florida, and they are among the top ten largest districts in the country. Together, these two districts serve over 110,000 children in special education programs, of which 29,000 are African American (Florida Department of Education Graduation Rates, n.d.). 
For the current study, African American individuals were considered those of African descent living in the United States, excluding Caribbean-born individuals. Parents were defined as biological or step parents, grandparents, aunts, uncles, or nonbiologically related persons who were the custodial caregivers of children with special needs. The term "parents" did not include foster parents, non-custodial parents, or persons with whom the child resided temporarily.

A total of twenty candidates were contacted for this study, 18 women and two men. Both male candidates and one female candidate agreed to participate during the initial screening process; however, after several unsuccessful attempts to finalize a meeting time, none were selected for the study. Two female candidates were not selected to participate because they initially self-identified as African American, but later, after thorough questioning, they revealed that they were of Caribbean descent. The remaining fifteen candidates were included in the study (see Table 1). Twelve are the biological mothers of children with special needs, one is a grandmother, one is an adoptive mother, and one is an adoptive aunt. Though it was not the intention of the researcher, the fact that all participants in the study were female is indicative of the mother's leadership role in children's education and educational matters (Cooper, 2009; Sharp \& Ispa, 2009).

Specific information regarding the relationship between "mother" and child is not detailed because several of the study participants were not comfortable with having that information shared and paired with their occupation and their child's gender, as they felt that these specifics could possibly breach confidentiality. Ten of the mothers were very eager to participate in the study, seven of whom the researcher had a previous relationship either through church or personal acquaintanceship. Of the other five 
mothers who were reluctant to participate initially, all became more relaxed and comfortable as the interviews progressed.

Convenience sampling was used to select the initial participants, followed by a snowball sampling, where selected participants were asked to recruit study candidates who fit the criteria (Onwuegbuzie \& Leech, 2007a). Four participants, with whom the researcher had previous affiliations through church, were selected in the initial sampling round. Three participants were recruited by the leader of the church's tutoring program, as she was privy to the educational backgrounds of many of the students who attended the church. Six participants were recruited as a result of snowball sampling (four through current participants and two through personal acquaintances). Two participants, who had no affiliation with anyone from the church, were personal acquaintances of the researcher. See Table 1 for more information about participants.

The disability categories used in this study were those recognized by the state of Florida as qualifying a child for an active IEP, excluding Homebound/Hospitalized and Gifted (Florida Department of Education: ESE Eligibility, n.d.).

Table 1

Participants' Demographic Information

\begin{tabular}{|c|c|c|c|c|c|c|}
\hline $\begin{array}{l}\text { Participant's } \\
\text { Pseudonym }\end{array}$ & Age & Occupation & $\begin{array}{c}\text { Marital } \\
\text { Status } \\
\end{array}$ & Child & $\begin{array}{c}\text { Childs' Level } \\
\text { in School } \\
\end{array}$ & Disability \\
\hline \#1 Jennifer & 54 & Lawyer & Married & Judy & $\begin{array}{l}\text { High } \\
\text { School }\end{array}$ & $\begin{array}{l}\text { Deaf/Hard of } \\
\text { Hearing }\end{array}$ \\
\hline \#2 Tabitha & 38 & Paralegal & Divorced & Tony & $\begin{array}{l}\text { Elementary } \\
\text { School }\end{array}$ & $\begin{array}{l}\text { Other Health } \\
\text { Impaired } \\
\text { (ADHD) }\end{array}$ \\
\hline \#3 Georgia & 57 & $\begin{array}{l}\text { Business } \\
\text { Owner }\end{array}$ & Separated & Gary & $\begin{array}{l}\text { High } \\
\text { School }\end{array}$ & $\begin{array}{l}\text { Intellectual } \\
\text { Disability }\end{array}$ \\
\hline \#4 Betty & 52 & $\begin{array}{l}\text { School Bus } \\
\text { Driver }\end{array}$ & Single & Breana & $\begin{array}{l}\text { Middle } \\
\text { School }\end{array}$ & $\begin{array}{l}\text { Specific } \\
\text { Learning }\end{array}$ \\
\hline
\end{tabular}




\begin{tabular}{|c|c|c|c|c|c|c|}
\hline & & & & & & Disability \\
\hline \#5 Ethel & 53 & Nurse & Married & Edward & $\begin{array}{l}\text { High } \\
\text { School }\end{array}$ & $\begin{array}{l}\text { Specific } \\
\text { Learning } \\
\text { Disability }\end{array}$ \\
\hline \#6 Sarah & 63 & Teacher & Divorced & Sabrina & $\begin{array}{l}\text { Elementary } \\
\text { School }\end{array}$ & $\begin{array}{l}\text { Emotional / } \\
\text { Behavioral } \\
\text { Disability }\end{array}$ \\
\hline \#7 Gloria & 37 & $\begin{array}{l}\text { Radiology } \\
\text { Technician }\end{array}$ & Single & Grace & $\begin{array}{l}\text { Elementary } \\
\text { School }\end{array}$ & $\begin{array}{l}\text { Intellectual } \\
\text { Disability }\end{array}$ \\
\hline \#8 Henrietta & $30 \mathrm{~s}$ & $\begin{array}{l}\text { Stay-at-home } \\
\text { Mother }\end{array}$ & Single & Harmony & $\begin{array}{l}\text { Elementary } \\
\text { School }\end{array}$ & $\begin{array}{l}\text { Autism } \\
\text { Spectrum } \\
\text { Disorder }\end{array}$ \\
\hline \#9 Ivory & 42 & Asst. Principal & Divorced & Isaac & $\begin{array}{l}\text { Elementary } \\
\text { School }\end{array}$ & $\begin{array}{l}\text { Specific } \\
\text { Learning } \\
\text { Disability }\end{array}$ \\
\hline \#10 Rhonda & 45 & $\begin{array}{l}\text { Stay-at-home } \\
\text { Mother }\end{array}$ & Married & Rochelle & $\begin{array}{l}\text { Elementary } \\
\text { School }\end{array}$ & $\begin{array}{l}\text { Intellectual } \\
\text { Disability }\end{array}$ \\
\hline \#11 Keisha & 39 & $\begin{array}{l}\text { Corrections } \\
\text { Officer }\end{array}$ & Single & Keona & $\begin{array}{l}\text { Elementary } \\
\text { School }\end{array}$ & $\begin{array}{l}\text { Deaf/Hard of } \\
\text { Hearing }\end{array}$ \\
\hline \#12 Cynthia & 35 & Social Worker & Single & Cedric & $\begin{array}{l}\text { Elementary } \\
\text { School }\end{array}$ & $\begin{array}{l}\text { Emotional / } \\
\text { Behavioral } \\
\text { Disability }\end{array}$ \\
\hline \#13 Nadia & 35 & $\begin{array}{l}\text { Day Care } \\
\text { Worker }\end{array}$ & Separated & Nelson & $\begin{array}{l}\text { Elementary } \\
\text { School }\end{array}$ & $\begin{array}{l}\text { Specific } \\
\text { Learning } \\
\text { Disability and } \\
\text { Speech } \\
\text { Impaired }\end{array}$ \\
\hline \#14 Monica & 35 & $\begin{array}{l}\text { Para- } \\
\text { Educator }\end{array}$ & Single & Michael & $\begin{array}{l}\text { Elementary } \\
\text { School }\end{array}$ & $\begin{array}{l}\text { Emotional / } \\
\text { Behavioral } \\
\text { Disability }\end{array}$ \\
\hline \#15 Angel & 41 & $\begin{array}{l}\text { Federal } \\
\text { Government } \\
\text { Employee }\end{array}$ & Married & Anthony & $\begin{array}{l}\text { Elementary } \\
\text { School }\end{array}$ & $\begin{array}{l}\text { Autism } \\
\text { Spectrum } \\
\text { Disorder }\end{array}$ \\
\hline
\end{tabular}

Of the 15 participants selected for the current study, their children were receiving services through seven disability categories including Autism Spectrum Disorder, Deaf or Hard-of-Hearing, Emotional/Behavioral Disability, Intellectual Disability, Other Health Impairment, Specific Learning Disability, and Speech Impairment. At the time of data 
collection, all students were enrolled in a Florida public elementary, middle, or high school and had a current IEP.

\section{Data Collection}

Data collection procedures and the development of the interview protocol are discussed in this section. As discussed previously, in phenomenological studies, researchers seek to discover the essence of the lived experiences of the study participants (Patton, 1990). Quite often, however, the "researcher knows too much, rather than too little, of the phenomenon under study" (Paul, Kleinhammer-Tramill, \& Fowler, 2009, p. 171), and having an extensive knowledge of the topic one is exploring may prejudice the results. Therefore, before any data collection procedures commence, the researcher should engage in the bracketing process (Moustakas, 1994). This requires that the researcher brackets, or sets aside any preconceptions, assumptions, or viewpoints so that the participants' experiences can emerge, rather than the experiences of the researcher (Ashworth, 1999; Creswell \& Miller, 2000; Moustakas, 1994).

In the current study, the researcher engaged in the bracketing process prior to the parent interviews. Specifically, the researcher wrote a personal statement of her own experiences concerning the phenomenon. That statement highlighted the researcher's past experiences as a classroom teacher of children with special needs in the inner city of Miami-Dade county and the researcher's current position as an education consultant in the special education arena. Personal and familial connections to special education were also highlighted, as the researcher explained that she has an older brother who has learning disabilities and a younger brother who received services in the intellectual disabilities program throughout his high school years. 
Through the bracketing process, the researcher also discussed her lived experiences as a child who witnessed her mother's anguish whenever she returned home from her older brother's IEP meetings, and as a granddaughter who helped her grandmother navigate the often confusing process of having her younger brother identified, evaluated, and placed in a special education program. Conversely, the researcher also shared her experiences as a classroom teacher who faced limited participation from her own students' parents, and how that impacted her efforts as a teacher. Recognizing her own positive and negative feelings about parents' experiences with participation in special education, and communicating with the parents using their words and not jargon from the field (Paul et al., 2009), helped the researcher to set aside her own personal and professional feelings and biases and focus on the lived experiences of the study participants.

\section{Interviews}

Study participants were engaged in one-on-one, semi-structured interviews which had no predetermined time limitations. The duration of the interviews ranged from 50 minutes to $2 \frac{1}{2}$ hours. For families with two parents, the mother assumed the role as the one who would be interviewed. All husbands declined to be interviewed. The interviews were voice recorded using the researcher's cell phone as the primary recorder and another cell phone as the back-up recorder. Participants were given the opportunity to meet in a setting that was comfortable and convenient for them. Seven interviews were conducted in the participants' homes, five were conducted in the researcher's office (non-school-site location), two were conducted at the outside dining area of fast food restaurants, and one was conducted at the participant's place of employment. 
Each study participant was asked to provide a copy of their child's most recent IEP and any additional IEPs that they had. The IEPs were used during the screening process to confirm that the child was presently receiving services in a special education program. One participant forgot to bring her child's IEP to the interview and could not be reached after several attempts to contact her. The researcher had previous knowledge of this child's educational status as a student serviced in the special education program.

During the interview, the researcher reviewed the parent statement section of the IEP with the participant to gain a deeper understanding of the participant's perceptions of the IEP process and her level of involvement in that process. Specifically, during the interview the parent's comments that were recorded on the IEP document were reviewed with the participant to determine whether or not an accurate portrayal of her involvement in that meeting was recorded on the document.

The interviews were constructed with a combination of more-structured and lessstructured questions (Seidman, 2013). More structured questions were used to ascertain the participants' description of parent involvement, teachers' actions that affect their level of involvement, the depth of knowledge of their child's special education program and types of services provided at the school. Open-ended, or less structured, questions were used to generate thoughts and to clarify or move forward to more in-depth conversation (Creswell, 2003). The open-ended structure of the interview allowed participants to use their own words (Seidman, 2013) to describe how they perceived the behaviors of their child's teacher and how these behaviors influenced their level of involvement.

Probing questions were also used to give the participants an opportunity to clarify any information, and for the researcher to gain a deeper understanding of the participant's 
thoughts (Rubin \& Rubin, 2005). Probes were also used to explore with the participant (Seidman, 2013). That is, if participants provided general or abstract information, probes such as, "can you explain that a little further," or what do you mean by that" helped the participant articulate deeper and more meaningful experiences.

Before the interviews ended, the participants were given the opportunity to provide additional information that they felt was relevant to the discussion. They were able to provide any necessary clarification, and gave their final thoughts about the topic, the interview, and the research process. For the interview protocol, see the Appendix.

\section{Data Analysis}

Data analysis procedures are discussed in this section. The purpose of data analysis is to bring meaning, structure, and order to the data (Bogdan \& Biklen, 2007). Analyzing data in the form of rich, thick descriptions helps support the research credibility, because it allows as much detail as possible to convey the participants' experiences (Creswell \& Miller, 2000). In the content analysis process (Patton, 2002), raw field notes or transcripts of data are read through thoroughly and primary patterns in the data are identified, coded, categorized, classified, and labeled. Next, codes and categories are developed from patterns that emerge from the data. Then the codes are analyzed to determine which codes fit together. This initial process is known as convergence (Patton, 2002). Once the categories, or patterns, have been developed, divergence commences. In this process, categories are built upon, or extended, connected to other categories, or bridged, and new categories are developed if necessary. This process continues until sets of categories have been saturated, when no new categories emerge. 
For the current research, the interviews were recorded using the researcher's cell phone as the primary recorder and a second cell phone belonging to the researcher was used as a back-up. Each of the interviews was transcribed verbatim. It was the desire of the researcher to personally transcribe each interview. However, due to time constraints, 11 of the 15 transcriptions were completed by a third party. Once transcribed, the researcher thoroughly reviewed the raw data for accuracy by listening to the recorded session and reading the transcript making corrections when appropriate.

Using the transcriptions, the researcher then followed Patton's (2002) multi-step process to analyze the data, as previously described above. To facilitate the convergence level of content analysis, the researcher used sticky notes to highlight and code data into 18 meaningful patterns, some of which included Parents Define Parent Involvement, How Schools React to Parent Involvement, Parents' Childhood Experiences with Parent Involvement, Advocating for Their Child, Parent Involvement and Culture, How Parent Involvement Impacts Student Achievement, and Parent Involvement Outside of School. The codes were then analyzed to identify any meaningful categories. There were a total of 65 categories that emerged from the established patterns. For example, the five categories that emerged from Advocating for Their Child included Parent Teaching Child to Self-Advocate, Parent Advocating for Child, Parent Self-Advocating, Child Advocating for His Own Rights, and Parent Brought Friend/Family to Advocate on Her Behalf.

After this convergence phase, the established categories were developed into new categories. This process continued until saturation, where no new categories emerged. The four overall themes that emerged from the data analysis process are Perceptions of Parent Involvement, Facilitators of Parent Involvement, Barriers of Parent Involvement, 
and Recommendation to Teachers and School Administrators to Increase Parent Involvement.

Member check, or the process of involving the study participants in the reviewing and interpretation of the data, was also employed to ensure the validity of this current study (Creswell \& Miller, 2000). After the interviews were transcribed, coded, and interpreted for possible themes, the study participants were asked to review the information for the accuracy and intent of their words. No participant reported any discrepancies or misinterpretations. Furthering this current study's validity, the researcher kept a journal documenting the details of each interview, thus establishing an audit trail. Specifically, the dates and times of each interview, the duration of the interviews, the participant being interviewed, the participant's body language and non-verbal communication during the interview, and any details pertinent to the interview process were recorded. Additionally, the researcher's initial thoughts were also recorded immediately after each interview (Brantlinger et al., 2005; Lincoln \& Guba, 1985).

\section{Identity of the Researcher}

The researcher is an African American female who has had extensive education and experiences with children and parents of children with disabilities. She previously worked in urban communities as a classroom teacher in the special education setting. In addition to her professional involvement with parents and children with special needs, the researcher is the sibling of persons with disabilities, which are her older and younger brothers.

Because of her previous and current affiliations with schools and school personnel, the researcher chose to select participants who were not directly related to any 
specific school. Instead, the study participants were selected from faith-based organizations using a snowball sampling procedure. This selection method minimized the likelihood that participants would feel compelled to sway their responses for fear of reprisal from their child's teacher or school administrator, thus maximizing the reliability of the participants' statements.

\section{Chapter Summary}

The purpose of this study was to investigate African American parents' perceptions of special education programs, teacher actions, and school policies that influence parent involvement of African American parents of children with special needs. A phenomenological design was used to explore the phenomenon of being an African American parent of a child with special needs who is involved or not involved in that child's education.

The setting for this study was the southeastern region of Florida. More specifically, participants were selected from churches and other faith-based organizations in the African American community. Study participants were African American parents of school-aged children with special needs. Their children all had current IEPs. The participants were engaged in semi-structured interviews where they answered open-ended interview questions. The IEPs were also used in the study to verify that the child did in fact have a disability and to determine the extent to which parent concerns were included and addressed in the child's IEP.

The interviews were transcribed and coded. The codes were analyzed for emerging themes, patterns, and concepts following a constant comparative analysis procedure. Additionally, the parent statement section of the IEPs were reviewed and 
coded using the constant comparative analysis as well. Using both the interviews and the narrative parent statement section, IEP documents triangulated the findings to form themes from the codes that emerge from the data. Also, member checking with study participants help to establish the accuracy of their, thus adding to the study's accuracy. 


\section{CHAPTER IV}

\section{RESULTS}

The researcher conducted this study to investigate the phenomenon of being an African American parent of a child in a special education program. It was the intention of the researcher to investigate these parents' perceptions of parent involvement and teacher traits, characteristics, or actions that either promote or inhibit their level of involvement in the educational development of their child with special needs. To answer these questions, study participants engaged in face-to-face interviews, during which time their children's IEP documents were reviewed and discussed. Data were collected, analyzed, and categorized as follows: Perceptions of Parent Involvement, Facilitators of Parent Involvement, Barriers of Parent Involvement, and Recommendations to Teacher and School Administrators to Increase Parent Involvement (see Figure 1). This chapter provides a detailed explanation of the results of the study, which are presented using the rich descriptive words of study participants. The quotes from the participants are presented verbatim to give an authentic voice to the mothers' lived experiences. Pseudonyms are used to protect the privacy of all participants, their children, and anyone with whom they are associated. 


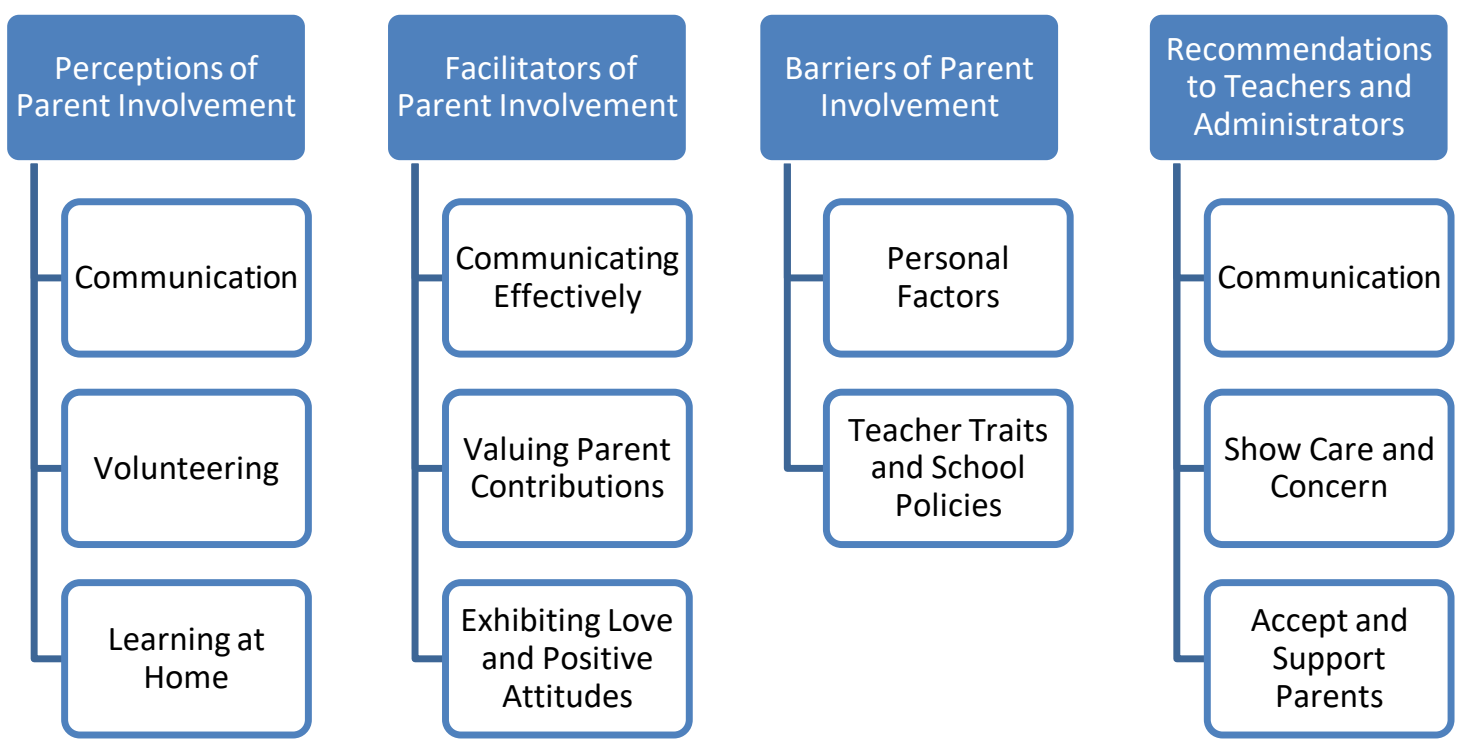

Figure 1. Organizational chart outlining the four major themes and sub-categories

\section{Perceptions of Parent Involvement}

When queried about how they would define parent involvement, the participants in this current study provided initial responses that were more traditional in nature (e.g., helping with homework, attending Open House events, attending parent-teacher conferences). However, as the interviews progressed, they revealed family activities and routines that may not be readily recognized as parent involvement (e.g., involving the family in prayer and devotions, toilet-training a pre-teen, teaching other family members about medication dosages in the event of an emergency at home or school, educating oneself about the child's special needs). According to Abdul-Adil and Farmer (2006), parent involvement "consists of any parental attitudes, behaviors, styles, or activities that occur within or outside the school setting to support children's academic and/or behavioral success" (p. 2). 
Although there were a myriad of unique examples of parent involvement activities discussed throughout the interviews, they were predominantly exclusive to the individual child based on his or her special educational, medical, psychological, or behavioral need. However, when taken globally, the parents' perceptions of their parent involvement activities were based in three categories: Communication, Volunteering, and Learning at Home.

\section{Communication}

Sarah is the adoptive mother of Sabrina, who is in elementary school. Sabrina has emotional and behavioral disabilities. She attends school in a specialized setting equipped to educate and support children who have difficulty regulating their behaviors. Sabrina's siblings attend a traditional school and are not in any special education programs. Sarah explains how ineffective communication with Sabrina's teachers impacts the whole family.

Actually when her IEP meeting was held, the teacher started telling me about negative behaviors that she was displaying. And I said, "Her point sheet [behavior chart] does not reflect what you're telling me." So, one of the comments was that we don't inform the parent of every behavior a child has. I have her siblings in the house... I know exactly what they do because they bring home a report. [If her point sheet is] not there for me to give them a consequence, then I don't know what she's doing at school. I already have behavior problems from the younger two because they look at it as if I'm giving her too much attention because of her negative behavior so now they're displaying negative behaviors, because they look at it as if I need to get attention I'm going to get it any way I want to get it.

Sarah further explains her frustrations when she receives Sabrina's report card and learns that the child is failing. She shares that this lack of communication on the teachers' behalf does not give her many options to intervene and try to help before Sabrina fails. 
So I said, "If she's doing something inappropriate then I need to know she's doing something inappropriate". The PE teacher for example gave her, think it was C3D [grades for academics, effort, and conduct]... So it's unfair to give her that grade when I didn't know and I didn't have the opportunity to say, "Okay, let me be able to work on her behavior." Now, whether it improves or whether it changes I don't know, but give me the opportunity as a parent to be able to do that.

So, I'm saying okay, during a meeting you want to tell me about her inappropriate behaviors but it did not reflect it on her daily report. I need to know if she's doing something inappropriate because if she did something inappropriate and she comes home and she sees her sisters or brother getting the consequence, she's not getting the consequence, she feels she's getting away with it.

Another participant explained how she was able to communicate her concerns and desires for her children only after she sought assistance and educated herself. Monica is the mother of 10-year-old Michael. Michael also has emotional and behavioral disabilities (EBD), and is currently receiving services in the self-contained setting at his elementary school. Monica explained that she has an older child who had also received services in the EBD program before he graduated from high school. However, when her older child was placed in the special education program, Monica was not aware of the many district policies and procedures. Due to her lack of knowledge, she was not able to advocate for her child, nor was she able to support him in making the most appropriate decisions for his future.

That was my oldest child, he was born in 1997, he's 19 now. He got into the whole system with this IEP stuff when he was in like the first grade. No, I didn't have all the knowledge. Yes, I was tricked into the different programs. Umm... everything wasn't given to me. Like all of my options wasn't laid out on the table for me. And being a young adult, they just felt like, "Ok he being bad, he's doing this." We just gon' put him in self-contained. All of my options wasn't given to me. So me not knowing all of my options and I stick my son in this class and I'm saying like something ain't right. So of course I'm like, "Ok I got to do something.

After seeking information via The Yellow Pages, the Internet, and from acquaintances who were knowledgeable about special education programs, Monica 
armed herself with information about the EBD program, various placement options, and schools that could adequately service her children. With this wealth of information, Monica was in a greater position to appropriately communicate her concerns with Michael's teachers, the ESE specialist, and the school administrators.

My second experience was a breeze because it was no way in the world I was going to send my child to a self-contained class because they thought that he was umm EBD or whatever. ...I knew that he didn't have a learning disability. And I read a lot so I'm looking for signs. I'm just paying attention to it all. I knew off the top of my head he was EBD. And umm they did, they was like... well 'cause his teacher was a guy and he would challenge the guy. The guy came [and] he said, 'You just need to sign papers so he can just be in self-contained because that's where he needs to be.' I said, 'That is not where he needs to be. We're going to design this IEP and you're going to do your part and I'm going to do my part and whomever will do their part and he's going to stay here and receive all the services he needs.'

Monica later shared that she felt more positive about herself and her ability to provide for her children. She said that she can share the information she learned with other parents who may be going through the same difficulties with their children.

In the above discussions, the importance of communication is highlighted. One parent, Sarah is a special education teacher. Although she was knowledgeable about special education and general school related policies and procedures, she experienced difficulties with communicating effectively with her daughter's teachers to provide the appropriate services. The other parent, Monica was not well-versed in her and her son's rights and responsibilities. Once she educated herself, she was then able to advocate for herself and for Michael, and make sure that he receives the appropriate services. She wants to teach other parents to do the same. 


\section{Volunteering}

With a similar desire to help parents whose children are in special education programs, Nadia is another study participant with the desire to help other parents through volunteering. Nadia, the mother of eight-year-old Nelson, spends much of her time at work in a child care center and in her community, where she interacts with other parents of school-age children. Nadia feels that some parents do not prioritize education with their children. She feels that less important topics, such as sports and social media, consume the attention of young parents. However, she would like to educate parents on the importance of being involved with their children's education, as it will have a great impact on their futures.

But then it goes to show you, when it comes back to that education, your 3-yearold doing the twerk but can she do some ABCs and 123s? Like they on Facebook talking about this Running Man Challenge. What about the Education Challenge with our kids? But it goes to show you, you go on Facebook Running Man Challenge, police officers they doing all this. But put something on there about the bible challenge, put something on there about education challenge what you gonna get? Zip. Know why? 'Cause some people is not educated. There's not a main concern for them. But as you go back to it, the foundation of a parent, if you not involved with your kids and you not showing support to your kids' education, what you leave them to? Cause like now it's not... [shaking head]. ...I want to be able to speak at his school. You know? Like speak to parents at his school. You know, go to like even like the PTA, we can start there....

Nadia feels passionate about sharing information with parents as early in a child's

life as possible. As a worker in a child care center, she already sees the educational disparities in children as young as two years old. She feels that parents need to understand the importance of teaching their children basic skills at home.

Angel, the mother of eight-year-old Anthony, is equally as passionate about volunteering in her son's school. Since entering her new career with the federal 
government, however, her schedule is more rigid and does not allow her the flexibility to volunteer as much as she did previously. She feels that being present in her son's school has a positive impact on his education, because it shows the teachers and administrators that she cares: "Let them see that we care about our children just as they care about their children". And because they know that she cares, she feels that they will provide him with a better education.

In the discussion, Angel reminisced on her own childhood and explained why her mother volunteered at her younger brother's school.

But I think she did that [volunteer] because he, my brother, went to Orange School. Predominantly, at that time, it's not, it's kinda half and half now, predominantly White at that time. And I think she just felt, "Okay, I got a boy, I got a Black boy. They need to see my face. So, I don't wanna be that parent like..." She would say to me, "I don't wanna be that parent to come out to your school, and this is the first time that they're seeing me when you done cut up..."

Angel's mother was compelled to volunteer at her son's school because she felt that it was important for the teachers and school administrators to recognize her prior to any encounters due to a negative report or some other trouble. She felt that the teachers needed to know her character and that she raised her children to be well-mannered. Likewise, Angel expressed her desires to volunteer in Anthony's school so that the teachers and administrators could identify her as being a caring and dedicated mother. Because Anthony does not use words to communicate, she fears that if he is ever mistreated or if something does not go well in school, she would have no way of knowing: "I'm depending on somebody else to tell me, 'Oh he had a good day.' I'm looking, is there a scratch on him, the clothes he came in are the clothes he came home with? It was nerve-wracking. It's still nerve-wracking". It was important to Angel that she 
developed a trusting relationship with Anthony's teachers so that they, too, would have his best interests at heart. Therefore, volunteering in the classroom or in the school would help the teachers understand how devoted she is to her son and that they should be just as devoted.

Like most of the mothers in this study, neither Nadia nor Angel was actively volunteering in her child's school at the time of the interview. However, both mothers were visibly desirous of spending time in their child's classroom or school. These mothers shared the same sentiment as the majority of study participants, who felt that volunteering was not only an avenue for being involved in their children's education, but viewed volunteering as a necessity for children's educational development.

\section{Learning at Home}

Gloria is another participant in this current study. She shares similar sentiments about the importance of teaching children basic skills at home. Gloria is a single mother of 11-year-old Grace, a child with Down syndrome in the Intellectual Disabilities program at her school. Gloria works extended hours as a hospital radiologist and has limited time with her daughter. However, Grace's well-being takes priority for her and for the rest of her family. Gloria shares that, although Grace's education is important to her, she is more concerned with her daughter's ability to care for herself and to become a self-sufficient adult.

They were using the goals that benefit her in her classroom. They weren't concerned with our home. Their goals were scholastic I should say. It wasn't holistic. It was scholastic. So I'm like, ok if you need my daughter to do A, B, and $\mathrm{C}$ in order for her to be effective in your classroom and that's what you're basing your goals on, I'm not going to tell you to throw them all out. Because you're with her every day. And I want her to be able to, you know, thrive in your setting. I'm not concerned, I got my setting. My setting is wonderful, you know, she's great in 
mine. And I want her to be great in yours as well. So I don't dispute goals at all. Because this is what you... even if you look at those goals, there's goals about her pottying independently. And I'm like, "Child please my baby run her water, set the temperature, pulls out her panty liner, her panties, her bra. What are you talking about? Independent toileting?" (waves her hand dismissively)

Although Gloria's focus for Grace was not academic in nature, the skills she taught her at home are required for a life of independence, which is what Gloria desires for her daughter's future. She shared that in the past, she used to dispute some of the goals that the teachers set for Grace; however, she has since decided to allow the school to develop the goals that they feel are appropriate and she would continue to provide her daughter with the skills that she feels are necessary for her holistic growth and development.

Gloria is among several other parents in this study who have decided to relinquish the development of the IEP goals and services to the school and provide home learning activities according to what they feel is most beneficial to the child. Nadia is the mother of eight-year-old Nelson. Nelson has learning and speech disabilities. He also has difficulty remaining focused for an extended time period. In an effort to help Nelson improve his focus and attention span, she explained that she allows her other children to play while Nelson is completing his homework:

Nadia: It's just me and his brothers and sisters. You know that's his support team. We know his focus span is short. So when it's time for homework, I make sure everybody playing. And you sitting to the table. I say, "Nelson you gotta focus. No matter what distractions you see going on you gotta still do that homework".

Researcher: And why do you do that? Why do you have that?

Nadia: Because he's in class, you're going to have distractions everywhere. So for him to stay focused, that's the only way he's going to stay focused. You got to learn how to tune things out and get your work done. 


\section{Researcher: Is that working for him?}

Nadia: Mmmhmm. He gets frustrated a little bit, but that's normal. He gets frustrated but it works. If Nelson wants to play, he gone get that work done.

Nadia also shared her method for helping her children understand that their job is to attend school and earn good grades. In turn, they will earn monetary incentives to purchase things they want. Her method also helps Nelson with his writing skills:

$[\mathrm{N}]$ ow I have a point system. So Nelson clean up if he do a book report and he don't like to write. He's lazy when it come to writing. So Nelson do a book report and he write a paragraph about what he read. Nelson gets 10 points. At the end of the 2 weeks, because momma don't get paid every week, I add up the points and what it total up to a dollar per 10 points. So at the end of 2 weeks there go $\$ 10$. So they gone work towards that. You know why? Because they want them $\$ 10$. Cause they want to go to the store, they want the ice cream truck come down the street.

By helping Nelson learn to self-regulate his focus and attention in settings that are noisy and distracting, and by helping all of her children to understand that they must work to earn the things that they want, Nadia has gained control over what her children learn. Like Gloria, Nadia's desire is for her children to learn life skills that will help them become successful adults.

Perceptions of parent involvement is the first of four themes that emerged from the study data. When asked directly about how they defined or viewed parent involvement, these mothers provided responses that were typical of mainstream society (Epstein, 2002), including attending school events, helping with homework, and communicating with the classroom teacher. However, throughout the interviews, they indirectly provided examples of their individual styles of participation. These mainly centered on communication, volunteering, and learning at home. 


\section{Facilitators of Parent Involvement}

The second theme that emerged from the data highlights areas that the mothers felt facilitated their involvement. That is, they engaged in rich conversation about how teacher, school administrator, and staff actions compel parents to engage in their child's education. Their statements were categorized as follows: Communicating Effectively, Valuing Parent Contributions, and Exhibiting Love and Positive Attitudes.

\section{Communicating Effectively}

According to Boyd and Correa (2005), “an important component to developing a positive relationship between parents and professionals involves effective interpersonal communication and emotional support (p. 3). In Epstein's explanation, effective communication is defined as school-to-home and home-to-school communications to increase understanding and cooperation (Epstein, 2002). However, ineffective communication systems often result in weak connections between African American parents and their child's school (Brandon, 2007).

In this current study, Communicating Effectively was the largest category that emerged from the research data. The majority of study participants referred to communication directly and all participants made at least a general reference to its importance. The abundance of data from this category was organized into three subcategories: Communication Methods, Proactive Communication, and Communication Follow-Through.

Communication methods. Study participants preferred various forms of communication methods ranging from conventional to contemporary. More than half of the participants preferred communicating with their child's teacher via phone. In fact, 
teachers and other school personnel were referred to favorably by parents who received phone calls regularly, or who shared their cell phone number with their students' parents. For example, Tabitha, who described her son's teacher as caring, explained how she and that teacher communicated:

So, she was really... she really cared about the kids. You could tell. And it was a total difference. Like he ya know, he was... he performed better. So yeah....Yeah, I had her cell phone, um she had my cell phone to call... yeah.

Another preferred conventional communication method was sending and receiving written notes. When asked what type of communication method they preferred, participants responded that they prefer written communication almost as often as they responded that they prefer phone calls. Participants suggested that teachers could write notes in their child's daily agenda, on the child's quarterly progress report, or have the child to bring home. Betty shared that she prefers phone calls or notes rather than emails or electronic communication methods because she is not comfortable with using a computer. When asked if she has ever communicated via email, she responded, 'I don't know how to get on that [laughs]. I don't really know how.... Really, I'm still learning that. But um.... Yeah [chuckles] ...Either note or phone call."

Three participants shared that they either currently communicate or would be comfortable with communicating via email. However, all three of these parents commented that phone calls were preferred methods when communicating with their child's teacher. This is an intriguing detail considering that 10 of the 15 participants have careers that require at least a moderate level of computer literacy skills. Although they may use emails to communicate professionally, these study participants report that they prefer conventional methods of phone calls and hand-written notes. 
Two parents shared their thoughts about using more contemporary forms of communication. One parent, Jennifer, reported that she receives much of the general information from the school's website. She learns about field trips, various school-wide activities, and the like at the website. She shared that her daughter's school promotes independence and responsibility in the students. Therefore, much of what is required of the students is detailed publicly on the website.

Tabitha also suggested a more contemporary method of communication. As other study participants also shared, she is not able to attend the district-sponsored meetings for parents of children in special education programs due to her work hours and long commute. Therefore, she suggested that the district makes podcasts or downloadable videos available to parents. Using this method, she explained, parents can then view these meetings at a time that is more convenient for them.

Monica suggested that one-on-one communication through home visits with parents would be beneficial for teachers to gain a better understanding of the family's personal lives and how their lives may impact the child in the classroom.

Go to these people homes. See how, just do a home visit. Because sometimes that's all it takes. If you go and you actually go to a person house and you can see how they living and you can get a much better picture as to why they holding back. Or why they not coming around or you can talk with the parent and see what is it coming from. Like sometimes you can...you can pick it up like that. You can pick it up. I think home visits are very important.

Monica was the only study participant who suggested home visitation as a method of communication. Most of the participants suggested conventional methods such as phone calls and written notes. Some mentioned using emails, though this was not their preference. Other suggestions involving online methods were also proffered. 
Proactive communication. Proactive communication is the second subcategory under the Communicating Effectively theme. Data analysis revealed that when participants referred to proactive communication practices, they described communication that occurred often, was delivered immediately, was positive in nature, and detailed the teacher's specific concerns and possible solutions to those concerns.

Participants explained that when teachers communicate often with parents, it shows that the teachers care for their children. Nadia shared, "You have some teachers from experience, they care about they job. It shows that they care about they students. They'll show favoritism but sometimes we tend to do that sometimes... The way your teacher communicate with you."

Keisha shared memories from her childhood about how she felt cared for, and how the teachers seemed to want the best for the students. She explained why communication is so vital to her:

Communicate more with the parent. And people...we grew up thinking teachers they care about us. They wanted the best for us and everything. If you know that my child or any child is having a problem, reach out to the parent. You never know what you gon' get on the other end of the phone, you know, when you reach out. And then, like I said, when you got a parent like me that's constantly trying to reach out to you, respond. Even if you say I'm busy. Maybe within the next two weeks ok that's fine, say something you know. Don't be nonchalant about the situation. So I think in general, overall communication is the key.

In addition to communicating often, participants were appreciative of teachers who communicate in a timely manner. Jennifer explained that she and her husband informed their daughter's teacher that they expect immediate notification if her grades or performance start to decline.

But when we meet with them, we also tell them we expect that she does...we expect for her to do her homework, to pass, to complete all of the assignments. 
And if she's not, we want to know about it. Ya know? If you're having any problems let us know so that we can deal with it. So I'll...ya know, we want to make sure that they know that we're on the same page that they're on.

She explained further, however, that, in her experience, most correspondence between the school and the parent occurs via email. Therefore, for those parents who do not have computer or Internet access, or for those who lack computer literacy, getting an immediate notification of student progress is not likely to occur. She shared, “...we're at an age right now where if you don't have access to a computer to be able to check, then there's nothing coming home..."

Study participants expressed a desire for teachers to communicate positive behaviors in their children. They welcomed phone calls and other forms of communication that were for the sole purpose of delivering positive reports. Betty shared that she rarely receives phone calls from her granddaughter's school that are of a positive nature. When asked if she would like to receive more positive calls, she responded,

I would! I would. Mmmhhhmmm. Positive feedback instead of the negative feedback all the time, ya know? But her teacher, the um... the last class, the one that helps...the um...the History teacher, that's the...he's the one that always gives a positive [report]. Yeah.

Georgia explained that she received phone calls from the teacher to discuss what her son, Gary, was not doing or to inform her of his negative behaviors. However, she would have liked to receive phone calls that were positive, constructive, and informative of his abilities.

I would prefer sometimes...uuu... calling. But not only with the bad stuff, and it was mainly he's not doing this, he's not listening... uuuu, ya know... whatever, whatever. I would prefer...I would have preferred that it would be mixed with uuu...ya know... we're working on this... uuummm... he has some good strong points here and ya know, but we need to work on this... and... leave me with something positive. 
When communicating with parents, some study participants explained that it was important that teachers provided detailed information about their child's progress and any areas of concern. And if there were areas of deficit, participants wanted the teachers to suggest possible solutions. As a school administrator, Ivory shared her thoughts about what was appropriate professionally, but then, as a parent of a child with a disability, she also had a personal perspective.

And I feel like as a teacher, we need to always give strengths, like a sandwicheffect. We need to make sure we start out with the strength, and at least get one layer of weakness, don't give 10 layers in the same conversation, but one layer of weakness, and then come back with another strength...

When explaining an interaction she had with her son's teacher, who she described as

phenomenal, Ivory shared:

Excellent teacher. This is when we started seeing everything. This teacher, phenomenal. "He's doing this, this is what's going on. I don't know why he's not understanding." And I said, "Pinpoint, tell me what it is, so I [will] know." She gave me all the results and everything. We had meetings, we had conferences. She was thorough, amazing.

In addition to voicing their opinion about their child's teacher, study participants

also shared their views about school administrator being proactive in their

communications with parents. Keisha expressed frustrations about school administrators communicating with parents only during the times that the state tests are given. She shared,

Don't wait til testing time to send all these voice recordings and all this type of stuff. I don't want to hear that then. 'Cause you ain't call me no other time. Now you want everybody here testing. Make sure they get a good night's rest, make sure they eat breakfast. I don't want to hear that because they do that anyway regardless, so I don't need you to remind me of that. But if you saying, "Ok parents, come on let's do a bake sale, parents let's get out and raise money for the school, the kids want to do this or" you know? More interactive stuff, that'll be 
good. As far as the administrators 'cause if I'm understanding the principal is the one that control the school, right? You could have got the parents involved in so many ways. But no. Y'all wait til testing time come to send us all these voice mails.

Monica also explained that she felt frustrated when both the school and the district neglected to notify her that her children will be attending another school due to the change in the school boundaries. She was particularly upset because her child's special education services would be affected by the changes.

Prior to last day of school, I got a letter in an envelope with my seven year old daughter with a copy of his um IEP goals telling me that on 6/9/2016 they will be withdrawn. And their home school will be ABC Elementary. And I called the region and they was like, "Oh because the district, the boundaries changed." But they have been there forever, like ok, I understand that... Yeah ok fine the boundaries changed but if that was going to be the plan, don't you think in November, October you should have given us the opportunity to apply for the magnet program? If we wanted to keep our children, there? Nobody gave us that opportunity.

With respect to children in special education program specifically, study

participants had several comments about teachers being proactive in their communication with parents. In general, these parents wanted to receive reports about their children's progress more often than what is typically provided school-wide. Tabitha stated:

If they communicate successfully to the parent, if they inform the parents about everything that's going on and not, ya know, wait to be reactive... ya know. They need to be proactive. At least once a quarter like, in the beginning of the quarter, right, or beginning, middle, and maybe end, ya know, if they reach out to the parent, not just the Interims [mid-term progress reports] when you have a special needs child. Not just the Interims, but just say half the time before you get to the Interims.

Monica shared that Michael's teacher would send weekly or daily updates about his IEP reading goals: 
Yes, he has reading goals. And like I can tell like clearly I can tell and every week this lady would send me a email or even every other day. Michael is this and Michael is that and from the last IEP he has improved. Like she sending me stuff like clockwork.

Keisha expressed her desire for the teachers to be more current and specific about her daughter's abilities when they communicate with her at IEP meetings. Rather than rating her abilities based on numbers and scores, Keisha was more interested in reviewing Keona's actual work samples in her class folders.

...when they together it's just based on this print out and they little laptop they got sitting there in front of them. But why you can't interact with me? Let's go through Keona's work folder. What she's been doing with you these last couple of days. Show me where she started from and where she at now. That's how I would like to see it.

Regarding proactive communication, study participants were vocal about teacher actions that were disconcerting. Many felt that communication from the teacher starts after the child has already failed or has already gotten into some trouble. Tabitha explains her frustrations:

For instance, like she could send home the work that is... ya know, that she's giving him. She does periodically send home like the failing test scores or like the failing test papers. She send it home and say, ya know, "Go over this with him at home." Ok, but he's failed that. So what about prior to him failing, if you seeing him not doing well, what are we doing before he gets to the point of failing? Hello. That's my concern. That's what I've been saying all along. Why wait until he fail to just do something about it?

When conflicting or incomplete information comes from the school, for example when the report cards contradict what the teacher has reported, parents become confused and discouraged. Keisha explains that the teacher continues to tell her that Keona is doing well, but statements on her report card indicate that she is working below grade level. 
Keona is doing good from what they are saying. But like I say, in her comments it's below grade level. So she's really not doing good to me. You know, I don't know if I should be excited or not but, I don't think she's doing good. Because if she was doing good, it wouldn't say she was below grade level. So I'm just at like this school year almost over I'm relocating. I'm gonna try something different, that's where I'm at right now.

According to study participants, unresponsiveness from the teacher or other school personnel was equally as frustrating as inadequate responses. Georgia explained that she received no feedback or assistance from Gary's school when she wanted him placed in a different setting. When asked if anyone at the school assisted her, she responded, "No, not from that school. That...that you have to do on your own."

Keisha and her mother have been trying to schedule a parent-teacher conference for a few months. Every time they reach out to the school, they are given various reasons why the meeting cannot be scheduled. Keisha is also concerned that racial stigmas will be attached to her if she expresses her anger and frustration. She has considered relocating to a different state to get better educational opportunities for her daughter.

I reached out to the assistant principal. Ms. X knows me. She knows me very well. With the no correspondence from the ESE teacher or her main teacher. It's always, "Ok we're going to deal with it. Let's set up a parent conference meeting with all of us." Ok I'm waiting... I'm waiting, 'cause I'll take off if I gotta call in sick. I'm taking off. I'm waiting... I haven't gotten nowhere. Nowhere.

Like I said, I had my mom try it today. So she said they wasn't available. Whoever she spoke to in the office said the ESE teacher... she said they wasn't umm available. I don't know what to say about this ABC school [Pause, Looking through phone text messages]. Umm... she text me at 1:13, "They wasn't available. They was supposed to be in a meeting or something."

Researcher: So how do you, how does that make you feel as a parent?

Agitated. Cause if you go out there and show out, you just a Black parent acting a fool. You done tried all your resources to be professional, but you ain't getting nowhere. So like what can you do? You on they terms really, you on they terms. 
Tabitha's frustrations occur when the teachers are not forthcoming without being prompted. She feels that if he does not reach out to the teacher constantly, then she will receive no information about Tony's progress.

She'll respond when I... when I reach out to her... and say whatever, then she'll respond back. But she's not being proactive. Like...she's not telling me ahead of time. It's almost like she doesn't care. Like she...she just push him to the side, like ya know, it doesn't matter. And then when I say something, then all of a sudden, "Ok, I'll pull all his stuff", ya know.

Communication follow-through. Communication Follow-through is the third subcategory under the Communicating Effectively theme. One study participant shared a comment about a positive experience she had with her granddaughter's tutor. Betty explained that Breana was having some difficulty in her science class. She happened to mention it at church. One of the church's choir members agreed to come to Betty's home and tutor Breana. Betty explained that he came over, tutored Breana, and even stated helping her regularly with her homework. She explained that this is the type of behavior that she expects from the teachers at Breana's school; however, more often than not, they do not follow-through with their promises to help Breana.

[Indicating that this is what the science teacher said] "Oh, oh, oh, ok. We can go online and I would give you, ya know, I would give you the website she can go to help her, and she can do it at home on her own pace", ya know, and stuff like that. Nothing! I ain't get nothing. He said he was gon' email me, I ain't get nothing from this man.

During an IEP meeting, Ethel was also promised that someone from the school would assist her in securing a tutor for Edward. Not only did the school fail to followthrough with a tutor, but no one from the school ever contacted her to follow up with the recommended IEP services. 
I remember one of them telling me they would get back to me on some people maybe that could possibly help me [find a] tutor, and not getting back to me. Then me getting back with them and people not following through.

Betty also shared that she would like the teacher to follow-up with her after meetings or phone calls to let her know whether or not the strategies, recommendations, or interventions that they discussed were being effective.

"[I'll have] an idea of what's going on, or what she weak in, or what she struggle in, and how she's doing. "She's doing very well because you doing THIS.

Tutoring is really helping her", ya know, let me know, ya know. Especially in the Science class. That's what she struggle in. "Ok, the tutoring is really helping her. I can see a difference in her", something like that. That's what make me get involved even more.

Tabitha also her shared her frustrations with her son's teacher. During Tony's IEP meeting, the teacher agreed that she would report his progress of lack of progress to his mother. The teacher did not communicate that there were any concerns. Tabitha felt that he was finally making progress. She was disappointed when she received his report card and learned that he was failing.

....and the teacher that he has is not doing that, like she's not cooperating with the plan. She's supposed to, ya know, notify me, inqu-... um, she's supposed to correspond with me with, ya know, [if] his progress is decline whatever. I didn't know anything until, like, his progress reports or something. Like I'm thinking he's doing good 'cause I didn't hear anything, and then all of a sudden, it was like, he had Ds and Fs, ya know [sighs and chuckles].

Study participants shared that they were reaching out to the teacher because they knew that their child needed help. They were willing to get involved, but the teacher's inactions and lack of following through with requests did not support them in their efforts. Keisha had a similar experience with Keona's teacher. This mother explained that she had asked the teacher for a conference to discuss her daughter's poor academic growth. After several days of asking the child if her teacher had given her a response and 
the child responding that the teacher had not, Keisha wrote a note in the child's agenda book. The response she received from the teacher was, "I get to work at 7:30." The mom explained that Keona has to be in school by 7:00 to eat breakfast and report to class by the last bell, which rings at 7:25. So the teacher's response that she gets to work at 7:30 did not make sense. She never got an appropriate response to the question of scheduling a conference with the teacher. This is an example of what makes her frustrated when trying to get involved in her daughter's education.

Yall need to communicate better than what yall do. Yall really getting on my nerves. Cause I'm reaching out to you and you're not responding back to me. Then when you do respond it's not the answer that I want to hear. Because we not solving the problem and we not getting nowhere. So I'mma need yall to do a whole lot better.

The parents in this study clearly articulated their desire to develop a positive relationship with their child's teacher. Through effective communication, the participants expect teachers to provide various avenues of communication, whether traditional or contemporary. They also expect that educators contact them early and often in an effort to prevent future failure. Further, these parents appreciate when teachers and school administrators follow through with suggested plans of action. Communicating in this manner helps these parents feel more connected to their child's teacher and school.

\section{Valuing Parent's Contributions}

Capital, or worth, “contributes to a person's symbolic and material wealth, status, and power" (Trainor, 2008, p. 150). Social capital (assets acquired through social networks) and cultural capital (knowledge, skills, and behaviors shared within a cultural group; Wilson, 2015) are two forms of capital that are significant in discussions about parent involvement (Martinez-Cosio, 2010; Trainor, 2008; Wilson, 2015). Because 
members of the dominant culture generally determine the importance of one form of capital over another, as well as the hierarchy within the individual forms of capital (Martinez-Cosio, 2010; Wilson, 2015), parents in marginalized groups may be seen as deficient in their abilities, including parent involvement (Trainor, 2008). When parents perceive that teachers and other school personnel do not value their abilities and attributes, those perceptions may lead to feelings of rejection and discontent with the school (Martinez-Cosio, 2010; Trainor, 2008; Wilson, 2015), thus adversely affecting parent involvement.

In this current study, Valuing Parent's Contributions was another significant category that emerged from the research data. Study participants articulated their thoughts about how teachers and other school personnel either recognized or ignored the value they provided to their child's academic development. The data review process revealed two major subcategories: Value of Individual Strengths and Value of Collective Strengths.

Value of individual strengths. Parents in this current study voiced their perceptions of being judged based on what teachers and school personnel assumed they could not do, what they would not do, or what they were not already doing. Specifically, parents felt that it was assumed that they could not engage with the school or the child because of the parent's level of education. Secondly, participants felt that some teachers were reluctant to provide additional resources because they assumed that parents would not use the materials or resources. Furthermore, parents shared that teachers inaccurately assumed that they were not already involved with their child because their type or involvement was not deemed important or recognized at all. 
Keisha welcomed opportunities to be involved in her daughter's school. In fact, she shared ideas about assembling parents to fundraise for school supplies, field trips and other necessities. She also shared her desires to be more involved with her daughter's special education program. She has been trying to schedule a parent-teacher conference so that she can gain knowledge and have a better understanding of how to help her child. However, she felt that school personnel continued to overlook her and did not value her desire to be involved based on her level of education or what they assumed that level to be.

Because they don't feel that we are as educated as them. We might not have all the degrees but that don't mean we not educated you know. Some smarter than others in every race. But you got some of us who are willing to take that time out and learn like what's going on? Teach me, show me what can I do to assist.

She shares that, even without a college degree, parents can still contribute to their child's academic success. Schools should not assume that they have no value because they have no degree.

Isaac's mother, Ivory shared a similar opinion. She maintained that teachers and school personnel should be equal in the way they treat parents, regardless of their perceived level of education or intellect. Furthermore, she said that schools should be clear and up front about the types of involvement they need. According to her, teachers should not make a predetermination of who they will or will not share information with based on what they assume the parent will or will not do. She shares:

Explain to them, make it visual, what type of involvement you're looking for as a teacher." [The teacher should explain to the parent] "I would like for you to call me. I would like for you to interact. I would like for you to sign his homework, her homework. Let me know that you have the homework. Sign a weekly progress. Give me a brief description of what's going on, so I can make sure that we stay in contact." Give them, maybe, some choices, 'cause maybe parents don't 
like to talk on the phone so, "Could you just put a check that you saw this?" Give them multiple choices of what they can do.

Give everyone the same information and allow the individual parent to determine what he or she will or will not do. However, this choice should not be unfairly taken from the parent before he or she has had the opportunity to know what is required or expected.

Monica, who rated herself as a five (highest level) in parent involvement, shared that she engages with her children in various activities outside of school. However, the school may erroneously view her as being limited in parent involvement based on their concepts of parent involvement. She describes her activities with her children:

I'm at all meetings. When my children were in Head Start, I was umm the secretary, the treasurer. I'm helping with fundraisers. I'm there volunteering when I could. Umm, my children are active in sports. I'm there at practices, I'm there at every game and I don't drive. ... We have family meetings once a week, twice if needed. We cook together, go to church together, start and end each day with prayer.

She commented that, at times, schools develop their opinions based on the child's special education label. In her case she feels that because her son has an emotional and behavioral disorder, the school has judged him as being a trouble maker. Likewise, she feels judged because she is a single mother of eight children.

Being a young adult and you hear people say, that girl got all them children. But that's ok. That girl got an education and she got a brain. No I didn't have my high school diploma when I had my children. I actually went back to school and all of that. And like I just make it work. ...I know for a fact I don't want my children to slip through the cracks and I don't want them to struggle like I had to struggle or anything.

Monica feels that parents should be supported and not judged based on what the school assumes that parent is not doing. Parents may do many things with their children or they 
may not; however, all parents should be seen as valuable regardless of their perceived contributions.

Study participants also discussed their thoughts on how race and socioeconomics affect the way parents and children in the African American community are valued by those who are privileged and hold power in society. Ivory offered her opinion that teachers prefer to teach children who are more affluent because those children require less effort and resources from the teacher. She gave a scenario of two children from different races and opposite ends of the socioeconomic continuum. Andrew is a White child whose family is affluent. Johnny is a Black child whose family is not financially secure.

Okay. Let's say football. Johnny is African-American, Andrew is WhiteAmerican, Caucasian-American. Johnny and Andrew have the same skills, they can run fast, they can catch the ball wherever, but Johnny is gonna have a problem 'cause he can't afford the uniform, 'cause his grades are lacking, his mom can't bring him to the practices, he didn't eat last night, he didn't have breakfast this morning, he had to watch his little sister and brother, his mom and dad or mom and boyfriend or whomever, just had a fight, and now, he can't deal with it, so he's gonna lash out on the field instead of showing the skills he need.

Andrew on the other hand, he's gonna eat a well-balanced breakfast, he's gonna have a great dinner, he's gonna have a great night sleep. The nanny's gonna bring him if the mom can't come. His parents are together. He can speak to his dad about male situations or a male figure can be in his life. His mother is not as stressed because she has a support team and a support group. If Andrew has a problem, they can afford a counselor, they can afford a therapist, he can go to a mental clinic and get some help.

Johnny will take more work because that means coaches or assistant coaches or whomever is around, they gonna have to pull out of their pocket to help Johnny do what he needs to do. They're gonna have to have a grant writer to write up something just to get money... Let me take Andrew, 'cause Andrew is coming well-prepared. We don't have to do anything to help Andrew. He's coming well prepared. But then Johnny may have been the one to take them to the top, but it's too much work to have Johnny on a team. "Then we just keep Andrew. We'll take Andrew, because... [participant's words ended as she shook her head] 
In Ivory's example, the coaches were reluctant to take on the student with less social and financial capital. He would prove to be too much of a responsibility. Ivory felt that this was a typical situation that happens in classrooms every day. Teachers who highly value financial and social capital tend to devalue parents who are perceived as financially and socially bankrupt. In turn, parents who do not feel valued are less likely to engage with their child's school (Trainor, 2008; Williams \& Sanchez, 2012).

Conversely, Gloria felt that teachers respected her because she is an African American woman who is perceived as intelligent and financially stable. Because the dominant culture views her as atypical, she feels that it works to her advantage.

You know what, let me say, me being African American wows them. I get that, I get that some of the respect they have for me is based on she's a young Black woman. And I see her come by here in her uniform and she comes and spend time on her way to work. And I've got some of their respect based on that. Brown skin. And it's like, no I have a child and I work very hard for one. And I get their respect sometimes based on that and I see it in them.

A careful review of the study data revealed some positive behaviors from teachers and other school personnel as described by the study participants. These parents felt a sense of worth and self-efficacy when teachers listened and followed their suggestions.

Betty expressed feelings of personal satisfaction when Breana's teacher followed her suggestions about how to engage the child. Based on Betty's recommendations, the teacher made sure to give Breana various activities throughout the class period to prevent boredom and negative behaviors. This would help her to stay focused and finish tasks. The ESE specialist also provided a platform where Betty could participate in making educational decisions for Breana. Betty conveyed that she felt good about herself to be included in her child's education. 
When Grace started kindergarten at a traditional public school, Gloria felt very unsure about her daughter's ability to progress in the new setting. She was also uncertain of the teacher's ability to care for Grace in light of her medical condition.

And then, she was so understanding in that she would let me bring Grace to school and stay in the classroom for an hour [Laughter]. So she gave me those freedoms so that I could, you know, do the separating that I need that was healthy for me. Cause I was still very fragile, emotional. Like, like emotionally those were some of the most unstable times in my life.

To her delight, the classroom teacher allowed Gloria the space and time that she required to reduce her own separation anxieties. Gloria felt that her position as Grace's mother was valued.

Value of collective strengths. According to Yosso (2005) Familial Capital refers to cultural knowledge among members of a community and assumes a commitment to the well-being of that community. In addition to including members of one's immediate family, familial capital incorporates members of the extended family, and can also include those in sports, school, and religious settings. Benefits to obtaining and maintaining familial capital are the ability to connect with others, bond around common issues, and lessen one's own burdens (Yosso, 2005). This is what Goss (2015) refers to as Village Consciousness. In this current study, participants discussed the impact of their "village" on their parent involvement activities. Their experiences are organized in three sub-categories: The Roles of Village Members; Teachers as Village Members; and Giving Back to the Village.

Roles of village members. Because, as parents reported, they have a substantial responsibility, they often solicit assistance from their immediate and extended family, friends, and associates. Gloria discussed several instances when she relied on the help of 
her aunt. This family member was instrumental in providing respite support to Gloria, as she was well aware of Grace's medical needs, including her medications. Additionally, this aunt was comfortable with Grace's disability and supported her strengths and challenges.

... [M]y Aunt Gina, she's one of my aunts that I entrust with the medical side of things. So she knows about Grace's medicines and stuff like that. So Grace can go to her house and spend days. This one aunt knows the medicines, knows the doses, knows the frequencies, have clothes at her house, has shoes at her house, has everything Grace needs at her house.

Gloria further explained that this same aunt is more than an occasional relief for her. Because Gloria is a single mother and Grace is an only child, providing the type of family structure that Gloria wants for Grace is not possible. Gloria explains that exposing Grace to a family with a mother, father, and children was very important to her. She also wanted Grace to have the experience of growing up with siblings. Gloria's aunt, uncle, and cousins provide that family structure that Gloria desires for her daughter.

So it was important for me to cultivate that relationship with my aunt and my uncle, their children so that they have that... Grace has that experience. 'Cause I can't give that to her here. So sometimes I pick Tika and Tony [cousins] up and we go to the movies. All on me. Because it's like I'm going to cultivate a relationship with you guys so that when Grace needs you, you're going to cultivate that with her, and they do.

Monica also explained how she and Michael were supported by her mother. When Michael was having a particularly bad day, or when he experienced conflict with his teacher, he would call his grandmother to pick him up from school.

And it was to a point where he would call my mom every day at one. Cause I'm all the way here. And he'll be like, "Come pick me up I'm sick". So my momma would actually go and pick him up because that's the class where he got in the most trouble at. 
Monica shared another incident where she had to solicit the help of her sister and brother-in-law. In this case, Monica's other son had run way from the teacher and out of the building. The school alerted her that he had run away. She immediately called her sister, who worked closer to the school and would get there faster.

We can't find him. I'm like, "You can't find him?" And they was like ohh all kind of stuff. So I was like, "Oh my God, Jesus Lord." So I called my sister 'cause she works at Miami Children's. So she called my brother-in-law and was like since you close to get there, and I'll meet you there.

Not only do "village" members help with respite care and unforeseen emergencies, they can also be instrumental in providing support to parents with their children's school-related matters. Henrietta relies on members of her immediate family to accompany her to her daughter's IEP meetings. In her particular situation, Henrietta's mother, who is a teacher, attends Harmony's meetings and supports Henrietta with a better understanding of the IEP goals, Harmony's services, and other related factors.

Besides being dependent on immediate and extended family members, study participants also relied on the help of school employees who were not directly connected to the child academically (i.e., child's teacher, principal, therapist, and the like), but were connected to the child through acquaintanceship with the child's family. These "village" members are essential to the parents for various reasons. Some have a deeper understanding of school policy and day-to-day operations, and this can be beneficial in helping to make educational decisions. For example, a friend of Betty suggested that she consider enrolling Breana into a charter school: "She say, 'Well Betty...won't you put her in a charter school? I think she'll get more help there.' And that's when I, ya know, seek the charter school." 
Another reason why parents relied on acquaintances who were school board employees is their knowledge of special education programs and policies. Some parents indicated that they needed help navigating the school system to get evaluations and/or services for their children. Some felt frustrated and sought the assistance of those who were special education teachers, specialists, or service providers. Ethel tried to solicit a tutor through the school system. She was told that they could assist, but after waiting and not getting a response, she asked a close family friend who had experience with teaching children with special needs.

She was a girl that went to school with my husband ...And she taught umm kids that had... severe learning [problems] like with autism and umm she used to tell me that umm Edward... kids learn in different ways and that she really thought that he was more of a visual kind of learner. And so when she would tutor him, she would umm the way that she would present things to him was so differently. Like sometimes she would even take him outside and they would do stuff on the sidewalk. I think she was probably like really the most positive influence on him to really help him get to a better understanding of things.

Monica reached out to two different people who were both helpful in educating her on her rights and on the evaluation process. Because they explained to her what the proper procedures were, Monica was better equipped to advocate for her son's needs at the school.

So and I'll never forget this lady name either, Ms. X, she was the lady that came to my mom's house. And we sat and she said, "No, no, this is not how it go, and they shouldn't do this." And I also got my friend saying, "They didn't offer you this." So we started, I started setting up meetings and going and when they seen that I was on the ball, it was like, "Ok, we gotta step back."

Teachers as village members. Although some participants relied on the help of school employees who were not directly connected to the child academically, some also relied on their child's classroom teacher, special education teacher, school administrator, 
therapist, and the like. When explaining the child's teacher and his or her relationship to the child, parents used phrases such as, "member of the family", "part of her team", and "part of the village." Parents who shared these sentiments seemed to trust their child's teacher, and there seemed to be a mutual respect between teacher and parent.

Nelson's mother, Nadia shared that, although teachers are held accountable and have responsibilities to the child, parents must also do their part. She sees herself and the teacher both as part a community.

You know, so you hold these parents accountable for not coming in for meetings, not being involved, not communicating with the teacher. 'Cause the teachers can't do it by themselves and we can't do it by ourselves. It's like a whole community. Like it say, it take a whole tribe to raise a... I'm saying it wrong. It take a whole village to raise a tribe. That's what we have to do.

Monica indicated that she did not agree with her son's school placement. She felt that the school was being unfair to him and they were not considering his behavioral disability in their decision. However, after witnessing Michael's growth and the social connections he was making, she knew that Michael was in the right place. She was happy that they helped her make the right decision.

Um even in middle school, he ended up going to XYZ Alternative School. I tried to avoid that, but that was the best situation because he met some really important people there that's really important in his life now today. And like all those trials and tribulations it just molded him. You know how it says it takes a village to raise children? It's true.

Giving back to the village. Parents were enthusiastic about their own responsibility and membership to the "village." Some expressed an interest in giving back to their community by educating other parents who may have a child with special needs. They recognize the importance of having the support of those who understand the educational system and how to navigate through it. Their suggestions ranged from small 
ideas like joining the PTA and carpooling to district parent meetings to large-scale decisions such as becoming a motivational speaker to educate other parents. Tabitha stated that she shares her experiences with other parents and lets them know that they have to be persistent in order to get the proper services.

Nadia wants to become a motivational speaker to empower other parents. She cannot attend many district meetings due to her work hours, and she knows that other parents experience the same hardship. Therefore, she would like to learn as much as she can and then share that information with the parents who cannot attend the district meetings.

Now with the job I have now, I don't leave until 5:30. So if they have something [district meeting] at 6, I can't get there. Sometimes it make me mad and upset. ...I want to be there because that's involving my child. Not only him, that can give me the knowledge to help other people who have the issue that I'm going through. ...I want to be able to speak at his school. You know. Like speak to parents at his school.

Tabitha has a desire for African American parents to come together to support causes that deeply impact her community. She suggested that if many parents come together in protest of unfair policies or decisions that present a hardship to members of the community, then perhaps their collective voices will effect some change.

If we stood together as a unit and raised our voices, did a petition, bombard theses school boards for equal opportunities, then I think it would bring about change. But you can't even get us to come together for PTA meeting. So how are we gonna voice an opinion to a school board? It has to be in numbers. When it's a problem in other areas, they voice theirs... they go to the school board, to the president... You know what I'm saying?

Valuing the capital that parents contribute to the school, either directly or indirectly, can have a positive impact on the parents' willingness to be involved in their children's education. Here, parents shared how valuing their individual strengths as a 
parent and their collective strengths as a community deepens their desire to participate in their child's education. Schools and teachers who want these parents to be involved must value their contributions.

\section{Exhibiting Love and Positive Attitudes}

According to the authors of a study investigating the relationship between parent involvement, student behavior, and classroom teacher's emotional support, "Teachers who are emotionally supportive in the classroom can be expected to interact with and engage with parents in qualitatively different ways than teachers who are less emotionally supportive" (McCormick, Cappella, O’Connor, \& McClowry, 2013, p. 280). Parents view emotionally supportive teachers as more collaborative and respectful. This viewpoint may draw parents to the classroom more often.

Likewise, McDermott and Rothenberg (2000) found that African American and Hispanic parents ascribed more favorable descriptions to teachers who they perceived as loving towards their children and respectful towards parents. The parents in their study also esteemed teachers who had good communication skills and communicated positively and frequently through notes and phone calls.

In this current study, Exhibiting Love and Positive Attitudes was the third major category that emerged from the research data. Similar to the parents in the two aforementioned studies, the parent participants in this current study shared more favorable thoughts and remarks about teachers who they perceived as loving towards their children or to them. The data review process revealed three major subcategories: Emotional Support Towards Parents, and Emotional Support Towards Children. 
Emotional support towards parents. Teachers who displayed emotional support towards parents were described by study participants as loving and understanding. One parent, Gloria, compared her behavior at work to how she expects her daughter's teachers to behave at work.

Like I get paid to take an x-ray. I do not get paid to get on one knee and say, "Hi sweetheart, how are you? What happened, you got a booboo?' That's not what I get paid to do. My job is to effectively get the x-ray. And so it's my personal convictions that says, "Hi sweetheart. What happened, you got a booboo? Can we take a picture? We take a picture, we can fix your booboo." So it takes an inner conviction from you that says this is my job description, and this is what I'm going to bring of me to it. And if you have a teacher that don't want to bring me to it, your convictions, your character, your love, your understanding, your empathy, your sympathy, I don't think you're ever going to get parent involvement.

Other participants described the supportive and loving ways that teachers

communicated with them. Ivory, a school administrator, shared how she creates a positive environment for her students' parents.

...but what I would do is I would send out letters with the students to let the parent know, "I'm here for you." I would mail the letters as well. I would send home notes. I would ask for cellphones, I would ask for things I could communicate with, people I could communicate with to get them involved.

Tabitha expressed gratitude for the way one of Tony's teachers communicated with her.

Like that White teacher... I think that she was just special because she cared, like she went all out, out of her way. Like she didn't have to do the things [she did], ya know? But she... she took the time to do it. She didn't have to communicate with me as much as she did either. But she wanted to see him succeed.

Betty referred to the special education specialist as "a lovely lady." She explained that, during a meeting with her, the specialist talked about her family, and she made Betty feel comfortable and positive. She described the conversation as "real nice." 
Not only did the study participants discuss the respectful and loving manner in which some teachers communicated with them, they also described the qualities of an emotionally supportive environment. Although she did not provide much detail, Henrietta said that feels welcomed in Harmony's school and classroom. Jennifer shared similar thoughts about her daughter, Judy's school and class. She described the murals of the walls of the school as warm and inviting. She further stated that the school administrators are welcoming. Jennifer did, however, take notice that her daughter's school did not have pennants of any historically Black colleges and universities (HBCUs) on display where all the other colleges were displayed. Nonetheless, she still felt welcomed at her daughter's school.

With respect to the special education program specifically, study participants shared their thoughts about how teachers and other school personnel could be more positive and encouraging in their interactions with parents. Ethel suggested that, in order to make parents feel hopeful, teachers should explain that special education is not punitive, and they should clearly delineate what parents should expect. She also suggested that teachers display positive energy and confidence that the children will progress and succeed academically.

Georgia gave a very emotional explanation of her experiences with her son's teachers and how their insensitivity affected her.

Don't make the parent feel like, oh...oh...oh you ain't doing this, you ain't doing that, you ain't doing this, you ain't doing that. It's like telling somebody, ok, you don't walk in my shoes, but walk in my shoes.... [W]orking with kids that have special needs, is... it has to come from the heart. Ummm, it has to come from the heart. If it's not coming from the heart, you get frustrated, because things are not... your typical developing kids (unintelligible) frustrated, and ya know, angry, and 
umm... give up. But as a parent, it's not easy, but each day, you learn. Each day you go, ya know... it's not easy...it's not... we get frustrated too.

Emotional support towards children. When teachers are emotionally supportive towards parents, parents feel encouraged to participate in their child's education.

Likewise, when teachers and other school personnel are emotionally supportive towards children, parents have positive feelings towards the teacher, which will encourage the parent to become more involved.

One way that teachers or other school personnel display genuine care and love for the students is by communicating positive aspects of the child's development, while not focusing on only negative aspects. Betty described how the school psychologist was more concerned about what Breana is able to do, while the classroom teacher focused only on what Breana was not able to do.

[Indicating that the school psychologist was speaking to the classroom teacher] "We don't want a... the negative. We want to bring her to the positive, and try to help her. And how can we help her in school, not... not dwell on the problem, ya know the negative." She said, "We know, we know, we got all that. We're here to help. So how can we help her?" And she kept going back to the problem and all that. And she say, "Ok, we're done with you. I'm just gonna talk to the parent right now" [Chuckles]. [She] got upset with her.

A significant attribute of emotional support that study participants discussed was the teacher's willingness to do more than what was required or expected. When teachers went out of their way to assist students, parents regarded that teacher as loving. Tabitha shared the following:

Ya know, so he... she love him, and she was like, "Oh "Tony, you can do it." She always push them and stuff. So he... it was good like she was veeeery nice. Even after school was over she'd call up the parents and she was like, Oh I'm gonna have a party ya know at the center, so all the parents like she wanted to like say goodbye to the kids or whatever first. So, she was really, she really cared about 
the kids. You could tell. And it was a total difference. Like he, ya know, he was... he performed better. So yeah.

Betty also mentioned that, before Breana was evaluated and placed in special education, the special education teacher took Breana to her class when Breana's classroom teacher had put her in the hallway as a punishment for her hyperactive behavior. Betty appreciated that the special education teacher went out of her way to help her granddaughter, even though she had no obligation to her. Betty described the teacher as a nice and patient.

Henrietta felt that her daughter's school was a good place for her to be. When Harmony got older and it was time for her to transition to another school, there was an IEP meeting to discuss her progress, new goals, and placement for the upcoming school year. During the meeting, Henrietta explained that there was some controversy about which school Harmony would be attending because not all schools have programs for children with autism. She said that the teacher at Harmony's current school was supportive and that she "hope[s] to see my daughter there for this year."

One study participant told of an instance when she felt that school administrators were being emotionally supportive to another child. Jennifer's job obligations require her to visit the courthouse often. On one occasion, she saw one of the school administrators from a school that she was considering for her daughter. She later learned that the administrator was in court in support of a child who had gotten into trouble. The situation did not occur in school; however, the administrator was present in court simply to support a child who was a student in her school. Jennifer was happy to know that the administrators go beyond what is required to support their students. She shared, "...but in 
actuality, because she was there, I thought more highly of the school and that's...that made me want to put her [my daughter] there."

There were several comments from the study participants about other school personnel who were emotionally supportive. Parents shared comments such as, the assistant principal is willing to "make it work", she is caring and concerned (Georgia); she is confident in the child's progress in speech because of the speech therapist's positive interaction with the child (Henrietta), and that the paraprofessional was a "sweet lady" (Betty).

When these mothers view teachers and administrators as emotionally supportive, they reported that they feel a sense of collaboration and respectfulness. These are the elements that generate more involvement from these parents. Specifically, they are appreciative of teachers who are emotionally supportive towards them. Likewise, teachers who show emotional support toward the children are seen more favorably by the parents.

\section{Barriers to Parent Involvement}

During the course of each of the interviews, the participants were asked to rate their own level of parent involvement, one being completely uninvolved and five being the most involved. Eleven of the 15 mothers rated themselves as either a four or five. However, in addition to the mothers who rated themselves three or below, these mothers all cited areas where they felt their involvement was deficient. Even those with multiple children and full time jobs thought that there was more that they could do. When questioned about the barriers to their involvement, they shared personal factors and teacher traits and school policies that hindered their involvement. 


\section{Personal Factors}

According to research (Williams \& Sanchez, 2011), several barriers have been identified as having a negative impact on parent involvement, including, but not limited to time poverty, lack of access, and lack of resources. Additionally, single parenthood presents circumstances that limit the parent's school engagement (Newman \& Chin, 2003). These barriers can lead to frustration and isolation, which diminishes the likelihood of the parent being involved in his or her child's school.

Parents in this current study shared very similar sentiments as they discussed personal barriers to their own involvement or the involvement of African American parents in general. They cited several factors that deter parents from being involved. These include the related factors of socioeconomics, single parenthood, and lack of time.

Socioeconomics. Several of the mothers in this study shared their frustrations with not being able to provide a better educational foundation for their children due to lack of finances. Tabitha, for example, explained that she had a desire to secure tutoring services for her children. She commented that her level of knowledge limited her ability to help her children with the rigorous standards they are now required to learn. She comments:

We can't afford that. So, you don't invest like that because you don't have the means. It may not be so much that we don't really think that that's important. It's just like I... maybe just the means of it. And so it's frustrating. And you can't really do anything about it because you don't even understand yourself half of the stuff they teach... they're being taught. So you can't help them. And it's like, it makes you feel, you know... um... discouraged or whatever like you feel less.

Some parents also discussed how economics plays a role in the level of resources the school provides. For instance, during their individual interviews, both Ethel and Ivory 
made comments about how the lack of resources available to the school negatively impacts the students' education. In Ethel's experience, because she and her husband purchased a home in a high poverty area some years ago, she now sees the educational impact the lack of resources has on her children's school. For Ivory, she recognizes where her son's school is lacking, and tries to provide as much as she can; however, her own limited resources hinder her desires to provide more.

Single parenthood. Some of the study participants cited single parenthood as a hindrance to their parent involvement. Some of the hardships they shared included lack of childcare to attend meetings or school events, the noncustodial parent having limited involvement with the child due to custody issues, and the need of a single parent to work additional hours to compensate for the lack a second income instead of being more involved with the child's education. One parent explained, “...[I] can't tell FPL I had a meeting at school. I have to pay my bills..."

Lack of time. Time is a resource that is not available for some study participants. Two participants whose children attend school in Broward County both stated that they would attend the monthly district-sponsored meetings if they were offered at a different time. Due to working hours, neither of them could attend the meetings. Another obstacle facing parents is receiving meeting notifications with little time to plan or to make arrangements at work. Due to their other obligations, time is a valuable resource for these parents.

\section{Teacher Traits and School Policies}

Notwithstanding personal circumstances, parents also expressed a number of hindrances to parent involvement imposed by the teacher and the school. Cousins and 
Mickelson (2011) describe parents' feelings of discouragement and isolation when they do not understand the inner-workings of the school. This could be the result of poor communication. They further explain that teachers who do not respect parents' contributions that are different from those of mainstream parents risk alienating families, thus minimizing their involvement.

The current study's participants shared their views about teacher traits and school policies that hinder their involvement. These barriers include inadequate communication and devaluing parents' contributions. Teacher traits and school policies will be discussed together, as the parents often attributed the teacher's actions to the overall culture of the school or school system collectively.

\section{Inadequate Communication}

Negative calls and notes. One significant theme that emerged from the data centered on the lack of positive reports from school. Parents felt that they received phone calls from their child's teacher or school administrator only when their child misbehaved or experienced an academic failure. Rarely did the teacher call to share good news about the child's progress or mastery of a goal. Instead, the teachers reach out to the parents after the failure has occurred, taking a reactive approach rather than a proactive one. Tabitha sighed, "It's almost like she doesn’t care."

Conflicting information. Parents were bothered by the conflicting information they received from the teacher and from the school. For example, Keisha shared that her daughter's teacher continually expressed to her that Keona was performing well. However, when she received her report card, the child had failing grades. Furthermore, the teacher did not inform Keisha that Keona was in jeopardy of failing the grade. 
Monica's similar experiences with Michael's teachers developed into a lack of trust in the teacher and the school.

Unresponsiveness and lack of follow-through. The frustrations that study participants felt were evident as they discussed the teacher's and/or the school's unresponsiveness and lack of follow-through. Parents' experiences included teachers not responding to phone calls and meeting requests, teachers and district personnel not providing information as they promised, and recommendations that made during IEP meetings not being addressed as required. These inactions left many parents feeling defeated ("I just want to pull my daughter out"), confused ("So she had all Bs [on her progress report], and him [History teacher] with a C. I said, "Ohhhhh, ok. She's doing good now. She progressing." Got her report card... F), unsupported ("I depend on the teachers to help. And this particular teacher this year has not been that way"), and frustrated ("I'm reaching out to you and you're not responding back to me. [W]e not solving the problem and we not getting nowhere").

Negative demeanor. There were a number of teacher characteristics that parents felt diminished their desires to be involved in their child's education. Parents perceived teachers as being negative when their facial expressions and body language seemed cold and uninviting. Teachers who presented many problems but failed to provide solutions were also seen as being negative. One parent described a school principal as being cold and untruthful in his interactions with her. Ethel summed up her feelings with:

I think you know when you get a teacher that seem like they're overwhelmed and they're only focusing on the negative, then it's kind of hard for you to really even, you know, come up out of that whole thing to feel encouraged, or to ask questions... 


\section{Devaluing Parents' Contributions}

Parents' expertise. There were some study participants who shared that they were limited in their knowledge and understanding of their child's disability. Conversely, there were some parents who researched and studied their child's specific disability to gain a deeper understanding of what he or she needed to be successful. Additionally, parents have naturally had numerous interactions and experiences with their child, which enables them to have a unique vantage point. Be this as it may, some parents still experienced feelings of inadequacy when teachers ignored their suggestions about strategies that work best for their child. For example, during Grace's IEP meeting, the teachers were developing her goals. Gloria was not comfortable with the goals because she felt that they were too low. She tried to explain to the team that Grace had already mastered most of the goals that they were proposing. She suggested other goals that were more appropriate; however, the team disregarded those suggestions with comments that they needed to see Grace perform specific tasks at school, regardless of her ability to do them at home. They did not add any of Gloria's suggested goals to her daughter's IEP.

Parents' abilities. According to study participants, not only did teachers and school personnel disregard their expertise, they also showed indifference towards parents' abilities. For example, Georgia volunteered to attend field trips with her son's class to help with not only her child, but with all the children. She also expressed her willingness to volunteer in her child's classroom to assist the teachers, to share information with them about her son's disability, and to help with the other children in the class. However, her offers were met with silence from the teachers and the school. 
Their inaction spurred feelings of inadequacy in this parent, as she felt that they did not view her as knowledgeable or capable.

Not only did this parent feel inadequate, she also felt attacked and blamed for her son's disability. As she explained, the school did not welcome her attempts to be involved, but they always called her when her son was misbehaving. The teachers would question her about why he was acting out, and seemed to blame her for his misbehavior. She tried to explain to them that this was the reason why she wanted to volunteer in his class and share with them some of the characteristics of children with his type of disability. Unfortunately, she was not able to share that information with them. Soon after, she moved her son to another school.

Parents' preferences. One of the chief complaints from the parents in this study was the teachers' nonchalant attitudes about the parents' time. For example, the parents explained that they often received meeting notifications within just a few days of the meeting, not giving them adequate time to prepare. Also, one participant shared feelings of frustration when trying to schedule a meeting with her daughter's teacher. After several attempts to reach the teacher, she responded with, "I'm here from 7:30 - 2:00. After that, I can't help you." The parent's anger was very evident during the interview as she remembered the teacher's attitude and how she was being unjustly treated. She shared that the school administrators were not helpful either, as she attempted to speak with them several times, to no avail.

Another recurring problem that emerged from these parents' lived experiences was the disregard for their communication preference. One parent explained that she preferred receiving phone calls from her child's school because she is not comfortable 
with using technology. She has a cell phone, but uses it primarily to make and receive phone calls. She has a computer at home, but she does not use it. When the teacher has important information to share, she explained that he posts the information on his website. Therefore, if her child has a project to complete, or if she needs to study for an upcoming exam, for example, the parent will not be aware. She explained this to the teacher several times. She asked if he could simply print out the information and give it to the child so that she can bring it home. The teacher agreed, but has not done so.

However, the child has since missed several assignments.

\section{Lack of Emotional Support from Teachers}

Parents in this current study were very forthcoming about their experiences with the lack of emotional support from teachers and school personnel, and the impact it had in them and their children. One parent shared that the teacher's body language could be a deterrent, and this may be something that the teacher has not recognized as a problem with parent-teacher communication. Nadia commented:

So some teachers will come off strong, and might be intimidating to parents. The parents don't feel comfortable with coming to the teacher. ...Your body language, the way you carry yourself, like your posture, your face expressions, it tell...a person exactly how you feeling without you even knowing.... You got some that have a frown on they face already. They probably came to work with a attitude. Something going on home personally.

Ethel shared that negativity from teachers may leave parents feeling discouraged

and not wanting to ask questions:

Umm and umm I think you know when you get a teacher that to me they seem like they're overwhelmed and they're only focusing on the negative? Then it's kind of hard for you to really even, you know, come up out of that whole thing to feel encouraged, or to ask questions and get the kind of the answers you're looking for. 
Study participants also shared their feelings about teachers or school personnel

who seemed to generally report only negative behaviors or make only negative

comments. These comments had a negative impact on the parents in this study. Tabitha

made this comment:

Well yes, if that teacher is constantly...um... nitpicking every bad thing or every negative thing that the child does as if, you know, that child is a nuisance to them, that would deter a parent as well because you're like, "All they see is wrong that they do. She don't care. She just...." Ya know. And it just put a neg... you know, the parent in an uncomfortable situation, ya know?

Betty felt hurt when she learned that her kindergarten-aged granddaughter was

sitting in the hallway after being kicked out of class. The security guard shared that the

child had been sitting there and just singing church songs all by herself.

Betty: ... She really [needed] that one-on-one with that, ya know, to help her stay focused. She don't understand what's going on with her. And, that teacher, she (chuckles) kicks her out, too. And the security, Mr. J, we was close, and he would let me know, Breana sitting out the classroom in a chair, outside the classroom. What is that? That hurted me. So how is that happening? ... Because they not, they just kicking her out and how she learning like that? She don't know. He say Breana, she was in church a lot. He say Breana having church outside the classroom. She singing. They didn't bother her. She didn't know. He said she singing outside... He say, "Your granddaughter out there clapping and singing church songs outside of the classroom."

Researcher: And how did that make you feel?

Betty: That hurt me.

Henrietta shared her feelings of discontent when she attended an IEP meeting for her daughter. The team was discussing school options because her daughter was at the age where she was transitioning from the pre-kindergarten setting to the full kindergarten setting. Several schools were invited to the meeting. Henrietta shared that a representative from one of the schools immediately made her feel uncomfortable because this person 
started by explaining what the school was not going to be able to do, and if her daughter needed any special services the school was not equipped to provide them. Henrietta commented, “Umm, I don't think people realize that if you have a negative, I guess, tone or negative persona you [a parent] don't want to be bothered.

Georgia shared her thoughts about how teachers and school personnel must invest in the emotional development of children and their families. She understands that teaching children with special needs can be challenging. But she wants teachers to understand that raising children with special needs is also demanding. She suggested that teachers and parents commit to accepting and loving the child with his or her disabilities.

And then somebody will call you and, and, and virtually say, "So did you wash his face this morning?" Or... "Are you sending him out like that, like this", ya no (chuckles)? And it's like, so you, you feel bad because you feel like you're being attacked and it's like... Well then it lets me know that that para (pause) doesn't know the extent of the disability. She's just thrust there to do a job, and she may get aggravated because she has to wipe the nose, ya know, or do some other things, but they might be a part of the disability. Because we, WE have to deal with this 24 hours a day, ok. Uummm (pause), we have to learn to live with it, accept it, deal with it, and still love...our child. And I feel like if you're on a job, that's what you need to do. Learn how to deal with it, deal with it, (long pause) and still love the child.

Study participants were very forthcoming about hindrances to their parent involvement. They acknowledged that, although they had the desire to participate more, there were personal barriers impeding their involvement. They also discussed specific teacher traits and actions that deterred them from being more engaged, as well as some school policies that made participation difficult. 


\section{Recommendations to Teachers and School Administrators to Increase Parent Involvement}

Near the end of each interview, parents were asked to share their thoughts about what teachers, school administrators, and other school personnel needed to know to increase the level of parent involvement of African American parents of children with disabilities (See Table 2). After analyzing their suggestions, the data revealed three significant categories, which include Communication, Showing Care and Concern, and Accepting and Supporting Parents.

\section{Communication}

One recurring theme that has persisted throughout the data involves communication. Parents recommended that, in order to get African American parents involved in their child's education, teachers and other school personnel must communicate what they expect of the parent. That is, teachers must be specific about the various types of parent involvement activities that they expect, and then make several suggestions to parents so that parents feel that they have a choice in how to be involved. Moreover, they suggested that teachers communicate with parents on a personal level to gain a deeper understanding of the individual parent's needs. In this manner, teachers will be able to provide specific answers to the parent's specific questions, and become a resource to the family of the child.

\section{Show Care and Concern}

Study participants also recommended that teachers and other school personnel show genuine love, care, and concern about their students and the students' parents. They suggested that teachers engage with parents on a personal level and welcome them to the 
school and the classroom. They also offered that teachers should take an interest in the whole child beyond academics and see the child's full potential. By moving beyond what is required and getting to know the child and family on a deeper, more personal level, parents feel compelled to become involved. They feel hopeful.

\section{Accept and Support Parents}

One of the ways that these parents felt teachers could show care and concern is by accepting parents as they are and supporting their efforts to be involved. Because not every parent experiences the same life circumstance, nor is every parent as informed as others, teachers should be aware of each parent's level of knowledge and support them where they are. Furthermore, participants explained that it is important for teachers to treat all parents in like manner, regardless of the parent's level of involvement. If teachers practice seeing from the parent's perspective, perhaps they would realize that some parents may not be involved for legitimate reasons, supporting their suggestion that parents not be judged, but treated as equally as parents who are more involved. For those parents who make an effort to be involved, teachers should accept and support their actions.

Table 2.

Participants' Responses to What Teachers, Administrators, and Other School Personnel can do to Increase Parent Involvement of African American Parents of Children with Disabilities

\begin{tabular}{lll}
\hline Participant & & \multicolumn{1}{c}{ Recommendation } \\
1-Jennifer & - & Be proactive \\
2-Tabitha & - & Be proactive in communicating with parents \\
& - Don't wait until the child fails \\
& Tell me what to do for my child to be successful \\
3-Georgia & - & Care about the child and the family \\
\hline
\end{tabular}


- See the child's potential

4-Betty - Communicate with the parent

- Be specific in letting the parents know what they can do to help

5-Ethel - Make parents feel hopeful

- Tell parents what to expect and provide more insight about child's disability

6-Sarah - Communicate more

- Show care and concern about the child

- Be proactive and don't wait until the behavior is out of control

7-Gloria - Know children on a personal level

- Do more than what is required

- Show love and concern

8-Henrietta - Help general society understand disabilities

- Be aware of the parent's level of knowledge and support the parent

9-Ivory - Treat every parent the same, even the ones who are not as involved

- Be specific about what type of involvement would be helpful

- Provide choices of various types of involvement

10-Rhonda - Communicate with parents

- Be a resource to parents

11-Keisha - Communicate and provide an answer to the problem being discussed

- Cooperate with parents who are trying

- Don't judge parents

12-Cynthia

- Engage in personal interactions with parents (greet and welcome them)

- Show care and concern

- Try to see things from the parent's perspective (Put yourself in their shoes)

13-Nadia - Better communication

14-Monica - Show interest in the child as a whole - not just academics

- Treat all parents the same, even the ones who do not participate

- Communicate one-on-one with the parent and get to know the parent on a deeper level to find out why they are not as involved

15-Angel - Understand that parents may see parent involvement differently

- Reach out to parents and invite them in

- Accept various forms of parent involvement

- Be specific about what the parent can do to help the child

- Support parents in what they say they need 


\section{Chapter Summary}

Fifteen study participants engaged in one-on-one interviews where they discussed the phenomenon of parent involvement from the perspective of an African American parent of a child with special needs. The voice recorded interviews, which included the IEP reviews, and field notes were transcribed and the transcriptions were coded. Those codes were organized into categories, subcategories, and themes. The four themes that emerged from this rich data include perceptions of parent involvement, facilitators of

parent involvement, barriers of parent involvement, and recommendations to teacher and school administrators to increase parent involvement. 


\section{CHAPTER V}

\section{OVERVIEW, RECOMMENDATIONS, CONCLUSION}

Parent involvement is associated with positive educational and behavioral outcomes for school-aged children (Anderson \& Minke, 2007; Williams et al., 2011). However, parents in disenfranchised groups, specifically African American parents, are less likely to be involved (Jeynes, 2003; Al-Kandari \& Al-Qashan, 2010). There is an abundance of research that theorizes and postulates why African American parents are not involved and provides suggestions for increasing their involvement (Lewis et al., 2011; Williams \& Sanchez, 2012; Williams et al., 2011). However, for the vast majority of these studies, teachers, administrators, and other professionals are questioned; a very scant amount of scholarly work includes the voices of the parents themselves. This is even more problematic in the area of special education (Davis, et al., 2005).

The current study was conducted to provide a platform for African American parents of children with special needs to voice their perceptions of their own parent involvement, as well as their perceptions of teacher traits, characteristics, or actions that either promote or inhibit their level of involvement in the educational development of their child. As the 15 mothers who participated in this study shared their personal stories and insight, several themes emerged from the data. This chapter will provide an overview of those themes and make connections between the current research and scholarly work previously conducted in the field. Following the overview, this chapter will discuss the current study's limitations, implications for current practices, and recommendations for future research. 


\section{Broader Perspectives of Parent Involvement}

Though it is widely accepted in the educational arena that African American parents of children with special needs engage in parent involvement activities at a significantly lower rate than their White, middle class counterparts (Al-Kandari \& AlQashan, 2010; Durand, 2011; Jeynes, 2003; Kim, 2009; McDermott \& Rothenberg, 2000; Williams \& Sanchez, 2011), the parents of the current study provide a different point of view. These mothers reported that they are, in fact, involved in their children's education. When viewed from the perspective of these 15 participants, the concept of parent involvement is broader and more nuanced than definitions and illustrations adopted by the mainstream. There were three types of activities that were significant in the parents' explanations of their involvement, which include communication, volunteering, and home learning.

\section{Communication}

Previous research with African American parents supports having a positive and effective communication system between the parent and the school (Boyd \& Correa, 2005; Brandon, 2007; Williams et al., 2011). In the current study, parents also cited communication as a significant component of their parent involvement activities. First, parents preferred the more traditional communication methods, such as phone calls and written notes. Though they welcomed various types of communication, including emails, websites, and podcasts, most parents in this study preferred the more personable methods. They spoke more favorably of teachers who shared their cell phone numbers with parents and who made and received calls often. 
Secondly, parents were quite vocal about their desires for educators to be proactive in communicating with them. That is, these parents would like teachers and school administrators to contact them at the first sign of academic or behavioral problems with their children. Parents shared their frustration with the school's reactive response to problems that, in the parents' opinions, could have been avoided had the school taken a more proactive approach of involving them from the start.

Lastly, parents spoke of their desires for their children's teachers to be more positive. Positive phone calls or notes from the teacher were rare, and positive calls from school administrators were not specific to their child, but more informational in nature (i.e., testing and school-wide activities). Receiving positive communication specific to their child made parents feel that the teachers cared about their child and cared about them as a parent. These actions, they shared, made them want to be more involved in their child's education.

As previously detailed in Chapter 4 , the mothers in this study provided several examples of their communication efforts with either their child's teacher or with the school administrators. They requested parent-teacher conferences, they attended IEP meetings, they informed the school of their communication preferences, and some used emails or similar technologies in an effort to acquire or share information pertaining to their child's education. Unfortunately, their efforts went unanswered or were often disregarded. Study participants also shared their preferences and expectations for how teachers and other school staff should reciprocate their communication efforts. Specifically, parents would prefer that teachers use traditional forms of communication, alerting parents in advance of potential difficulties, and sharing student successes. When 
teachers, school support staff, or administrators failed to communicate with parents in ways that they expected or preferred (for example, sending emails to parents who do not use the computer, reaching out to the parent after the child has already failed, and contacting the parent solely to convey negative information) parents reported feeling disillusioned and disrespected. These actions, they reported, deter parents from wanting to be involved.

Similarly, researchers investigating the involvement of parents from culturally disenfranchised groups found that when schools fail to communicate with parents in ways that they prefer or that they feel to be more effective for them, parents become less involved (Kim, 2009; Williams et al., 2011). Further, parents stop reaching out to the school when they do not get a response or when they feel that their input is not needed or appreciated. When parents feel that communication with the school is generally negative, they are less likely to initiate or reciprocate dialogue, leading to diminished levels of parent involvement (Williams, et al., 2011).

When asked about their level of parent involvement, or when discussing their involvement activities, these study participants felt that they have a parental responsibility to communicate with their children's teachers. Through consistent and open dialogue, the parents are able to ascertain their child's progress, intervene in academic and/or behavioral concerns, share specific characteristics and needs of their children, and learn about the overall day-to-day happenings at the school.

\section{Volunteering/Involvement at School}

Another significant aspect of parent involvement discussed by study participants was volunteering or being present in their child's school. This is particularly interesting 
since, of the 15 mothers, two are stay-at-home parents, one is self-employed, and the remaining 12 have full-time jobs away from home. Though the majority of these parents have career obligations that demand much of their time during school hours, they felt that being present in school was important for the academic development of their child. In most instances, these mothers visited their child's school at the invitation of the teacher or other school personnel (i.e., Exceptional Student Education (ESE) specialist) for IEP meetings or for disciplinary reasons. In fact, the participants reported that they rarely missed an IEP meeting. Even if given short notice of only a few days for example, they would make arrangements with coworkers to cover their shifts, take personal time off work, attend the meeting via phone conferencing, or ask another family member to attend the meeting in their stead.

Even though these mothers never or rarely missed an IEP meeting, they reported that very little of what was stated in the IEP parent statement section reflected their actual concerns for their children. With the exception of two mothers (Jennifer and Henrietta), all participants (excluding the mother who did not provide an IEP) shared that they had more input than what was written as their statement. When pressed further, one mother (Gloria) said that she refused to voice her actual concerns because the IEP team members from the school seemed to have already decided what her daughter's goals should be.

In addition to attending required meetings, such as IEP meetings and parentteacher conferences for behavioral reasons, these mothers also described how they participated in their child's education by volunteering for field trips and volunteering on special school committees. Some of their time spent in school was also dedicated to 
specific accomplishments and celebrations such as awards ceremonies and birthday parties.

These mothers were candid about the various ways they participated in their child's education by visiting the school for formal meetings and scheduled events, as well as informal and impromptu visits. However, many of them also shared their desire for being more involved. For example, several of the mothers whose children attend school in Broward County shared their discontent with not being able to attend the districtsponsored SPED meetings due to the inconvenient location. They did not cite transportation as a barrier; rather, they explained that by the time they navigate traffic and travel the far distance to the school location, the meeting would be finished.

Just as some participants shared a desire to participate in district meetings to learn more about their child's disability, some parents spoke of a desire to volunteer in their child's school to be an asset for other African American children and their families. Participating in fundraising activities, helping out in the classrooms, and joining the school's Parent Teacher Association (PTA) were mentioned as possible volunteer options. Similar to the participants in earlier studies (Epstein et al., 2002; Williams and Sanchez, 2012; Williams, Sanchez, and Hunnell, 2011), the participants in this current study shared that volunteering in their child's class or school was important because it showed that they were interested in their child's progress and that they were concerned about other African American children succeeding in school as well. These parents recognized that not all parents could spend time at their child's school to be sure that he or she received a quality education; therefore, they felt that it was necessary for them to do as much as they could to ensure that all the children were succeeding. 
As previously stated, it is generally understood that African American parents are less involved in the educational develop of their children than other cultural groups. However, the parents in this current study have shared several examples of their involvement through volunteering and other in-school activities. Furthermore, they described how they overcome obstacles to be present at their children's schools, not only for the benefit of their child, but to be supportive of other African American families of children with special needs. These study participants have a perception that not all of their contributions or efforts are recognized. Therefore, the belief that they are not involved in their children's education is a narrow view of their actual involvement.

\section{Learning at Home}

Learning at home was noteworthy in discussions with the study participants about how they define parent involvement. Of the 15 participants, 13 spoke of some form of homework help, including direct and indirect assistance. Some parents sat with their child and provided one-on-one help and supervision. Other parents, specifically those of children in the advanced grades, solicited help from family, friends, and tutors when the academic demands were beyond their understanding. Others spoke of less direct homework involvement - their support included providing homework essentials, such as a quiet environment conducive for learning and study materials.

The range of home learning support that these participants described providing to their children echoes the various types of home learning activities addressed in previous research (Cunha, Rosário, Macedo, Nunes, Fuentes, Pinto, \& Suárez, 2015; Van Voorhis, 2003). More importantly, however, by participating in home learning activities at any 
level, these parents exhibited that they do, in fact, have a desire to participate in their children's education (Epstein, 2002; Van Voorhis, 2003; Williams \& Sanchez, 2011).

Three of the participants (Nadia, Monica, and Gloria) shared their views on learning at home from a more needs-centered perspective. That is, the mothers developed their own home learning activities based on their perspectives of what their children needed. One child, for example, required additional academic support in reading and writing. His mother developed learning activities so that the whole family could be engaged in the learning process. Another parent whose child has cognitive deficits developed in-home learning activities so that her daughter could learn to be self-sufficient with her personal care needs. These mothers did not feel that they were getting the support they needed from the school. They felt that the teachers had their own opinions of what their children needed, disregarding the expertise and desires of the parents. Kalyanpur and Harry (2004) explained that when teachers disregard the desires of the parent, they send a message that parents are deficient in their parenting skills because that do not know what is required for the child to be successful. These practices disenfranchise parents from the educational system, thus minimizing the participation of African American parents of children with disabilities (Davis et al., 2005; Harry, 2008). In the current study, there were three types of activities that were significant in the parents' explanations of their involvement, including communication, volunteering, and home learning. The parents' perceptions were that they are, in fact, involved in their children's education. Their efforts were not always recognized or acted upon, however, in some cases, they continued despite the lack of support from the school. 
These parents described involvement activities that may not be recognized by educators. For example, some parents shared that they not only communicate with the school staff about their child, but they also communicate with others (i.e., family members, specialists, other educators, school district personnel) who may be influential in providing the support that they or their child need. Furthermore, their volunteer efforts reach beyond their child's school or classroom; some of these parents discussed ideas about volunteering in the community to teach other parents about their rights and about raising children with a disability. In the case of home learning, several mothers discussed that they focus on more than just school-related homework activities; they teach their children the necessary skills that are individualized to their specific needs.

It is imperative that educators broaden their view of parent involvement to include the perspectives of parents from marginalized cultural groups. To this end, they can first recognize the various ways that African American parents are involved in their children's education, and then support them at their current levels of need. That is, provide parents with feedback on their child's progress in view of the help that the parents may be providing, and then support them with additional resources that may be helpful in supporting the child's specific needs. This will help the parents feel valued and, in turn, increase their level of involvement.

\section{Facilitators and Barriers to Parent Involvement}

As the mothers discussed the various ways in which they were involved in the educational development of their children, they also discussed specific teacher qualities and school policies that encouraged their involvement. When these qualities and policies were not present, parents were deterred from being engaged. The data revealed that these 
participants favored practices such as effective communication, valuing parent contributions, and exhibiting love and positive attitudes.

\section{Effective Communication}

As previously stated, the parents in the current study deeply emphasized the importance of effective communication between their children's teachers and school administrators and themselves. Research supports this finding (Boyd \& Correa, 2005; Williams et al., 2011), and emphasizes that, "strong communication between parents and school personnel is fundamental to this partnership and to building a sense of community between home and school (Williams \& Sanchez, 2011, p. 56). One way that school staff can strengthen their communication with parents, according to the current study's participants, is by using more conventional forms of communication, which is a significantly different finding than findings from previous studies. That is, rather than providing information via emails, websites, and/or other technology-based methods, educators should be aware that some parents would prefer receiving phone calls and written notes or letters. Participants spoke highly of teachers and other school staff who shared their cell phone numbers with the parents, and those who used the child's agenda to communicate back-and-forth. Parents felt respected and appreciated when they received a personal call or note. Further, they felt that the teacher truly cared about their child when they were proactive and took the time to contact the parent to share information early and often. Parents were then more compelled to take any necessary action in supporting the teacher and school. 
Conversely, when parents did not receive calls or written notes, or when the communication came as a result of academic or behavioral failures, the parents felt that the teachers and administrators did not respect them or care about their children. They shared feelings of defeat and frustration because any assistance they could have provided was no longer useful, as the failure had already occurred, and at times, resulted in significant consequences for the child. None of the mothers indicated that lack of communication deterred them personally from being involved; however, when speaking about actions that may deter African American parents in general from being involved, ineffective communication was a substantial part of the discussion.

Therefore, if school administrators and teachers are sincere about increasing the involvement of African American parents of children with special needs, they must consider improving the ways that they currently communicate with these parents. Although schools operate in a technologically advanced arena, not all families are comfortable with receiving information via emails and websites. Utilizing more personable avenues of communication, such as phone calls and written notes may increase parents' participation. Further, teachers should be encouraged and supported in reaching out to parents to provide positive reports. Not all correspondence should be for the purpose of delivering negative information about students' progress. When there is effective communication and constructive feedback, parents feel more comfortable, they feel a greater sense of belonging, and their level of involvement increases.

\section{Valuing Parents' Contributions}

When members of the dominant culture use their own standards and principles to evaluate the actions of members of marginalized cultures, the contributions of the latter 
cultures may be devalued (Trainor, 2008; Wilson, 2015). Similarly, when African American parents of children with special needs, a marginalized group, contribute to their children's education according to their own social and cultural capital, oftentimes those contributions are not recognized as valuable by teachers or school administrators, who have historically adopted the dominant culture's standard for what parent involvement should encompass (Banerjee et al., 2011; Bower \& Griffin, 2011). When parents perceive that their actions are not valued, feeling of discontent with teachers and other school personnel may arise (Martinez-Cosio, 2010; Trainor, 2008; Wilson, 2015). The mothers in the current study shared similar sentiments.

Current study participants discussed their individual and collective contributions to their children's education. Individually, several parents shared that, regardless of the educational level they had attained, they were still able to contribute to the educational growth of their child. However, their perception was that their children's teachers did not recognize their contributions, nor did they value them because the parents were not college graduates. They felt that the teachers assumed what they were or were not capable of doing or willing to do. In some instances, they shared that they were actually already doing what it was assumed they were not doing. Although, according to the parents, this did not directly deter them from being involved, it did lead to feeling of inadequacy and overall dissatisfaction with the school.

In addition to valuing their individual strengths, the participants also discussed their collective strengths. The village concept was often referred to during the interviews. The parents shared that they often relied on family members and close friends to assist with school-related matters. This included, but was not limited to respite care, emergency 
situations, and tutoring or homework support. More specific to special education, the parents discussed the importance of having support during IEP and similar meetings to help in making educational decisions for the children. To this end, the parents talked openly about teachers and other school member having membership in the village. That is, these parents relied on their children's teachers to keep them informed of the day-today happenings in school as well as any information pertinent to their child's individual needs.

\section{Exhibiting Love and Positive Attitude}

Researchers have found that when teachers and other school personnel are emotionally supportive, parents engage with the teacher and the school differently than if they were not (Kim, 2009; McCormick et al., 2013). Parents view these teachers as more collaborative and respectful, which increases the parents' involvement. Likewise, the parents in this current study shared their feelings of content with their children's teachers who openly exhibited a loving demeanor towards them and their children. This is a significant finding, as only a few studies have been conducted which discuss emotional support and parent involvement.

The mothers in the current described various ways in which teachers and the school environment were warm and welcoming. One parent (Tabitha) recalled a time when her child's teacher communicated with her much more than it was required and more than she had expected. This parent felt that the teacher had a desire for her son to do well. Another parent (Jennifer) described the welcoming atmosphere at her daughter's school, explaining that the entrance of the school was painted with murals that that felt inviting. 
With respect to love and support shown to the children, one parent (Betty) recalled the time when her child had been referred for an evaluation. The school psychologist was more interested in hearing about the child's accomplishments and abilities. This made the parent feel that her child mattered beyond the test scores.

Conversely, lack of emotional support from educators evoked negative feelings in the parents, such as discouragement and isolation. Some examples of teachers' behaviors included negative body language and facial expressions, reporting only negative reports about the child's progress, and negative actions from the teachers, like kicking the child out of class with no regard for his or her disabling conditions. These types of actions were deterrents to parent involvement according to these study participants.

Perhaps teachers, school administrators, and other staff could benefit from professional development activities focused on preparing them to be more emotionally supportive to families in marginalized cultural groups who are raising children with special needs. This is a unique population that has been found to be the least involved in their children's education, when involvement is defined using mainstream values. Yet, due to the significant learning and/or behavioral challenges of their children, African American parents of children with special needs are in need of the greatest support.

\section{Personal Barriers to Parent Involvement}

In addition the actions and attitudes of teachers and school administrators, participants spoke of personal circumstances and life situations that impeded their involvement in their child's education. Having limited financial resources was a significant deterrent for some of the mothers in this current study. Because they had limited income, these parents could not provide the additional support that their children 
needed to succeed academically. Hiring a tutor, for example, was a desire that some of the participants wished to provide for their child who struggled in math, science, or reading. Not only did they mention how their financial situation impacted their child, these parents also mentioned how schools in low socioeconomic areas do not provide an adequate education to the children due to their own limited resources. The views of the parents in the current study mirror previous research outcomes that found that limited financial resources often deter African American parents from being involved in their child's education (Cousins \& Mickelson, 2011; Williams \& Sanchez, 2011).

Single parenthood and limited time were also discussed in the interviews with the study participants as deterrents to their involvement. These barriers seemed to occur concomitantly - because the single mothers worked additional hours and because they had multiple responsibilities as the primary caregiver, their days and evenings were consumed with very little time to contribute to parent involvement activities that occurred outside of the home. Newman and Chin (2003) referred to this phenomenon as time poverty, where poor working families lack free time to dedicate to their child's educational concerns. Other studies also found that single parents and teen parents were less likely to be involved in their children's education due to a lack of economic and time resources (Cousins \& Mickelson, 2011; Williams \& Sanchez, 2011).

\section{Parents' Recommendations to Increase Parent Involvement}

Before closing the interviews, the study participants were given an opportunity to share their thoughts and suggestions for increasing parent involvement of African American parents of children with special needs. Their suggestions to teachers and school administrators included communicating effectively and often with parents. They should 
be sure to communicate in a method that is preferred by the parent, and they should include positive comments in the conversation. Providing positive comments makes parents feel that their child is loved and valued. When parents sense that they and their child are esteemed, they desire to be more engaged. They contribute to the educational development of their children and support the schools. Lastly, when parents volunteer their time and services to the school, or when they support their children according to their own financial, educational, or familial resources, their efforts should be valued and appreciated.

\section{Limitations}

The current phenomenological study has several limitations that should be noted. First, fourteen of the fifteen participants rated themselves as being moderately or highly involved in their children's education. Including the voices of parents who perceive themselves as having limited or no involvement in their child's education should be considered. Also, all study participants were female. Parent involvement from the perspective of fathers may enrich the results. Lastly, the researcher was acquainted with eight of the participants prior to the study; she and six of the participants attend the same church and she has professional relationships with two participants. This familiarity may have had some impact on the participants' comfort with sharing their thoughts and opinions.

\section{Implications for Current Practice}

Scholars propose that parent involvement in urban education significantly lags behind the involvement of parents in the dominant culture (Al-Kandari \& Al-Kashan, 2010; Jeynes, 2003; McDermott \& Rothenberg, 2000). According to researchers, this is 
even more detrimental in urban special education (Pang, 2011; Parette \& Petch-Hogan, 2000). However, parents in previous studies (Abdul-Adil \& Farmer, 2006; Williams \& Sanchez, 20002) as well as parents in the current study maintain that they are, in fact, involved in their children's education. African American parents consider both at-school and at-home activities when describing their involvement. Before ascribing value to a parent based on what may be misperceived as a lack of involvement, perhaps educators should consider expanding their understanding of parent involvement to include the activities of non-dominant cultures.

Additionally, African American parents may not always overtly indicate their desires to be involved (Abdul-Adil \& Farmer, 2006); however, it should not be assumed that they do not have a desire or the ability to be involved in their child's education. Rather than erroneously assuming that parents could not or would not contribute effectively to their children's education, teachers and administrators should specify how parents could be useful and then provide various options and opportunities for their involvement.

To assist teachers and other school personnel with recognizing the contributions that parents from various cultures already make towards their children's academic growth, and to help educators support parents with potential involvement efforts, the school systems in both Broward and Miami-Dade Counties should offer professional development activities in Cultural Reciprocity (Kalyanpur \& Harry, 2012). With this principle, parents and professionals can develop a cultural self-awareness and recognize, among other things, that parent involvement may be perceived differently by persons of various cultures. Furthermore, when parents and professionals learn to respect one 
another's differences as attributes, new lines of communication could be opened and broken lines of communication may be repaired. This could lead to parents being and feeling more valued as co-partners in the education of their child, possibly compelling them to become more involved.

\section{Recommendations for Future Research}

Recommendations for future research include exploring the perceptions of parents in other culturally and linguistically diverse groups, namely Hispanic, Haitian, and Jamaican parents since these are large cultural groups in the southeastern region of Florida. These groups are also disproportionately overrepresented in special education programs across the United States, with Haitians and Jamaicans being categorized with African Americans.

Another recommendation is for future researchers to include the voices of parents who chose to not attend their children's IEP meetings. Significant educational decisions for children are considered at these meetings. Providing parents the opportunity to discuss why they do not attend these meetings may provide school districts with additional information necessary to enhance their efforts to include these families.

A final recommendation to future researchers is to include the voices of both the African American teachers and the African American parents of the children they teach. Getting bilateral viewpoints may yield richer data from which findings can be drawn. Perhaps the influence of social capital may be recognized.

\section{Chapter Summary}

African American parents of children with special needs were asked to participate in this research study designed to ascertain their perceptions of their own involvement, 
and of how teacher actions and school policies hindered or facilitated that involvement. Participants perceived themselves as being involved in their children's education through their communication, volunteering, and home learning efforts. Parents also shared that when educators communicated effectively, valued their contributions, and expressed love towards them and their children, they were more compelled to be involved. When these things were missing, participants were reluctant to be involved. Parents also recommended that educators communicate early and often, show care and concern for parents and children, and be accepting of parents' efforts in order to increase participation of African American parents. This final chapter also outlined limitations to the current research, shared implications for current practice, and made recommendations for future research. 


\section{REFERENCES}

Abdul-Adil, J. K. \& Farmer, A. D. (2006). Inner-city African American parental involvement in elementary schools: Getting beyond urban legends of apathy. School Psychology Quarterly, 21(1), 1-12.

Al-Kandari, H. Y., \& Al-Qashan, H. (2010). Maternal self-efficacy of mothers of children with Intellectual Development Disabilites, Down Syndrome, and Autism in Kuwait. Child and Adolescent Social Work Journal, 27, 21-39.

Anderson, K. J., \& Minke, K. M. (2007). Parent involvement in education: Toward an understanding of parents' decision making. The Journal of Educational Research, 100(5), 311-323.

Ashworth. P. (1999). "Bracketing" in phenomenology: Renouncing assumptions in hearing about student cheating. Qualitative Studies in education, 12(6), 707-721.

Bailey, L .B., Silvern, S. B., Bradham, E., \& Ross, M. (2004). The effects of interactive reading homework and parent involvement on children's inference responses. Early Childhood Education Journal, 32(3), 173-178.

Banerjee, M., Harrell, Z., \& Johnson, D. J. (2011). Racial/Ethnic socialization and parental involvement in education as predictors of cognitive ability and achievement in African American children. Journal of Youth and Adolescence, 40(5), 595-605.

Beech, M. (2012). Developing quality individual education plans: A guide for instructional personnel and families. (3rd ed.). Tallahassee, FL: Florida Department of Education Bureau of Exceptional Education and Student Services

Bogdan, R., \& Biklen, S. (2007). Qualitative research for education: An introduction to theories and practice (5th ed.). New York, NY: Pearson Education.

Bower, H. A., \& Griffin, D. (2011). Can the Epstein Model of parental involvement work in a high-minority, high-poverty elementary school? A case study. Professional School Counseling, 15(2), 77-87. 
Boyd, B. A., \& Correa, V. I. (2005). Developing a framework for reducing the cultural clash between African American parents and the Special Education system. Multicultural Perspectives, 7(2), 3-11.

Brandon, R. R., (2007). African American parents: Improving connections with their child's educational environment. Intervention in School and Clinic, 23(2), 116120.

Brantlinger, E., Jimenez, R., Klingner, J., Pugach, M. \& Richardson, V. (2005). Qualitative studies in special education. Exceptional Children, 71, 195-207. Center for Parent Information and Resources (n.d.). Retrieved from. http://www.parentcenterhub.org/repository/idea/

Cooper, C. W. (2003). The detrimental impact of teacher bias: Lessons learned from the standpoint of African American mothers. Teacher Education Quarterly, 30(2), 101-116.

Cooper, C. W. (2009). Parent involvement, African American mothers, and the politics of educational care. Equity \& Excellence in Education, 42(4), 379-394.

Corbin, J., \& Struass, A. (2008). Basics of Qualitative Research: Techniques and Procedures for Developing Grounded Theory. Los Angeles, CA: Sage.

Creswell, J. W. (2003). Research design: Qualitative, quantitative and mixed methods (2nd ed.). Thousand Oaks, CA: Sage.

Creswell, J. W., Hanson, W. E., Clark-Plano, V. L., \& Morales, A. (2007). Qualitative Research Designs: Selection and Implementation. The Counseling Psychologist, 35(2), 236-264.

Creswell, J. W., \& Miller, D. L. (2000). Determining validity in qualitative inquiry. Theory Into Practice, 39(3), 124-131.

Cunha, J., Rosario, P., Mecedo, L., Nunes, A. R., Fuentes, S., Pinto, R., \& Suarez, N. (2015). Parents' conceptions of their homework involvement in elementary school. Psicothema, 27(2), 159-165.

Davis, C., Brown, B., Bantz, J., \& Manno, C. (2005). African American's parents' involvement in their children's special education programs. Multiple Voices, 5(1), 13-27.

Diamond, J., Wang, L., \& Gomez (2006). African-American and Chinese-American parent involvement: The importance of race, class, and culture. Family Involvement Research Digests: Harvard Family Research Project (no volume or issue number). 
Durand, T., M. (2011). Latina mothers' cultural beliefs about their children, parental roles, and education: Implications for effective and empowering home-school connections. The Urban Review, 43, 255-278.

Eccles, J. S. \& Harold, R. D. (1993). Parent-school involvement during the early adolescent years. Teachers College Record, 94(3), 568-587.

Education Information and Accountability Services Data Report (2011). Teacher Demographics in Florida's Public Schools, Fall 2010.

Elias, M. J., \& Schwab, Y. (2004). What about parental involvement in parenting? The case for home-focused school-parent partnerships. Education Week 24(8): 39-41.

Epstein, J. L. (1987). Parent involvement: What research says to administrators. Education and Urban Society, 19(2), 119-136.

Epstein, J. L. (2005). Attainable goals? The spirit and letter of the No Child Left Behind Act on parental involvement. Sociology in Education, 78(2), 179-182.

Epstein J. L., Sanders, M. G., Sheldon, S. B., Simon, B.S., Salinas, K. C., RodriguezJansorn N, Van Voohis, F. L. (2009). School, Family, and Community Partnerships: Your Handbook for Action (3rd ed.). Thousand Oaks, CA: Corwin Press.

Epstein, J. L., Van Voorhis, F. L. (2010). School counselors' roles in developing partnerships with families and communities for student success. Professional School Counseling, 14(1), 1-14.

ESSA. (2015). Retrieved from https://ed.gov/policy/elsec/leg/essa/index.html

Ferrara, M. M. \& Ferrara, P. J. (2005). Parents as partners: Raising awareness as a teacher preparation program. The Clearing House, 79(2), 77-82.

Feuerstein, A. (2000). School characteristics and parent involvement: Influences on participation in children's schools. The Journal of Educational Research, 94(1), $29-40$.

Florida Department of Education Bureau of Exceptional Education and Student Services (2012). A parent's introduction to exceptional student education in Florida. Retrieved from http://www.fldoe.org/academics/exceptional-student-edu/

Florida Department of Education: ESE Eligibility (n.d.). Retrieved from http://www.fldoe.org/academics/exceptional-student-edu/ese-eligibility/ 
Florida Department of Education: Graduation Rates (n.d.). Retrieved from http://www.fldoe.org/accountability/data-sys/edu-info-accountability-services/pk12-public-school-data-pubs-reports/students.stml.

Frew, L. A., Zhou, Q., Duran, J., Kwok, O., \& Benz, M. R. (2013). Effect of SchoolInitiated Parent Outreach Activities on Parent Involvement in School Events. Journal of Disability Policy Studies, 24(1), 27-35.

Gabriel, K. O. S., \& Getch, Y. Q., (2001). Parental training and involvement in sexuality education for students who are deaf. American Annals of the Deaf, 146(3), 287293.

Garcia, S. B., \& Guerra, P. L. (2004). Deconstructing Deficit Thinking: Working with educators to create more equitable learning environments. Education and Urban Society, 36(2), 150-168.

Goss, A. C. (2015). Toward a village consciousness: Organizing in the African American cultural tradition. Journal of Black Studies, 46(8). 797-816.

Green, C. L., Walker, J. M. T., Hoover-Dempsey, K. V., \& Sandler, H. M. (2007). Parents' motivations for involvement in children's education: An empirical test of a theoretical model of parental involvement. Journal of Educational Psychology, 99(3), 532-544.

Harry, B. (2008). Collaboration with culturally and linguistically diverse families: Ideal versus reality. Exceptional Children, 74(3), 372-388.

Harry, B., Kalyanpur, M., \& Day, M. (1999). Building Cultural Reciprocity with Families: Case Studies in Special Education. Baltimore, MA: Brooks Publishing.

Hocutt, A., \& Fowler, K. M. (2009). Case study research: An overview. In Paul, J., Kleinhammer-Tramill, J., \& Fowler, K. (Eds.), Qualitative Research Methods in Special Education (pp. 53-94). Denver, CO: Love Publishing Company.

Hoover-Dempsey, K. V. \& Sandler, H. M. (1995). Parent involvement in children's education: Why does it make a difference? Teachers College Record, 97, 310331.

Howard, T. C. \& Reynolds. R. (2008). Examining parent involvement in reversing the underachievement of African American students in middle-class schools. Educational Foundation, 22(1-2), 79-98.

Humphries, M. L., Strickland, J., \& Keenan, K. (2014). African American preschoolers' social and emotional competence at school: The influence of teachers and mother. Journal of Education, 194(1), 11-18. 
IDEA. (2004). Retrieved from http://idea.ed.gov

IDEA-B. (2004). Retrieved from http://idea-b.ed.gov/explore/home.html

Jacobi, E. F., Wittreich, Y., \& Hogue, I. (2003). Parental involvement for a new century. New England Reading Association Journal, 39(3), 11-16.

James, P., Kleinhammer-Tramill, J., \& Fowler, K. (2009). Qualitative Research Methods in Special Education. Denver, CO: Love.

Jeynes, W. H. (2003). A META-ANALYSIS: The effects of parental involvement on minority children's academic achievement, Education and Urban Society, 35(2), 202-218.

Jones, L. N., (2014) . Barriers to parent involvement for children at risk (Doctoral dissertation, St. John's University). Retrieved from http://search.proquest.com.ezproxy.fiu.edu/results.

Kalyanpur, M., Harry, B. (2004). Impact of the social construction of LD on culturally diverse families: A response to Reid and Valle. Journal of Learning Disabilities, 37(6), 530-533.

Kalyanpur, M., Harry, B. (2012). Cultural Reciprocity in Special Education: Building Family-Professional Relationships. Baltimore, MD: Brookes.

Kim, Y. (2009). Minority parental involvement and school barriers: Moving the focus away from deficiencies of parents. Educational Research Review, 4, 80-102.

Layton, L. (2013, June 27). Academic achievement gap is narrowing, new national data show. The Washington Post. Retrieved from http://articles.washingtonpost.com/2013-06-27/local/40222935_1_achievementgap-reading-test-test-scores

Lee, J., \& Bowen, N. K. (2006). Parent involvement, cultural capital, and the achievement gap among elementary school children. American Educational Research Journal, 43(2), 193-218.

Lewis, L. L., Kim, Y. A., \& Bey, J. A. (2011). Teaching practices and strategies to involve inner-city parents at home and in the school. Teaching and Teacher Education, 27(1), 221-234.

Lincoln, Y. S., \& Guba, E. G. (1985). Naturalistic Inquiry. Thousand Oaks, CA: Sage Publishing. 
Lopez, G. R., Scribner, J. D., \& Mahitivanichcha, K. (2001). Redefining parental involvement: Lessons from high-performing migrant-impacted schools. American Educational Research Journal, 38(2), 253-288.

Mapp, K. (2003). Having their say: Parents describe why and how they are engaged in their children's learning. School Community Journal, 13(1), 35-64.

Marshall, C., \& Rossman, G. B. (2006). Designing Qualitative Research (4 ${ }^{\text {th }}$ ed.). Thousand Oaks, CA: Sage Publishing.

Martinez-Cosio, M. (2010). Parents' roles in mediating and buffering the implementation of an urban school reform. Education and Urban Society, 42(3), 283-306.

McCormick. M. P., Cappella, E., O'Connor, E. E., \& McClory, S. G. (2013). Parent involvement, emotional support, and behavior problems: An ecological approach. The Elementary School Journal, 114(2), 277-300.

McCray, R., Grant, C. M., \& Beacham F. D., (2010). Pedagogy of self-development: The role the Black church can have on African American students. The Journal of Negro Education, 79(3), 233-248.

McDermott, P., \& Rothenberg, J. (2000). Why urban parents resist involvement in their children's elementary education. The Qualitative Report [On-line serial], 5(3/4). Available: http://www.nova.edu/ssss/QR/QR5-3/mcdermott.html

Moustakas, C. (1994). Phenomenological research methods. Thousand Oaks, CA: Sage.

National Center for Educational Statistics (2012).Retrieved from https://nces.ed.gov/programs/digest/d12/tables/dt12_104.asp

No Child Left Behind of 2001. Public Law No. 107-110, 115 Stat. 1425(2002).

Onwuegbuzie, A.J.\& Leech, N.L. (2005). A typology of errors and myths perpetuated in educational research textbooks. Current Issues in Education [On-line], 8(7). Available: https://cie.asu.edu/ojs/index.php/cieatasu/article/viewFile/1604/647

Onwuegbuzie, A. J., \& Leech, N. L. (2007a). A call for qualitative power analysis. Quality \& Quantity, 41(1), 105-121.

Onwuegbuzie, A. J., \& Leech, N. L. (2007b). Validity and qualitative research: An oxymoron?. Quality \& Quantity, 41(2), 233-249.

Pang, Y. (2011). Barriers and solutions in involving culturally linguistically diverse families in the IFSP/IEP process. Making Connections, 12(2), 42-51. 
Parette, H. P., \& Petch-Hogan, B. (2000). Approaching family: Facilitating culturally/linguistically diverse family involvement. Teaching Exceptional Children, 35(2), 2-10.

Patton, M. Q. (1990). Qualitative Evaluation Methods (2nd ed.). Thousand Oaks, CA: Sage.

Patton, M.Q. (2002). Qualitative Research and Evaluation Methods. Thousand Oaks, CA: Sage.

Paul, J., Kleinhammer-Tramill, J., \& Fowler, K. (2009). Qualitative Research Methods in Special Education. Denver: Love Publishing Company.

Pena, D. C. (2000). Parent Involvement: Influencing factors and implications. The Journal of Educational Research, 94(1), 42-54.

Quezada, R. L., (2003). Going for the gold! Field reports on effective home-schoolcommunity partnership programs. School Community Journal, 137-156.

Seidman, I. (2013). Interviewing as Qualitative Research: A Guide for Researchers in Educational and The Social Sciences ( $4^{\text {th }}$ ed.). New York, NY: Teachers College Press.

Sharp, E. A, \& Ispa, J. M. (2009). Inner-city single Black mothers' gender-related childrearing expectations and goals. Sex Roles, 60, 656-668.

Sheldon, D. L., Angell, M. E., Stoner, J.B., \& Roseland, B. D. (2010). School principals' influence on trust: Perspectives of mothers of children with disabilities. The Journal of Educational Research, 103(3), 159-170.

Spann, S. J., Kohler, F. W., \& Soenksen, D. (2003). Examining parents' involvement in and perceptions of special education services: An interview with families in a parent support group. Focus on Autism and Other Developmental Disabilities, 18(4), 228-237.

Stanley, S. L. G., (2013). African American mothers of children with disabilities: Parent advocacy within rural special education (Doctoral dissertation, the University of Carolina at Greensboro). Retrieved from http://search.proquest.com.ezproxy.fiu.edu/docview.

Strauss. A., \& Corbin, J. (1990). Basics of qualitative research. Newbury Park, CA: Sage.

Thompson, G. (2003). What African American parents want educators to know. Westport, CT: Praeger. 
Thompson, P. W., (2014). African American parent involvement in special education: Perceptions, practice, and placement (Doctoral dissertation, University of California, San Diego). Retrieved from http://search.proquest.com.ezproxy.fiu.edu/results.

U.S. Department of Education. (n.d.). Retrieved from http://www2.ed.gov/parents/needs/speced/iepguide/index.html

U.S. Department of Education: Part A. (n.d.). Retrieved from https://www2.ed.gov/policy/elsec/leg/esea02/pg2.html\#sec1118

Van Voorhis, F. (2003). Interactive homework in middle school: Effects on family involvement and science achievement. The Journal of Educational Research 96(6), 323-338.

Vaughn, S., Bos, C. S., \& Schumm, J. S. (2011). Teaching students who are exceptional, diverse, and at risk in the general education classroom. Upper Saddle River, N.J: Pearson Education.

Williams, E. R., (2007). Unnecessary and unjustified: African American parental perceptions of special education. The Education Forum, 71, 250-261.

Williams, T. T. \& Sanchez, B. (2012). Parent involvement (and uninvolvement) at an inner-city high school. Urban Education, 47(3), 625-652.

Williams, T. T., Sanchez, B., \& Hunnell, J. (2011). Aligning theory with practice: Understanding school-family partnerships at an inner-city high school. Children and Youth Services Review, 33(5), 689-697.

Wilson, N. M., (2015). Question-asking an advocacy by African American parents at Individualized Education Program meetings: A social and cultural capital perspective. Multiple Voices for Ethnically Diverse Exceptional Learners, 15(2), 36-49.

Yosso, T. J., (2005). Whose culture has capital? A critical race theory discussion of community cultural wealth. Race, Ethnicity, and Education, 8(1), 69-91.

Young, C. Y., Austin, S. M., \& Growe, R. (2013). Defining parental involvement: Perceptions of school administrators. Education, 133(3), 291-297. 


\section{APPENDIX}

Possible interview questions are as follows:

\section{Preliminary / Personal Data Questions}

1. Please tell me a little about yourself.

a. What's your name and age?

b. Are you married?

c. How would you define your nationality, race, culture?

d. Are you employed? Where? What are your work hours?

e. What's your job's policy for taking off to visit your child's school?

2. Tell me about your children.

a. How many children do you have?

b. Which of your children are in the special education program?

c. What is his/her disability/exceptionality?

d. What is his/her age and current grade level?

e. What services does your child need? Who generally provides those services?

3. Tell me about your child's school.

a. Is your child's school traditional, charter, magnet, etc.?

b. How long has your child attended the school?

c. Do you live in the same neighborhood as your child's school?

d. How would you define the "atmosphere" of the school: friendly, intimidating, etc.?

e. Are you satisfied with your child's school?

\section{How is parental involvement defined / perceived for these members of the} African American community?

1. What does the term "parent involvement" mean to you?

a. What comes to mind when you think about that phrase?

b. Do you have any examples of what it is not?

2. Tell me about your experiences with parent involvement when you were a child?

a. How is your parent involvement with your son/daughter different or similar to your parents' involvement with you when you were a child?

b. Are you comfortable with your level of parent involvement?

c. Do you think that your child's disability impacts your level of involvement? How so? Why not?

3. How important is parent involvement to you? 


\section{How do conceptual differences in the definition of parent involvement between African American parents of students with disabilities and the mainstream culture impact parent/teacher dynamics?}

1. Do you think that other people have the same ideas about parent involvement as you have?

a. Tell me about that.

b. Do you think that your level or type of involvement is pretty much the same as everybody else's?

- Tell me more about that.

2. Do you think that other cultures define or experience parent involvement in the same ways as the African American community?

a. Can you tell me about a time or incident when you observed parent involvement of someone from a different culture?

b. Do you think that people from other cultures view African American parents the same way as themselves with respect to parent involvement?

- Do you think that other people think Black people are as involved with their children as they might be?

3. Do you think that parents of children who are not in the special education programs experience parent involvement the same as parents of children with special needs?

a. How is parent involvement different for parents of general education students?

b. How has your involvement changed since your child was placed in special education?

4. Do you think that your child's teacher sees you as an involved parent?

- How do you know that?

- What has the teacher done or not done to make you feel that way?

a. Do you think that the teacher's assessment of your involvement is a fair measure of your level of parent involvement?

b. How has the teacher's perceptions of you affected your relationship with him/her? Affected your level of involvement?

\section{What teacher characteristics/traits/actions, if any, are attributed to the level of parent involvement of African American parents of children with disabilities?}

1. Tell me about the last IEP meeting your attended?

a. How were you invited to the meeting?

- Was that the best way to contact you? 
b. Who were the members of the IEP team?

- Did you feel as though you were a member of the team?

- How did the other team members make you feel involved?

c. How much of what was happening at the meeting did you understand (a lot, some things, or very little)?

d. What concerns did you express at the meeting?

- Were those concerns addressed? How so? Why not?

e. How did you feel after you left the meeting?

2. Tell me about any other times that you visited your child/s school.

a. How do you feel when you visit the school?

b. Is there anything that the teacher does or does not do to make you feel welcomed?

c. Have any of your child's teachers ever made you feel welcomed at the school?

3. What can teachers do to maintain or increase your level or type of parent involvement?

\section{What teacher characteristics/traits/actions, if any, adversely impact the level of parent involvement of African American parents of children with disabilities?}

1. Tell me about a time when you visited your child's school and felt completely unwelcomed or uneasy about being there.

a. Have you ever discussed this experience with anyone else?

b. How did the classroom teacher help or hurt the situation?

c. How did that incident change the way you interact with teachers, either during that time or now?

2. What role do school administrators play in your level or type of parent involvement? 
VITA

\section{PRINCESS BRIGGS}

1994

Bachelor of Arts - University of Miami

Majors: Special Education and Psychology

Florida Teacher Certification

Exceptional Student Education

2005

Master of Science - University of Miami

Specializations: Exceptional Student Education, Pre-Kindergarten

Disabilities, and English for Speakers of Other Languages

$2013-2016$

Adjunct in EEX 3070 Course

Provided instruction to pre-service teachers for teaching children with special needs in an inclusive setting

2015 - $2017 \quad$ Doctoral Candidate - Florida International University

Specialization: Special Education

Areas of Interest: Teacher Education and Parental Involvement

\section{PUBLICATIONS AND PRESENTATIONS}

Briggs, P. (2011). Attention Deficit Hyperactivity Disorder. Presented at the Family and Parenting Conference, HOPE Church, Davie, Florida.

Briggs, P. (2012). Room 214: Nurturing an evolving classroom culture. In Wynne, J., Delpit, L., $\&$ Miles, R. (Eds.), Confessions of a white educator: Stories in search of justice and diversity (pp. 53-60). Dubuque, IA: Kendall Hunt.

Lopes, A, Hernandez, K. \& Briggs, P. (2012). Alternatives to Standard English as Stepping

Stones to Success. Presented at Council for Exceptional Children Conference, Denver, Colorado.

Cramer, E., Pelegrini-Lafont, C., Briggs, P., Taylor, K., \& Baptiste, B (2016).

Professional Development Needs to Implement State Standards for Students with

Disabilities. Presented at Council for Exceptional Children: Teacher Education Division Conference, Lexington, Kentucky. 